OSNY DA SILVA Filho

\title{
DIREITO DOS CONTRATOS \\ E DOUTRINA CONTRATUAL
}

\author{
Dissertação de mestrado \\ Orientador: Professor Doutor \\ Francisco Paulo De Crescenzo Marino
}

Universidade de São Paulo

FACUldade de Direito 
OSNY DA Silva Filho

\section{DIREITO DOS CONTRATOS \\ E DOUTRINA CONTRATUAL}

Dissertação apresentada à Banca Examinadora do Programa de Pós-Graduação em Direito da Faculdade de Direito da Universidade de São Paulo, como exigência parcial para a obtenção do título de Mestre em Direito, na área de concentração de Direito Civil, sob a orientação do Professor Doutor Francisco Paulo De Crescenzo Marino.

Universidade de São Paulo

Faculdade de Direito 


\section{RESUMO}

Silva Filho, Osny da - Direito dos contratos e doutrina contratual (2016), Dissertação de mestrado, Faculdade de Direito da Universidade de São Paulo.

Este trabalho cuida da história e da conformação presente da doutrina contratual. Seu propósito é avançar um argumento pluralista: um argumento conforme o qual a literatura jurídica não pode ser tomada de maneira monolítica, mas deve, em vez disso, ser desdobrada em três gêneros: a doutrina - seu gênero elementar, objeto específico da dissertação -, a teoria e a empiria. Incidentalmente, procura-se também destacar o papel constitutivo desempenhado pelos textos doutrinários no âmbito do direito dos contratos. O trabalho começa com uma narrativa sobre a formação da doutrina contratual moderna entre os séculos XI e XVII. Passa-se em seguida a uma articulação do argumento pluralista, que é realizada em duas frentes. A primeira corresponde à abstração histórica de um movimento de fragmentação da doutrina contratual entre os séculos XIX e XX. Teoria e empiria surgem, aqui, como desdobramentos dos textos doutrinários. A segunda frente do argumento pluralista corresponde a uma proposta de desfragmentação da literatura no campo contratual. Doutrina, teoria e empiria servem, neste caso, de referência para a mediação de tensões entre teoria e prática no pensamento jurídico e para propostas organização do discurso acadêmico.

Palavras-chave: direito dos contratos; literatura jurídica; doutrina; teoria; empiria. 


\begin{abstract}
Silva FilHo, Osny da - Contract Law and Doctrinal Scholarship (2016), Master's thesis, University of São Paulo School of Law.

This thesis deals with the past and present of legal literature on contracts, focusing on its doctrinal strand as recognized in the civil law tradition. It strives to advance a pluralist view of contract law scholarship by distinguishing three different legal-literary genres: doctrinal, theoretical, and empirical. Incidentally, it also seeks to highlight the constitutive role of doctrinal scholarship in contract law. After recounting the emergence of modern contract doctrine between the 11th and 17th Centuries, the aforementioned pluralist view of contract law literature is articulated in two steps. First, theoretical and empirical texts are gathered as doctrinal spin-offs during the 19th and 20th Centuries. Second, the three legal-literary genres - doctrinal, theoretical, and empirical-make ground to distinguish and reconcile current trends in the contract law scholarship. Eventually, the pluralist view will function as an exhaust valve to the tensions between theory and practice in legal scholarship, as well as a matrix to the organization of legal-academic discourse.
\end{abstract}

Keywords: contract law; legal literature; doctrinal scholarship; theoretical scholarship; empirical scholarship. 


\section{Agradecimentos}

Agradeço aos professores Rodrigo Mendes e Fernando Scaff, bem como ao meu orientador, professor Francisco Marino, pelas críticas e sugestões que me foram apresentadas na banca de qualificação deste trabalho em setembro de 2014.

Ao longo da pesquisa, o professor José Reinaldo de Lima Lopes permitiu-me acessar uma série de livros que eu não conhecia, além de me indicar o caminho das pedras em temas com os quais eu não tinha familiaridade. Devo já alguns anos de aprendizado ao professor José Reinaldo. Em numerosas oportunidades, pude discutir ideias desenvolvidas no trabalho com os professores João Alberto Schützer Del Nero, Otavio Luiz Rodrigues Junior, Bernardo Bissoto Queiroz de Moraes, Bruno Meyerhof Salama, Mario Gomes Schapiro, André Rodrigues Corrêa e José Garcez Ghirardi. Sou muito grato a todos eles.

Pelo período em que estive em Berkeley, agradeço o apoio dos professores Bruno Salama e Robert Cooter. Graças a eles pude frequentar as aulas do professor John Searle, com quem tive o privilégio discutir boa parte das relações entre direito e filosofia exploradas neste texto. Devo ao professor Searle, ainda, a participação nos indescritíveis encontros do Berkeley Social Ontology Group. Ana Luiza Nogueira, Andrea Fabiani, Charles Guo, Kyeongmin Park e Lorenzo Neri deixaram o período de estudos na Califórnia ainda mais agradável. Pedro Henrique Butelli acrescentou a isso uma grande amizade e algumas das conversas mais intelectualmente estimulantes que já tive. No encontro de 2014 da Law \& Society Association, em Minneapolis, pude testar as primeiras proposições deste trabalho em uma mesa presidida pelo professor Mark White. Ao professor White agradeço pelo debate e pela chance avançar a reflexão sobre os punitive damages no Brasil.

Antes de começar a redigir a dissertação, compartilhei com Luiz Felipe Rosa Ramos a experiência de escrever sobre a trajetória intelectual de Orlando Gomes. Muito do que absorvi nesse percurso está refletido aqui. A esse respeito, agradeço também aos professores Celso Fernandes Campilongo, que nos permitiu levar esse projeto a cabo, e Fábio Konder Comparato, que nos incentivou decisivamente na reta final dessa empreitada. Desde essa época, a professora Judith Martins-Costa vem franqueando, sempre com uma hospitalidade que eu nunca serei capaz de retribuir, acesso a ideias e textos fundamentais. Sua preocupação com a literatura jurídica brasileira é um exemplo para mim. 
Devo um agradecimento especial ao professor Mario Engler. Desde que passei a trabalhar no Mestrado Profissional da FGV Direito SP, na metade de 2014, o professor Mario foi a pessoa com quem mais aprendi direito e debati metodologia. Uma parte importante deste trabalho ganhou corpo enquanto trocávamos impressões sobre os textos de Harry Edwards, Jan Smits e Mark van Hoecke, discutindo em que medida suas preocupações e sugestões poderiam ser aplicadas à pós-graduação em direito no Brasil. Sem o apoio do professor Mario, da Talitha Saez e do Felipe Novais, amigos e colegas de equipe no Mestrado Profissional, eu não teria conseguido terminar de escrever esta dissertação.

Ainda na Fundação, mas desta vez entre 2012 e 2013, e em seu Programa de PósGraduação Lato Sensu, o GVlaw, tive a sorte de trabalhar com Emerson Fabiani, Fábio Ferreira Durço, Catarina Barbieri, Maria Cecília Asperti, Rafael Zanatta e Pedro de Paula. Os primeiros passos deste trabalho foram dados junto com eles. Agradeço também aos professores Oscar Vilhena Vieira e Roberto Dias, que me permitiram ter, no segundo semestre de 2015, uma experiência acadêmica inesquecível com os alunos e as alunas da disciplina de propriedade. A essa turma eu devo muito mais do que um agradecimento.

Adriano Camargo Gomes, Luiz Felipe Rosa Ramos, Rafael Barros de Oliveira, Rafael Helou Bresciani, Ricardo Savignani Álvares Leite, Rubens Eduardo Glezer e Sérgio Tuthill Stanicia leram longos trechos da dissertação e me ajudaram a corrigir ou clarificar uma série de passagens. Além de grandes amigos, eles foram incansáveis incentivadores. Não posso deixar de agradecer, também, o apoio dos amigos Bruno Nepomuceno, Henderson Fürst, Lívia Guimarães, Pedro de Paula, Sarah Marinho e Sergio Mendes Filho.

Meu último, mas não menos importante agradecimento, assim como a dedicatória deste trabalho, vai para os meus pais, Leila e Osny. 


\section{Sumário}

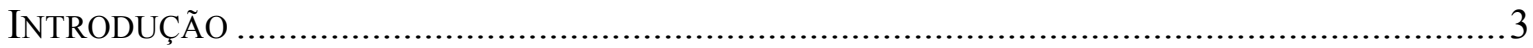

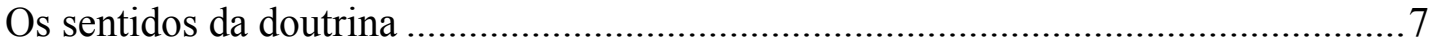

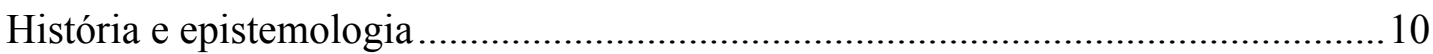

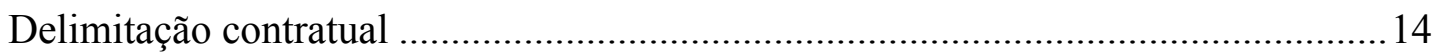

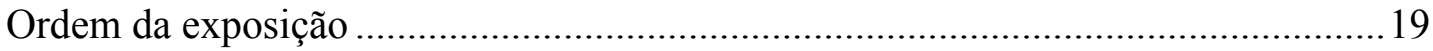

\section{I}

\section{A formação da doutrina contratual}

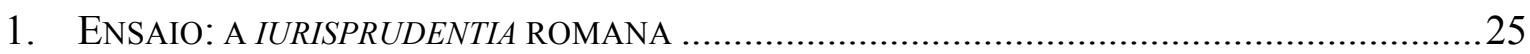

1.1. Organização social e modos de raciocínio ......................................................25

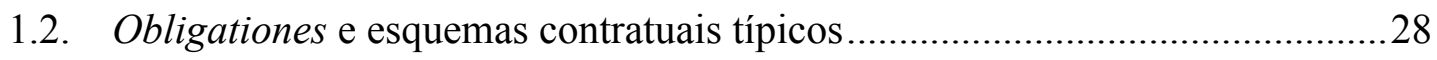

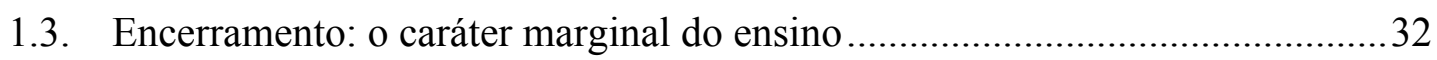

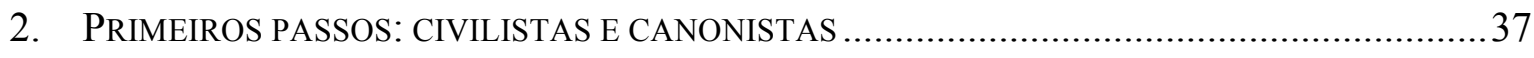

2.1. Os textos civilistas: vulgata, glosas e comentários ........................................40

2.2. Primeiro projeto: velhos textos para novos problemas ..................................43

2.3. Segundo projeto: transformando as partes em um todo ...................................45

2.4. Civilistas, canonistas e a composição do ius commune .....................................52

2.5. Ensino universitário e difusão da cultura do texto ..........................................57

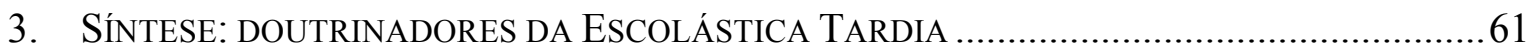

3.1. Caminhos e descaminhos: estrutura, fontes e métodos ...................................62

3.2. A filosofia levada ao direito: comutação e liberalidade ..................................65

3.3. Contractus est pactum obligans ex iustitia commutativa .................................68

3.4. Déjà $v u$ : teoria e doutrina, consenso e responsabilidade...............................73

\section{II}

\section{A fragmentação da doutrina contratual}

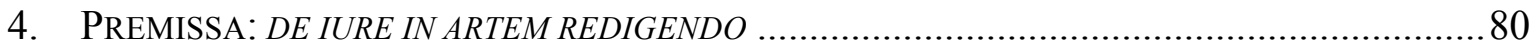

5. EPÍLOGOS DA SÍNTESE: TEORIA E DOUTRINA EM FUGA …................................................ 86

5.1. Jusnaturalismo: meios escolásticos, fins humanistas .....................................86

5.2. Consolidação pedagógico-doutrinária: Domat e Pothier.................................. 88

5.3. L'École de l'Exegèse: arrefecimento retórico da teoria ..................................93

5.4. Conversão dogmática: do usus modernus a Savigny .....................................97

5.5. Realinhamento: uma escola da exegese alemã............................................. 104 


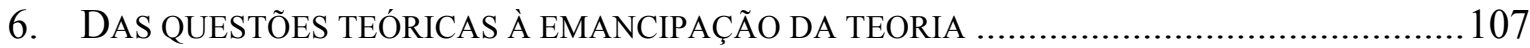

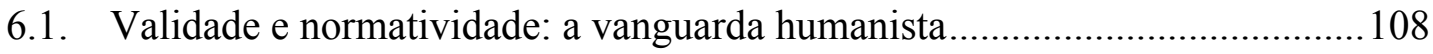

6.2. A tomada do voluntarismo jurídico: da aporia à abstração ................................111

6.3. Consolidação teórica: voluntarismo jurídico em debate ...................................116

6.4. Teorias do contrato desvinculadas do voluntarismo ......................................120

7. APORTES CIENTÍFICOS NO DIREITO: ENTRE FORMAS E FATOS ........................................... 127

7.1. Pretensões científicas na literatura jurídica (remissão) ...................................128

7.2. Alternativas factuais: vertentes do sociologismo jurídico...............................130

7.3. Excurso: ciência, doutrina e teoria do direito comparado .................................139

7.4. Uma alternativa formal: análise econômica do direito.......................................143

7.5. Direito como ciência social e pesquisa empírica.................................................. 148

\section{III \\ Doutrina, teoria e empiria: \\ uma proposta de desfragmentação}

8. TRÊS LEITURAS DO DIREITO,

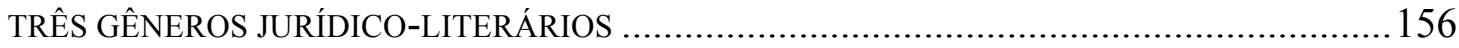

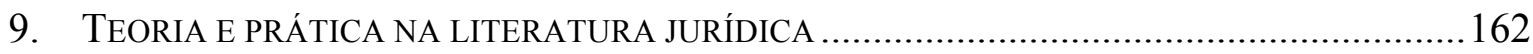

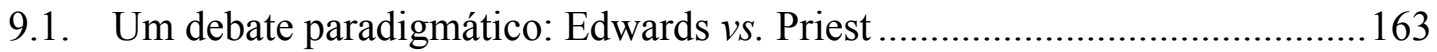

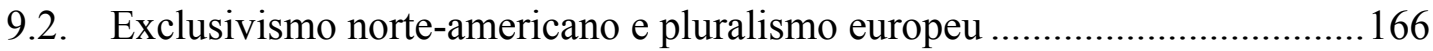

9.3. Um panorama do debate meta-literário brasileiro …………………………...... 171

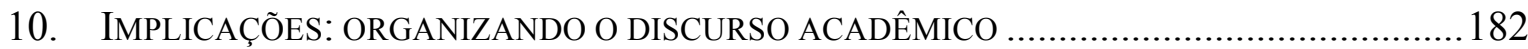

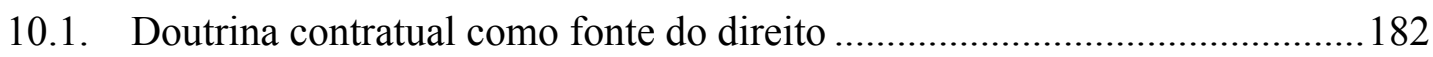

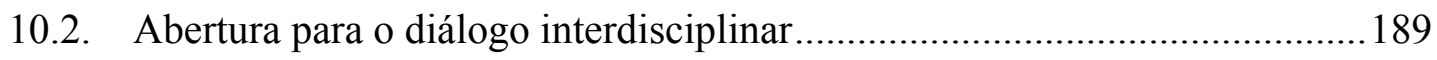

10.3. Possibilidade de internacionalização ..........................................................193

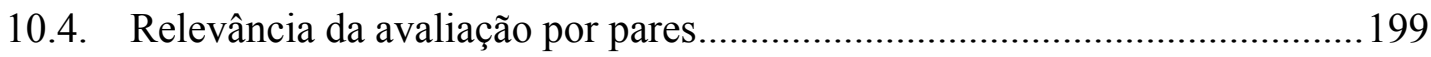

10.5. Nível de tolerância a desacordos ..............................................................200

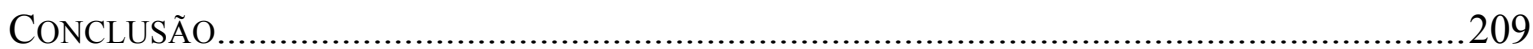

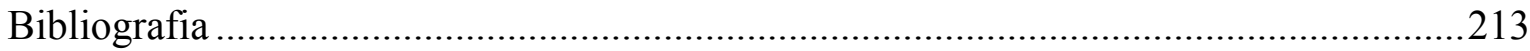




\section{INTRODUÇ̃̃̃O}

Pessoas que se dedicam academicamente ao direito não vêm expressando as melhores impressões a respeito da literatura produzida em seu campo. Censurada pelo seu alheamento prático e pelas suas fragilidades teóricas, pelas suas concessões interdisciplinares e pelas suas pretensões autonomistas, ${ }^{1}$ a pesquisa em direito parece, de fato, enfrentar uma 'crise de identidade'. ${ }^{2}$ Autoras e autores brasileiros também têm reconhecido que a literatura jurídica está em apuros, especialmente no que toca ao direito civil. ${ }^{3}$ Um analista menos generoso associaria os textos jurídicos contemporâneos à expressão de uma "ortodoxia monolítica estreita, conservadora, antiliberal, irrealista e enfadonha." ${ }^{" 4}$ E cenário não parece ser diferente quando o que está em jogo são as impressões externas. Acadêmicos e acadêmicas de outras áreas, sugeriu-se em um trabalho muito afamado, veriam na pesquisa em direito um território "tedioso e pouco criativo, marcado por uma série de charadas intelectuais salpicadas ao longo de imensas planícies descritivas."

Este é um texto sobre textos jurídicos. Mais especificamente, sobre textos doutrinários, e de modo ainda mais restrito, sobre a doutrina contratual. Seu propósito é oferecer, a partir desse campo, e por meio de um argumento pluralista, uma saída para a 'crise de identidade' da produção jurídica contemporânea. O desafio das próximas páginas será mapear a formação e a fragmentação da doutrina contratual para, a partir disso, discutir aquilo que vem sendo feito, exigido e esperado dela e de seus rebentos. Pretende-se mostrar que a

${ }^{1}$ cf. Harry T. Edwards, The Growing Disjunction Between Legal Education and the Legal Profession, in Michigan Law Review 91 (1992); e no mesmo volume, George L. Priest, The Growth of Interdisciplinary Research and the Industrial Structure of the Production of Legal Ideas: A Reply to Judge Edwards.

2 Jan M. Smits, The Mind and Method of the Legal Academic (2012), Cheltenham: Elgar, 149.

3 e.g. Judith Hofmeister Martins-Costa, Autoridade e utilidade da doutrina: a construção dos modelos doutrinários, in Judith Hofmeister Martins-Costa (organização), Modelos de Direito Privado (2014), São Paulo: Marcial Pons; e antes, Otavio Luiz Rodrigues Junior, Dogmática e crítica da jurisprudência (ou da vocação da doutrina em nosso tempo), in Revista dos tribunais 891 (2010).

${ }^{4}$ William Twining, Blackstone's Tower: The English Law School (1994), London: Stevens \& Sons, 141.

${ }^{5}$ Tony Becher, Academic Tribes and Territories. Intellectual Enquiry and the Culture of Disciplines (1989), Milton Keynes: Open University Press, 30. A referência seria omitida na segunda edição do livro: Tony Becher e Paul R. Trowler, Academic Tribes and Territories. Intellectual Enquiry and the Culture of Disciplines (1989; $2^{\mathrm{a}}$ ed., 2001), Milton Keynes: Open University Press, passim.

${ }^{6}$ Essa impressão não é nova. Em 1848, o jurista e filósofo alemão Julius von Kirchmann (1802-1884) já causava espécie na comunidade jurídica ao negar status científico à teoria do direito em seu panfleto Die Wertlosigkeit der Jurisprudenz als Wissenschaft (ou Da insignificância da jurisprudência como ciência). v. Jan M. Smits, The Mind and Method of the Legal Academic (2012), 3. 
literatura jurídica sobre o direito dos contratos - e esse argumento talvez possa ser expandido para a literatura jurídica em geral - não se esgota em um único gênero, mas se desdobra em três: a doutrina, a teoria e a empiria. Cada um desses gêneros, aqui tomados de modo tipológico, conta com métodos, propósitos e destinatários específicos. Faria pouco sentido discutir qual deles seja o melhor, mais promissor ou mais adequado ao direito em geral ou ao direito dos contratos em particular, na medida em que suas tarefas são distintas e interdependentes. Aquilo que se faz, exige e espera dos textos doutrinários, teóricos e empíricos, entretanto, não apenas pode, como deve ser discutido.

E deve ser discutido por pelo menos dois motivos. Primeiro, porque a doutrina contratual não se limita a descrever o direito dos contratos. Ela também o articula e constitui, possibilitando, no primeiro caso, a reprodução de práticas inarticuladas, e criando, no segundo, as condições de juridicidade de comportamentos contratuais inéditos. Pode-se dizer, por isso, que a doutrina é um componente do direito dos contratos, e não apenas seu reflexo. Aquilo que se faz, exige e espera de diferentes gêneros jurídico-literários também deve ser discutido porque as tarefas da doutrina contratual - a descrição, a articulação e a constituição - não podem ser desempenhadas a contento sem o suporte da teoria e da empiria. Afirmar a singularidade de diferentes gêneros da literatura jurídica não deve servir de subterfúgio para o seu isolamento. Textos teóricos, doutrinários e empíricos não sobrevivem em cativeiro. Para integrá-los, entretanto - retomando, assim, a unidade do pensamento jurídico contratual -, é preciso, antes, reconhecer e caracterizar sua distinção. ${ }^{7}$

O desafio enfrentado ao longo desta dissertação é histórico e epistemológico. Ele é histórico porque o argumento pluralista - o argumento em favor da distinção entre doutrina, teoria e empiria - não á apenas uma lente para encarar a literatura contratual contemporânea. Mais do que isso, ele corresponde a uma abstração da sua história. O desafio deste trabalho é também epistemológico porque embora textos doutrinários, teóricos e empíricos

\footnotetext{
${ }^{7}$ Esse argumento pode ser encarado como uma instância da discussão a respeito daquilo que Ricoeur chama de "preservação da integridade, da diversidade e da irreducibilidade de variados usos da linguagem." $v$. Paul Ricoeur, On Interpretation (1983), in From Text to Action (1991), Evanston: Northwestern University Press, 2: "throughout the developments of cultures to which we are the heirs, the act of storytelling has never ceased to ramify into well increasingly well-determined literary genres. [...] [१] In opposition to this endless fragmentation, I acknowledge the existence of a functional unity among the multiple narrative modes and genres." (Destaquei). Ricoeur deixa sua posição clara (ainda na página 2): "I have affiliated myself with those analytical philosophers who resist the sort of reductionism according to which 'well-formed languages' are alone capable of evaluating the meaning claims and truth claims of all non- 'logical' uses of language."
} 
possam compartilhar um mesmo objeto, que é o direito enquanto prática social, cada um deles conhece, articula ou constitui esse objeto de um modo diferente. Para a doutrina, a prática é um ponto de chegada; para a teoria, um ponto de referência; e para a empiria, um ponto de partida. ${ }^{8}$ Essas diferenças, como se defenderá no fim do trabalho, não podem ser negligenciadas na organização do discurso acadêmico. $\mathrm{O}$ argumento pluralista pode, nesse sentido, representar não apenas um achado histórico, mas também um caminho para o aperfeiçoamento da literatura contratual.

Investigar a formação da doutrina contratual é investigar o nascimento de um gênero jurídico-literário dotado de métodos, propósitos e destinatários específicos. Para alguns, essa história teria começado entre os séculos XVI e XVII, tempo de assimilação das fontes do direito romano clássico à filosofia de Tomás de Aquino (1225-1274), que, por sua vez, recobrava o pensamento de Aristóteles (382-322 a.C.), um autor então redescoberto na Europa. ${ }^{9}$ Seus protagonistas seriam teólogos e juristas como Luis de Molina (1535-1600), Francisco Suárez (1548-1617), Leonard Lessius (1554-1623), Pedro de Oñate (1568-1646) e Juan de Lugo (1583-1660), representantes de um movimento conhecido como segunda escolástica ou escolástica tardia. Há quem prefira dar alguns passos atrás e situar a origem da doutrina contratual entre séculos XI e XII, período de desenvolvimento da universidade medieval e reorganização da literatura jurídica. ${ }^{10}$ As figuras-chave, nesse caso, seriam Irnério (1050?-1130?) e Acúrsio (1182?-1263), seguidos, já no século XIV, por Bártolo de Saxoferrato (1313-1357) e Baldo degli Ubaldi (1327-1400), epígonos dos glosadores e dos comentadores, respectivamente. Um terceiro grupo de intérpretes, talvez o mais numeroso deles, prefere situar as origens da doutrina ainda antes, no curso do período clássico da $i u$ -

\footnotetext{
${ }^{8}$ A proximidade dessa tricotomia com as categorias empregadas por Paul Ricoeur para identificar diferentes usos da narrativa - 'organização', 'esclarecimento' e 'marcação' da experiência temporal - é significativa. Seria possível dizer, a partir delas, que a narrativa (como literatura jurídica) pode organizar (como doutrina), esclarecer (como teoria) e marcar (como empiria) a experiência temporal (como prática jurídica). On Interpretation (1983), in From Text to Action (1991), 2-3.

9 e.g. James R. Gordley, The Philosophical Origins of Modern Contract Doctrine (1991), Oxford: Oxford University Press; e no âmbito europeu, os textos reunidos em Paolo Grossi (organização), La seconda scolastica nella formazione del diritto privato moderno (1972), Milano: Giuffrè.

${ }^{10}$ e.g. Harold J. Berman, Law and Revolution. The Formation of the Western Legal Tradition (1983), Cambridge, Harvard University Press; e antes, Franz Wieacker, Privatrechtsgeschichte der Neuzeit unter besonderer Berücksichtigung der deutschen Entwicklung (1952), trad. (da 2a ed., 1967) de António Manuel Botelho Hespanha, História do direito privado moderno (1980; $3^{\mathrm{a}}$ ed., 2004), Lisboa, Calouste Gulbenkian. Wieacker associa a 'formação da ciência jurídica europeia' ao trabalho dos glosadores (38), mas reconduz "o início autêntico da doutrina ainda hoje viva" ao usus modernus pandectarum (238).
} 
risprudentia romana, isto é, nos os séculos II a.C e III d.C. ${ }^{11}$ Seus fautores, neste caso, seriam jurisconsultos como Papiniano, Paulo, Gaio, Ulpiano e Modestino.

Por razões que serão expostas ao longo do primeiro capítulo, esta última tese deve ser rejeitada em favor de uma combinação das duas primeiras. Diante do caráter sistemático assumido pelos textos jurídicos a partir do final do século XI, parece razoável, de fato, situar o nascimento da doutrina contratual nesse ponto; uma orientação doutrinária estável, no entanto - ou uma síntese teórico-doutrinária, para usar uma expressão que será recuperada em vários outros pontos desta dissertação -, só será estabelecida entre os séculos XVI e XVII, graças à apropriação da filosofia aristotélico-tomista por teólogos e juristas como Molina, Suárez, Lessius e seus discípulos de Salamanca. É aqui que o contrato, já tomado como um conceito autônomo, será plenamente associado à noção aristotélico-tomista de justiça comutativa. E é aqui que categorias familiares como consenso, erro, justo preço e causa ganharão os contornos que as acompanhariam a partir de então. Neste ponto da história, falar de contrato é falar de justiça, e todos estão de acordo quanto a isso.

Essa síntese, entretanto, duraria pouco. Ao longo do século XVIII, e na esteira de um movimento desencadeado ainda no século XVI, a justiça comutativa deixará de frequentar a literatura contratual. No século XIX, ela será definitivamente substituída pela ideia de vontade, que se torna, então, o conceito fundamental do direito dos contratos.

O abandono da justiça, porém, não será acompanhado por uma revisão das categorias construídas a partir dela. Ao invés, as categorias estabelecidas pela escolástica tardia se preservarão nas obras de jusnaturalistas como Hugo Grócio (1583-1645), Jean Domat (1625-1695) e Robert-Joseph Pothier (1699-1772), e depois nos código civis e precedentes consolidados, e depois nas descrições desses códigos e precedentes. A gramática fica, mas suas razões se vão. Entre os séculos XVIII e XIX, a síntese teórico-doutrinária construída ao longo da pré-modernidade encontra, assim, seu epílogo, que é também o estopim de sua fragmentação. Deste momento em diante, doutrina e teoria seguirão rumos diferentes: a

${ }^{11}$ e.g. Philippe Jestaz e Christophe Jamin, La doctrine (2004), Paris: Dalloz, 2-33; Tomás Rubio Garrido, La doctrina de los autores. De fuente jurídica primaria a la vulgarización e irrelevancia (2006), Granada: Comares, 5. No Brasil, por todos, Miguel Reale, Concreção de fato, valor e norma no direito romano clássico (ensaio de interpretação à luz da teoria tridimensional do direito), in Revista da Faculdade de Direito da Universidade de São Paulo 49 (1954), reproduzido com pequenas alterações em Horizontes do direito e da história (1956), São Paulo: Saraiva. 
primeira, enredada em discussões cada vez mais ensimesmadas, inconsistentes e distantes da prática; a segunda, fragmentada em orientações lógica e filosoficamente frágeis, ora porque excessivamente paroquiais, ora porque indiferentes às categorias que deveriam tomar como referência. Desprovida de uma "imagem da sociedade" que outrora refletira sem dificuldade, ${ }^{12}$ a literatura contratual encontrará, então, já no final do século Xx, uma esperança de reaproximação com a realidade na pesquisa empírica. Neste ponto, entretanto, já não teremos clareza de onde estamos pisando.

\section{Os sentidos da doutrina}

A doutrina se diz de vários modos. Ela significa, em primeiro lugar, o conjunto dos textos produzidos pelas pessoas que se dedicam ao direito fora de âmbitos oficiais, postulatórios ou negociais. Tomada nesse sentido, a doutrina se distingue, por exemplo, dos documentos legislativos, das certidões registrárias, das petições judiciais, dos instrumentos particulares e, a depender das circunstâncias, das decisões judiciais. ${ }^{13}$ Esse primeiro sentido da doutrina, que é bastante amplo, será preferencialmente designado ao longo do trabalho pela expressão 'literatura jurídica'. ${ }^{14-15}$ Recortando-o, encontraremos o segundo. Neste

\footnotetext{
${ }^{12}$ Franz Wieacker, Privatrechtsgeschichte der Neuzeit unter besonderer Berücksichtigung der deutschen Entwicklung (1952), tradução (da $2^{\mathrm{a}}$ ed., 1967) de António Manuel Botelho Hespanha, História do direito privado moderno (1980; $3^{\mathrm{a}}$ ed., 2004), 717

${ }^{13}$ A depender das circunstâncias porque em um dos sentidos enunciados aqui (o de doutrina como algoritmo decisório ou modelo de comportamento), a doutrina pode ser localizada nas decisões judiciais. Esse parece ser um locus privilegiado para a doutrina no common law.
}

${ }^{14}$ Nos últimos trinta ou quarenta anos, aproximações entre direito e literatura ganharam corpo no pensamento jurídico. Essas aproximações parecem desdobrar-se em ao menos duas vertentes. A primeira, metódica, procura investigar afinidades teóricas ou metodológicas entre direito e literatura; a segunda, ensaística, busca iluminar questões jurídicas a partir de referências literárias. Não se pretende filiar a ideia de 'literatura jurídica' referida acima a nenhuma delas. Trata-se apenas de um atalho expressivo para referir determinado conjunto de textos, e não de um referencial teórico específico ou de uma metáfora para aproximações literárias. Para uma ilustração do debate jurídico-literário metódico, v. Michael Robertson, Stanley Fish on Philosophy, Politics and Law: How Fish Works (2014), Cambridge: Cambridge University Press, 251-286 (sobre a controvérsia travada entre Ronald Dworkin e Stanley Fish na década de 80 a respeito da ideia de direito como chain novel); para uma série de exemplos da vertente ensaística, $v$. os trabalhos reunidos em Judith Hofmeister Martins-Costa (organização), Narração e normatividade. Ensaios de direito e literatura (2013), Rio de Janeiro: GZ, e sobretudo o ensaio da organizadora, O pacto no sertão roseano: os pactos, os contratos, o julgamento e a lei. Para um exemplo de interseção entre as vertentes metódica e ensaística, v. Richard A. Posner, Law and Literature (1988; $3^{\mathrm{a}}$ ed., 2009), Cambridge: Harvard University Press.

${ }^{15} \mathrm{O}$ emprego da expressão 'literatura jurídica' é particularmente significativo no contexto brasileiro. Como notou Antônio Cândido, "[a]nte a impossibilidade de formar aqui pesquisadores, técnicos, filósofos, [a literatura] preencheu a seu modo a lacuna, criando mitos e padrões que serviram para orientar e dar forma ao pensamento. Veja-se, por exemplo, o significado e a voga do Indianismo romântico, que satisfazia tanto às exigências rudimentares do conhecimento (graças a uma etnografia intuitiva e fantasiosa), quanto às da sensibi- 
caso, a doutrina diz respeito a um específico 'gênero' da literatura jurídica. ${ }^{16}$ Ela se apresenta, então, ao lado da teoria e da empiria, delas se distinguindo por seus propósitos, seus destinatários e seus cânones metodológicos. A doutrina serve, aqui, para orientar decisões, guiar condutas e prevenir conflitos. ${ }^{17}$ Nesta dissertação, a palavra 'doutrina' será empregada sobretudo neste segundo sentido.

Em um terceiro sentido, metonímia do segundo, a palavra 'doutrina' corresponde às proposições normativas aventadas nos textos doutrinários. Trata-se, aqui, de algoritmos decisórios ou modelos de comportamento voltados para a conformação da prática jurídica. ${ }^{18}$ Este parece ser o sentido mais comum da palavra na tradição anglo-americana. ${ }^{19} \mathrm{E}$ por razões que voltarão a ser exploradas, ele surge antes em decisões judiciais (sobretudo de segundo grau) que no âmbito da literatura jurídica. ${ }^{20}$ São algoritmos ou modelos de

lidade e da consciência nacional, dando-lhes o índio cavalheiresco como alimento para o orgulho e superação das inferioridades sentidas. [\$] Uma consequência interessante foi a supremacia dos estudos de direito. [ף] Se lembrarmos que o discurso e o sermão (sobretudo este) foram os tipos mais frequentes e prezados de manifestação intelectual no tempo da Colônia, veremos quanto a sua fusão no corpo da jurisprudência importa em triunfo do espírito literário como elemento de continuidade cultural. [ף] Justamente devido a essa inflação literária, a literatura contribuiu com eficácia maior do que se supõe para formar uma consciência nacional e pesquisar a vida e os problemas brasileiros.” Antônio Cândido, Literatura e Sociedade (1965; 9º ed., 2006), Rio de Janeiro: Ouro Sobre Azul, 121.

${ }^{16}$ A noção de 'gênero' jurídico-literário é plurívoca. José Reinaldo de Lima Lopes, por exemplo, prefere associá-la a diferentes modelos de exposição, e não propriamente a conjuntos de textos distintos por seus métodos, propósitos e destinatários. e.g. O direito na história. Lições introdutórias (2008; $4^{\mathrm{a}}$ ed., 2012), 206 (observando que o gênero predominante a partir de Suárez é o tratado) e 212 (lembrando que o 'gênero' favorecido pela reforma pombalina foi o compêndio ou manual).

${ }^{17} v$. José Reinaldo de Lima Lopes, Entre a teoria da norma e a teoria da ação, in Alfredo Storck e Wladimir Barreto Lisboa, Norma, moralidade e interpretação: temas de filosofia política e do direito (2009), Porto Alegre: Linus, 61.

${ }^{18}$ v. Marcus Faro de Castro, Formas jurídicas e mudança social (2012), São Paulo: Saraiva, 176, nota 39.

${ }^{19} v$. Emerson H. Tiller e Frank B. Cross, What Is Legal Doctrine?, in Northwestern University Law Review 100 (2006), 517 (sugerindo que a doutrina representa aquilo que "estabelece os termos para a futura resolução de casos em uma determinada área.")

${ }^{20}$ Em países que admitem modelos judiciais de formação do direito positivo (como é o caso da Inglaterra e dos Estados Unidos), as appellate judicial opinions costumam ser um manancial de algoritmos doutrinários mais rico que a literatura jurídica - que se concentra, então, sobre as razões (no âmbito teórico) ou as consequências (no âmbito empírico) desta ou daquela orientação judicial. Essa, aliás, é uma possível explicação para a escassez de textos doutrinários no âmbito do common law. Sobre essa percepção, v. Richard A. Posner, Legal Scholarship Today, in Harvard Law Review 115 (2002); e com referências empíricas, Reza Dibadj, Fashions and Methodology, in Rob van Gestel, Hans Micklitz e Edward L. Rubin (organização), Rethinking Legal Scholarship: A Transatlantic Interchange (2016), Cambridge: Cambridge University Press. Não surpreende, assim, que as decisões de segundo grau já tenham sido tomadas como um específico gênero jurídico-literário nos Estados Unidos. v. Robert Ferguson, The Judicial Opinion as a Literary Genre, in Yale Journal of Law and Humanities 2 (1990). Christophe Jamin oferece uma boa síntese dos diferentes olhares sobre o pensamento jurídico lançados no civil law e no common law no artigo $A$ construção do pensamento jurídico francês: interrogações sobre um modelo original à luz de seu antimodelo, in Revista de direito público da economia 21 (2008), 75: "Há alguns anos, meu eminente colega e amigo Philippe Jestaz foi convi- 
comportamento que estão em jogo quando falamos, por exemplo, de doutrina da violação positiva do contrato (positiven Vertragsverletzungen), de doutrina do terceiro cúmplice (tortious interference) ou de doutrina da culpa in contrahendo. ${ }^{21}$

Algumas pessoas dão outros nomes àquilo que aqui será chamado de doutrina. No século XIX, por exemplo, um grupo de autores alemães passou a falar de 'dogmática jurídica', expressão que ganhou força e se consolidou no nosso vocabulário, desprendendo-se de suas razões históricas e enucleando, em alguns casos, discussões teóricas em torno das noções de norma, ordenamento e argumentação jurídica. ${ }^{22}$ É comum, ainda, encontrar quem se refira à doutrina por meio da palavra 'teoria' ou da expressão 'teoria geral' ${ }^{23}$ Procurase, neste caso, distinguir aquilo que se produz na prática daquilo que se produz sobre a prática. Nesse sentido, qualquer texto da literatura jurídica - qualquer texto que, como se disse, não corresponda a documentos oficiais, postulatórios ou negociais -, será considerado teórico. Um terceiro grupo de pessoas refere-se à expressão 'ciência do direito', às vezes tomada em contraposição à dogmática, às vezes empregada como seu gênero próximo. Ao contrário da dogmática, entretanto, a 'ciência' logo ganharia outros conteúdos, do natu-

dado para fazer uma palestra no âmbito das famosas Wainwright Lectures da Universidade McGill em Montreal. [...]. Philippe Jestaz trabalhou durante vários meses na preparação dessa palestra sobre um tema bastante amplo, o parentesco, elaborando até uma espécie de teoria geral. [đ] No dia seguinte ao da sua conferência, um dos nossos colegas da Universidade McGill, onde tive a oportunidade de ensinar há alguns anos, telefonou-me para dizer que a conferência fora um sucesso imenso, porém mais para os advogados militantes do que para os acadêmicos. Os primeiros ficaram muito impressionados pela força e clareza de uma construção jurídica que restituiu a coerência a uma questão complexa. Foi justamente este ponto que não entusiasmou tanto os acadêmicos. As maravilhosas catedrais doutrinárias que nossos colegas franceses constroem são deslumbrantes do ponto de vista formal, mas já faz certo tempo que não acreditamos mais na sua pertinência. [đ]] Para tentar entender as razões que motivaram este julgamento do nosso colega norte-americano é que eu e Philippe Jestaz decidimos trabalhar juntos.”

${ }^{21}$ Alguém poderia lembrar, ainda, um quarto sentido da palavra 'doutrina', empregado para designar um conjunto mais ou menos homogêneo de proposições a respeito de certa área do conhecimento jurídico. Essas proposições, sugere-se, representariam a essência, os fundamentos, os propósitos dessas áreas. A doutrina, nesse caso, não é propriamente paráfrase ou reorganização dos textos legislativos, pois pode antecedê-los ou mesmo existir independentemente deles; também não é discussão das regras aplicáveis a casos determinados, porque diz respeito, antes, à disciplina em que casos se inserem; tampouco é o próprio roteiro para a solução de casos específicos, pois representa, antes, os fundamentos empregados nesses percursos. Esse sentido parece estar mais próximo daquilo que nesta dissertação será chamado de 'teoria'. Essa confusão é recorrente. As palavras 'doutrina' e 'teoria', aliás, encontram uma série de usos alternados nas línguas latinas. Enquanto em português a Reine Rechtslehre de Kelsen foi intitulada Teoria pura do direito, por exemplo, sua edição italiana contou com o título Dottrina pura del diritto.

${ }^{22}$ Esse uso é comum entre autores ligados ao pensamento jurídico alemão. e.g. Tercio Sampaio Ferraz Junior, Introdução ao Estudo do Direito. Técnica, Decisão, Dominação (1988; 6ª ed., 2011), São Paulo: Atlas, 47-51.

${ }^{23}$ e.g. Stephen Smith, Contract Theory (2004), Oxford: Oxford University Press, 4-37; e no Brasil, Renan Lotufo e Giovanni Ettore Nanni (organização), Teoria geral dos contratos (2011), São Paulo: Atlas. 
ralismo jurídico tão em voga no Brasil do início do século XX à contemporânea empiria. A ela se reservará um sentido bastante restrito neste trabalho.

\section{História e epistemologia}

"O sinal mais claro de que uma sociedade apropriou-se conscientemente de um conceito", sugeria Quentin Skinner, "está na geração de um novo vocabulário, um vocabulário em torno do qual esse conceito é então articulado e discutido." ${ }^{24}$ Skinner referia-se ao conceito político de Estado, mas não parece equivocado aplicar sua percepção também a conceitos especificamente jurídicos. Como o conceito político de Estado, os conceitos de pessoa, propriedade ou contrato foram socialmente apropriados ao longo da história, ensejando, assim, a criação de vocabulários específicos, paulatinamente devolvidos a grupos de especialistas neste ou naquele tema. Essa história, a história da apropriação social dos conceitos jurídicos, pode ser assimilada à história do desenvolvimento de diferentes vertentes daquilo que Paolo Grossi chamou de 'pensamento jurídico', um pensamento "autônomo em relação a outras aproximações da realidade.,"25

Há mais um traço comum às sugestões de Skinner e à história do pensamento jurídico. Da mesma forma que a teoria política, objeto primordial das preocupações do historiador inglês, ${ }^{26}$ a doutrina jurídica corresponde à formalização de ideias que, embora um tanto quanto complicadas para uma pessoa leiga, orientam-se acima de tudo pela prática. Estudar a história da doutrina é, nesse sentido, estudar a história de um gênero jurídicoliterário voltado para a orientação de comportamentos: um gênero que, por isso, não pode ser abstraído dos contextos em que se desenvolve. A orientação imediatamente prática da doutrina permite não apenas distingui-la dos gêneros que dela se desprenderam (em parti-

\footnotetext{
${ }^{24}$ Quentin Skinner, The Foundations of Modern Political Thought, vol. I (1978), Cambridge: Cambridge University Press, X. Similarmente, António Manuel Hespanha, Imbecillitas. As bem-aventuranças da inferioridade nas sociedades do Antigo Regime (2010), São Paulo: Annablume, 15.

${ }^{25}$ Paolo Grossi, Pensiero giuridico (Appunti per una 'voce' enciclopedica), in Quaderni fiorentini per la storia del pensiero giuridico moderno 17 (1988), 263.

${ }^{26} \mathrm{O}$ emprego da palavra 'teoria', aqui, é enganoso. Tal como conformada a partir do século XVI, a teoria política comporta raciocínios similares àqueles que aqui serão chamados de 'teóricos'. Seu núcleo duro, todavia, da mesma forma que o núcleo duro da doutrina no campo jurídico, está em questões práticas. v. Quentin Skinner, The Foundations of Modern Political Thought, vol. I (1978), XI: "I take it that political life itself sets the main problems for the political theorist, causing a certain range of issues to appear problematic, and a corresponding range of questions to become the leading subjects of debate."
} 
cular, da teoria e da empiria), como também ajuda a apartar, com algum grau de objetividade - e neste ponto reside, talvez, a novidade da leitura proposta nesta dissertação -, a boa doutrina da má. Essa ancoragem prática não elimina, entretanto, o caráter essencialmente conceitual - e, por isso, parcialmente indisponível - das categorias manejadas nos textos doutrinários. ${ }^{27}$ Tampouco garante imunidade contra requerimentos de 'proficiência formal', para usar a feliz expressão de Duncan Kennedy. ${ }^{28}$

Se a história da doutrina pode ser encarada como uma projeção da história deste ou daquele conceito jurídico, ela também pode ser tomada como uma história daquilo que se convencionou chamar 'direito dos juristas', uma noção-irmã do 'direito científico' de que falava Savigny em meados do século XIX. ${ }^{29}$ Tal 'direito dos juristas', explica-nos Koschaker, é o produto da diferenciação social de um grupo de pessoas que fazem da pesquisa jurídica sua profissão, e assim procedendo, compõem um particular estamento, habilitandose a produzir, reproduzir e organizar suas ideias a partir de cânones próprios. ${ }^{30}$ Discutir o 'direito dos juristas', por isso, é discutir epistemologia jurídica, vale dizer, os modos pelos quais o direito é conhecido e constituído por uma comunidade de autores e autoras. ${ }^{31} \mathrm{~A}$ importância dessa empreitada seria destacada por autores brasileiros como Miguel Reale e

${ }^{27}$ v. Paul Ricoeur, The Model of the Text: Meaningful Action Considered as a Text (1971), in From Text to Action (1991), Evanston: Northwestern University Press, 160: "That the meaning of human actions, of historical events, and of social phenomena may be construed in several different ways is well known by all experts in the human sciences. What is less known and understood is that this methodological perplexity is founded in the nature of the object itself and, moreover, that it does not condemn the scientist to oscillate between dogmatism and skepticism. As the logic of text interpretation suggests, there is a specific plurivocity belonging to the meaning of human action. Human action, too, is a limited field of possible constructions."

${ }^{28}$ Duncan Kennedy, Form and Substance in Private Law Adjudication, in Harvard Law Review 89 (1976), 1697 e passim.

${ }^{29}$ Friedrich Carl von Savigny, System Des Heutigen Römischen Rechts (1840-1849), tradução de Jacinto Mesía e Manuel Poley, Sistema del derecho romano actual, vol. I (1878; 2ª ed., 2004), Navarra: Anacleta, 87-89.

${ }^{30}$ Paul Koschaker, Europa und das Römische Recht (1947), tradução de José Santa Cruz Teijeiro, Europa y el derecho romano (1955), Madrid: Editorial Revista de Derecho Privado, 249 e 282 (observando que os jurisconsultos romanos nunca chegaram a constituir um 'direito dos juristas', embora o direito privado viesse a se tornar seu domínio elementar). Koschaker admite que a terminologia weberiana não é acidental.

${ }^{31}$ Esse não é o único sentido em que a ideia de epistemologia se apresenta na literatura jurídica. $c f$. Scott Brewer, Scientific Expert Testimony and Intellectual Due Process, in Yale Law Journal 107 (1998), 15381681 (empregando a ideia de epistemologia jurídica para referir-se às condições de justificação intersubjetiva de argumentos jurídicos). $v$. nota 41 infra. Ao que parece, esse domínio também poderia ser descrito por aquilo que Aristóteles chamava de poética. v. Paul Ricoeur, On Interpretation (1983), in From Text to Action (1991), 3: "We can term poetics - after Aristotle - that discipline which deals with laws of composition that are added to discourse as such in order to form of it a text that can stand as narrative, a poem, or an essay." 
Antônio Luís Machado Neto, ${ }^{32}$ e seu campo, organizado em um importante, mas já antigo livro de Christian Atias, ${ }^{33}$ retomado há alguns anos por Philippe Jestaz e Christophe Jamin. ${ }^{34}$ Dando continuidade às sugestões desses teóricos, e considerando que a longa duração histórica é um elemento fundamental para a conformação presente da epistemologia jurídica, ${ }^{35}$ esta dissertação procura traçar a gênese e as implicações dos diferentes gêneros assumidos pela literatura jurídico-contratual entre os séculos XVI e XX.

Não se trata, é verdade, de um propósito totalmente novo. Do ponto de vista histórico, percursos similares ao que será trilhado nos próximos capítulos já foram percorridos com muita acuidade por Tercio Sampaio Ferraz Junior no Brasil, Tomás Garrido Rubio na Espanha e James Gordley nos Estados Unidos, ${ }^{36}$ para ficarmos com três exemplos ape-

32 e.g. Miguel Reale, Miguel Reale, Filosofia do direito (1953; $11^{\text {a }}$ ed., 1986), São Paulo: Saraiva, 306; e do mesmo autor, O direito como experiência (1968; 1992), São Paulo: Saraiva, 124; bem como Antônio Luis Machado Neto, Teoria da ciência jurídica (1975), São Paulo: Saraiva, 186.

${ }^{33}$ Christian Atias, Epistémologie juridique (1985), Paris: PUF.

${ }^{34}$ Philippe Jestaz e Christophe Jamin, La doctrine (2004).

${ }^{35}$ A referência à 'longa duração' inevitavelmente nos remete a Fernand Braudel (1902-1985), figura-chave da nova história desencadeada no final do primeiro quartel do século XX por autores como Lucien Febvre (1878-1957) e Marc Bloch (1886-1944), fundadores da revista dos Annales. v. Peter Burke, The French Historical Revolution: The Annales School, $1929-1989$ (1990), tradução de Nilo Odalia, A Escola dos Annales (1929-1989). A revolução francesa da historiografia (1990; $2^{a}$ ed., 2010), São Paulo: Editora Unesp, 13 (destacando o papel de Braudel na transformação das ideias de Febvre e Bloch em uma verdadeira escola). Referências centrais, aqui, são o clássico La Méditerranée et le monde méditerranéen à l'époque de Philippe II (1949; $2^{\mathrm{a}}$ ed., 1966), Paris: Armand Colin, bem como a síntese metodológica apresentada em La longue durée, in Annales 13 (1958). A 'longa duração' referida no texto e explorada ao longo da dissertação, contudo, não diz respeito às ideias de Braudel, em que pese sua influência sobre o pensamento brasileiro ou recente recuperação de suas ideias. Trata-se apenas de reconhecer que a formação de diferentes gêneros jurídicoliterários é um fenômeno duradouro e cumulativo. Sobre a passagem de Braudel pela Universidade de São Paulo, v. Luís Corrêa Lima, Fernand Braudel e o Brasil. Vivência e brasilianismo (1935-1945) (2009), São Paulo: Edusp; e para um balanço da missão universitária francesa no Brasil, v. Paulo Eduardo Arantes, Um departamento francês ultramar (1994), São Paulo: Paz e Terra. Sobre a recuperação das ideias de Braudel, $v$. David Armitage e Jo Guldi, Le retour de la longue durée: Une perspective anglo-américaine, in Annales 70 , 2 (2015), 318: "Le retour de la longue durée est intimement lié à des mouvements d'échelle et de cadrage. À l'heure de l'explosion des inégalités, des crises de la gouvernance mondiale, du changement climatique, la moindre considération des facteurs qui régissent nos vies nécessite un changement d'échelle vers le haut. Cette nouvelle longue durée, quoique parée d'habits différents et tournée vers des objectifs renouvelés, requiert de revenir aux questions les plus fondamentales de la méthodologie historique: la sélection des problèmes, les limites qu'on assigne aux sujets, les outils qu'on utilise pour les étudier. La mémoire a le pouvoir de faire ressurgir le potentiel de persuasion, d'imagination et d'inspiration de la discipline historique. [...] Dans cette perspective, les nouveaux historiens de la longue durée devraient se servir de l'histoire afin de critiquer les institutions qui nous entourent, et la réconcilier ainsi avec son rôle de science sociale critique. L'histoire peut permettre de rejeter les anachronismes fondés sur la seule déférence envers la permanence des institutions. La pensée historique - de longue durée - doit nous aider à choisir lesquelles de nos institutions méritent d'être enterrées ou sauvegardées."

${ }^{36}$ Tercio Sampaio Ferraz Jr, Função social da dogmática jurídica (1980), São Paulo: Revista dos Tribunais; Tomás Rubio Garrido, La doctrina de los autores (2006); e James R. Gordley, The Jurists (2014), Oxford: Oxford University Press. 
nas. ${ }^{37}$ Cada um deles orientou-se por um propósito específico. O texto de Ferraz Junior concentrou-se sobre as relações existentes entre a sociedade e os processos de conhecimento do direito; o de Garrido Rubio, sobre as causas do desprestígio angariado pela doutrina nas últimas décadas; e o de Gordley, sobre a articulação de grupos de juristas em torno de sucessivos movimentos intelectuais na Europa e nos Estados Unidos. Quanto à epistemologia, já contamos com um vasto corpo de textos a respeito das tensões entre teoria e prática na literatura jurídica, ${ }^{38}$ geralmente articuladas em torno da ideia de 'crise da doutrina'. ${ }^{39}$ Problemas epistemológicos pontuais também vêm chamando a atenção da academia. É o caso das discussões sobre a doutrina como fonte do direito, sobre o papel da interdisciplinaridade no campo jurídico, sobre os limites de sua internacionalização, sobre os critérios de avaliação de sua literatura ou sobre os níveis de tolerância a desacordos nos textos jurídicos, todas elas especificamente retomadas no último capítulo da dissertação.

Em que pese a qualidade desses trabalhos, esta dissertação buscará trazer ao leitor ou à leitora algo que, ao menos isoladamente, suas fontes secundárias não parecem oferecer. Por um lado, e ao contrário dos livros de Ferraz Junior, Garrido Rubio ou Gordley, ela não tomará a literatura jurídica de maneira monolítica, mas procurará, ao invés, traçar-lhe a história a partir da emergência (e da posterior coexistência) de diferentes gêneros jurídicoliterários, reconhecendo-lhes, como já se disse, métodos, propósitos e destinatários especí-

\footnotetext{
${ }^{37}$ Para além deles, duas publicações brasileiras recentes procuraram explorar especificamente a história do direito dos contratos. Luciano Timm recobrou a tradicional narrativa da passagem de um 'modelo liberal' para um 'modelo social' de contrato para alcançar, a partir de Luhmann, um modelo 'sistêmico' ou 'complexo' de contrato, tomado como "interface entre todos os subsistemas sociais" - um modelo abandonado em favor da análise econômica do direito na última edição do livro, publicada no início de 2015. Cristiano Zanetti, por sua vez, concentrou-se sobre a história da regulação luso-brasileira dos contratos para investigar o que chama de 'fragmentação da liberdade contratual', hoje exercida "de maneira marcadamente distinta nos contratos subordinados às restrições clássicas, nos contratos de consumo e nos contratos concluídos por adesão que não regulam as relações entre o fornecedor e o destinatário final de produtos ou serviços." v. Luciano Benetti Timm, Direito contratual brasileiro. Críticas e alternativas ao solidarismo jurídico ( $O$ novo direito contratual brasileiro, 2008; $2^{\mathrm{a}}$ ed., 2015), São Paulo: Atlas, 151; e Cristiano de Souza Zanetti, Direito contratual contemporâneo (2008), São Paulo: Método, XXIX.

${ }^{38}$ e.g. Harry T. Edwards, The Growing Disjunction Between Legal Education and the Legal Profession, in Michigan Law Review 91 (1992); George L. Priest, The Growth of Interdisciplinary Research and the Industrial Structure of the Production of Legal Ideas: A Reply to Judge Edwards, in Michigan Law Review 91 (1992). cf. os textos reunidos em Mark Van Hoecke (organização), Methodologies of Legal Research: Which Kind of Method for What Kind of Discipline? (2011), Oxford: Hart Publishing; e a monografia de Jan M. Smits, The Mind and Method of the Legal Academic (2012).

${ }^{39}$ e.g. (apenas no Brasil) Otavio Luiz Rodrigues Junior, Dogmática e crítica da jurisprudencia (ou da vocação da doutrina em nosso tempo), in Revista dos tribunais 891 (2010); Humberto Bergmann Ávila, A doutrina e o direito tributário, in Fundamentos do direito tributário (2012), São Paulo: Marcial Pons; e Judith Hofmeister Martins-Costa, Autoridade e utilidade da doutrina: a construção dos modelos doutrinários, in Judith Hofmeister Martins-Costa (organização), Modelos de Direito Privado (2014).
} 
ficos. Por outro, e diferentemente dos textos que vem sendo dedicados a problemas epistemológicos do campo jurídico, esta dissertação buscará enfrentar os problemas da literatura jurídica contemporânea a partir de sua posição histórica, perquirindo-lhes as origens não apenas pelo gosto da narrativa, mas para compreender-lhes a conformação presente. E uma terceira particularidade deste trabalho será sua delimitação. Por concentrar-se sobre a história da literatura contratual, ele também percorrerá fragmentos da história da ideia de contrato, bem como algumas das vicissitudes da história de sua regulação. Ao fazê-lo, poderá contribuir para desfazer leituras historicamente insustentáveis do direito contratual, tais como aquelas que Unger associa a uma 'história mítica dos direitos privados', 40 sendo útil, assim, também às pessoas especificamente interessadas nesse campo.

\section{Delimitação contratual}

Por que concentrar a pesquisa sobre o direito dos contratos? Essa pergunta comporta ao menos duas respostas. A primeira é pragmática. Delimitar um tema amplo como a história da doutrina a um segmento mais específico como o direito dos contratos pode ajudar a reduzir o número de omissões e equívocos da narrativa, além de torná-la mais adequada ao grau acadêmico perseguido pelo trabalho. A segunda resposta, mais intrincada, é 'ontológica'. ${ }^{41}$ Ela diz respeito ao papel constitutivo assumido pela doutrina, ou ao menos por uma parte dela, no âmbito do direito dos contratos. ${ }^{42}$

\footnotetext{
${ }^{40}$ Esse ponto é resumido por Zhiyuan Cui em seu prefácio a Roberto Mangabeira Unger, Politics: The Central Texts (1997), tradução de Paulo César Castanheira, Política: os textos centrais (2010), São Paulo: Boitempo, 16: "Outro exemplo importante do fetichismo institucional é o que Unger descreve como a 'história mítica dos direitos privados'. De acordo com esta história mítica, o atual sistema jurídico ocidental de propriedade e contrato incorpora a lógica inerente à economia de mercado. Contrário a esta visão, Unger insiste em que a economia de mercado não encerra um conteúdo jurídico e institucional predeterminado. O mercado pode ser institucionalmente reinventado. O regime vigente de propriedade e contrato é menos um reflexo de uma lógica profunda de necessidades econômicas e sociais do que o resultado incerto de lutas políticas, e poderia ter assumido outras formas institucionais. Os casos e tendências divergentes dentro do direito atual de propriedade e contrato, tais como as relações pré-contratuais ou extracontratuais juridicamente protegidas, já sugerem elementos de um ordenamento legal e institucional alternativo da economia de mercado. Unger dedica parte importante de sua teoria social construtiva ao desenvolvimento de sistemas alternativos de propriedade e contrato. Mostra como se pode atingir esse objetivo mediante o redirecionamento das tendências divergentes dentro do atual sistema de direitos privados."

${ }^{41}$ Sigo aqui e ao longo do texto a ideia de ontologia tomada por John R. Searle. Por último, v. Making the Social World (2010), Oxford: Oxford University Press, 18. Para Searle, a ontologia diz respeito ao modo de ser das coisas. Ela é diferente da epistemologia, que diz respeito ao modo de conhecer essas mesmas coisas. Assim, quando falamos que algo é objetivo ou subjetivo, podemos estar nos referindo à ontologia ou à epistemologia desse objeto. Coisas ontologicamente objetivas são aquelas cuja existência não depende de experiências subjetivas. É o caso das montanhas, das bicicletas e dos micróbios. Coisas ontologicamente subjetivas, ao invés, só existem enquanto experimentadas pelas pessoas ou, em alguns casos, pelos animais. É o caso dos
} 
Dizer que a doutrina tem um papel constitutivo é dizer que ela pode, mesmo sem a intervenção dos tribunais, e mesmo sem a mediação direta ou específica da lei, definir o sentido da prática contratual. É que ao contrário do que ocorre, digamos, no campo da responsabilidade, no direito dos contratos a prática extrajudicial ou extra-arbitral (tomando a ideia de arbitragem em sentido estrito $)^{43}$ tem um peso considerável. ${ }^{44}$ Por conta disso, pa-

jogos de futebol, da Presidência da República e do contrato. Coisas ontologicamente subjetivas, não obstante, podem ser conhecidas de maneira objetiva - elas podem ser epistemologicamente objetivas.

${ }^{42}$ Novamente John R. Searle, Making the Social World (2010), 17-18. Neste ponto, sua reflexão remonta a How to Derive "Ought" from "Is", in The Philosophical Review 73 (1964); e ao seu conhecido Speech Acts. An Essay in the Philosophy of Language (1969; 2011), Cambridge: Cambridge University Press. Para um panorama do desenvolvimento de suas ideias, v. Barry Smith, John Searle: From Speech Acts to Social Reality, in John Searle (2003), Cambridge: Cambridge University Press. No direito, apropriações das ideias de Searle podem ser encontradas nos textos de Andrei Marmor, How Law Is Like Chess, in Legal Theory 12 (2006); Social Conventions: From Language to Law (2009), Princeton: Princeton University Press (mais próximo, aqui, de David Lewis que de Searle); e The Language of Law (2014), Oxford: Oxford University Press (retomando temas clássicos de Searle, sem, contudo, referi-lo); nos trabalhos de Peter M. Tiersma, The Language of Offer and Acceptance: Speech Acts and the Question of Intent, in California Law Review 74 (1987); Reassessing Unilateral Contracts: The Role of Offer, Acceptance and Promise, in U.C. Davis Law Review 26 (1992); e de Sanford Schane, A Speech-Act Analysis of Consideration in Contract Law, in Paul Pupier e José Woehrling (organização), Language and Law (1989), Montreal: Wilson \& Lafleur; bem como, ainda de Schane, e mais recentemente, Contract Formation as a Speech Act, in Lawrence M. Solan e Peter M. Tiersma (organização), The Oxford Handbook of Language and Law (2012), Oxford: Oxford University Press; nos artigos de Neil MacCormick, Legal Obligation and the Imperative Fallacy, in Alfred W. B. Simpson (organização), Oxford Essays in Jurisprudence. Second Series (1973), Oxford: Oxford University Press; Voluntary Obligations and Normative Powers, in Aristotelian Society Supplementary Volume 46 (1972); e What is Wrong with Deceit, in Sydney Law Review 10 (1983); bem como eu seu livro com Ota Weinberger, An Institutional Theory of Law (1986), Dordrecht: Reidel; na monografia de Carlos Ferreira de Almeida, Texto e enunciado na teoria do negócio jurídico, 2 vols. (1992), Coimbra: Almedina; nos artigos de Jaap Hage, What is a legal transaction?, in Maximilian del Mar and Zenon Bankowski (organização), Law as Institutional Normative Order (2009), Farnham: Ashgate; A Model of Juridical Acts: Part 1: The World of Law, in Artificial Intelligence and Law 19 (2011); e Juridical Acts and the Gap between Is and Ought, in Netherlands Journal of Legal Philosophy 42 (2013); e de modo pioneiro, nas monografias de Gaetano Carcaterra, Le norme costitutive (1974), Milano: Giuffrè; e La forza costitutiva delle norme (1979), Bulzoni: Roma (referindo-se especificamente a John L. Austin e a Searle).

${ }^{43}$ Trata-se, aqui, dos procedimentos de tribunais generalistas, constituídos sob a Lei 9.307/1996. Excluem-se dessa categoria os mecanismos de preenchimento ad hoc do conteúdo contratual, como ocorre, por exemplo, com a definição, por terceiros, do objeto de um contrato per relationem.

${ }^{44}$ Edward L. Rubin, The Nonjudicial Life of Contract: Beyond the Shadow of the Law, in Northwestern Law Review 90 (1995). Rubin alargaria o argumento em Obstructing Law's Future with Conceptions from its Past, in Sam Muller et alli (organização), The Law of the Future and the Future of Law, vol. II (2012), The Hague: Torket Opsahl, 415: "The law of the future has already arrived, but it still strikes us as a disconcerting potentiality because our concept of law is tied to the legal system that modernity has displaced. This system regarded law as a set of rules governing human behaviour that were promulgated in definitive form. The law that has already arrived, and will dominate our foreseeable future, will be concerned with producing real world results, rather than specifying decision-making procedures, it will be tailored to particular situations rather than being stated in general terms, and it will be seen as a means of administrative supervision, rather than a declaration of general principles." $v$. ainda, de volta ao campo dos contratos, Claire Hill, Bargaining in the Shadow of the Lawsuit: A Social Norms Theory of Incomplete Contracts, in Delaware Journal of Corporate Law 34 (2009), 220: "the now-established recognition of the importance of extralegal forces in contracting needs to be better integrated into the scholarship of contracting; the analysis of statu- 
rece correto dizer que seu modo de ser, ou de uma parte dele ao menos, independe de determinações judiciais ou arbitrais para conformar-se. ${ }^{45}$ Essa hipótese é reforçada pela ideia de que contratos complexos só chegariam ao Judiciário após sua estabilização pela prática. ${ }^{46}$ Quando assistida pela advocacia consultiva - retome-se o argumento -, esse segmento da prática contratual pode encontrar na doutrina referências autoritativas para sua segurança e, esperançosamente, para sua igualdade.

O reconhecimento do papel da doutrina é muito mais recente que seu exercício. Novos procedimentos, cláusulas e (no caso do civil law) tipos contratuais há muito vêm sendo forjados pela doutrina e incorporados pela prática antes mesmo de serem conhecidos pelos tribunais, ${ }^{47}$ e mesmo antes de qualquer referência direta ou específica pela lei. Pense, por exemplo, nos já antigos contratos de franquia e factoring, ou nos mais recentes contratos de swap e EPC. Doutrina e prática estabeleceram, aqui, uma ontologia contínua, ${ }^{48}$ porque alheia à mediação judicial, e apenas indiretamente referida à mediação legislativa. É o que ocorre, por exemplo, quando a atipicidade contratual (excluídos, para este efeito, os domínios societários) é legislativamente autorizada sob condição de aderência a 'normas gerais' estabelecidas pela lei ou 'interesses passíveis de tutela' pela ordem jurídica. ${ }^{, 49}$ Tra-

tory law and court-made law needs to take into account the limited and intricate role of law in parties' contracting behavior."

${ }^{45}$ Dizer que a ontologia ou o modo de ser de uma parte da prática contratual independe das determinações judiciais não significa afirmar a irrelevância da jurisprudência nesse âmbito. Significa apenas que essa parte da prática pode desenvolve-ser sem prejuízo do silêncio dos tribunais. É diferente do que ocorre, por exemplo, com a responsabilidade (ou ao menos com uma noção tradicional de responsabilidade), porque sua afirmação (ou confirmação) depende do Judiciário.

${ }^{46}$ e.g. Ronald J. Gilson, Charles F. Sabel e Robert E. Scott, Contract and Innovation: The Limited Role of Generalist Courts in the Evolution of Novel Contractual Forms, in New York University Law Review 170 (2013). Para os autores, os principais responsáveis pela inovação no campo contratual seriam os contratantes, e não os tribunais, como acreditariam alguns. O que se sugere ao longo deste trabalho é que essa inovação pode ser radicalizada - e especialmente equalizada - pela intermediação da doutrina.

${ }^{47}$ Esta é a hipótese central do texto de Gilson, Sabel e Scott referido na nota anterior.

${ }^{48}$ Rubin refere-se a uma coisa parecida quando fala da 'unidade discursiva' estabelecida entre doutrinadores e juízes. Edward L. Rubin, The Practice and Discourse of Legal Scholarship, in Michigan Law Review 86 (1988). Antes, Learned Hand referiu-se a juristas e juízes como "trabalhadores do mesmo vinhedo". Learned Hand, Have the Bench and Bar Anything to Contribute to the Teaching of Law?, in Michigan Law Review 24 (1926). Referindo-os, Jan M. Smits, The Mind and Method of the Legal Academic (2012), 20.

${ }^{49}$ v. Código Civil brasileiro de 2002, art. 425: "É lícito às partes estipular contratos atípicos, observadas as normas gerais fixadas neste Código." E Código Civil italiano de 1942, art. 1.322: "Le parti possono liberamente determinare il contenuto del contratto nei limiti imposti dalla legge (e dalle norme corporative). [†] Le parti possono anche concludere contratti che non appartengono ai tipi aventi una disciplina particolare, purché siano diretti a realizzare interessi meritevoli di tutela secondo l'ordinamento giuridico." 
ta-se de um âmbito em que o 'direito fixado nos livros' e o 'direito realizado na prática', instâncias celebremente apartadas por Pound, ${ }^{50}$ parecem convergir mutualisticamente.

Algumas pessoas podem considerar a delimitação contratual artificiosa. Essa é uma crítica razoável. Quando pensamos em um 'direito dos contratos', geralmente partimos de uma matriz metodológica conforme a qual o que distingue as disciplinas jurídicas são os limites do conjunto de disposições legislativas que lhe dizem respeito. Em boa medida, nossas faculdades de direito ainda são organizadas assim. Estudamos direito civil em cinco semestres porque são cinco os livros do Código Civil. Partimos da ideia de pessoa porque o Código Civil começa com a disciplina da personalidade e da capacidade. Terminamos o curso discutindo questões sucessórias porque essa é a matéria do último livro do Código Civil. ${ }^{51}$ Se formos além do direito civil, a perplexidade cresce. Aprendemos propriedade sem discutir questões urbanísticas porque estas últimas escapam aos domínios da legislação civil. Não estudamos as consequências tributárias dos contratos porque a tributação é objeto de leis específicas. Discutimos direito de família sem percorrer a disciplina do Estatuto da Criança e do Adolescente. E os exemplos poderiam multiplicar-se.

Essas não são, é verdade, divisões arbitrárias. Pelo contrário: na maioria dos casos, é possível justificar a ordem de estudos por razões teóricas e históricas bem sedimentadas e refletidas. Ainda assim, tais divisões fazem menos sentido na prática que nos códigos. Direito dos contratos, direito de família e direito das coisas, por exemplo, - para não falar de direito das relações domésticas, direito ambiental ou direito antitruste, - costumam ser claramente distintos nas leis, mas não na vida. ${ }^{52}$ Dificilmente encontraremos um contrato que não envolva questões familiares, administrativas, concorrenciais ou mesmo processuais

\footnotetext{
${ }^{50}$ Roscoe Pound, Law in the Books and Law in Action, in American Law Review 44 (1910). O sentido que Pound confere aos 'livros' é mais amplo do que o sugerido no texto, abarcando também a lei.

${ }^{51}$ Não quero sugerir que isso seja uma regra. No Código Civil de 1916, por exemplo, o direito de família antecedia o direito das obrigações, e uma boa amostra dos cursos oferecidos sob sua vigência (ou seja, até 2003) não seguia essa ordem. (Minha referência, aqui, são cursos oferecidos nos anos 80 e 90 nas Faculdades de Direito da Universidade Federal do Rio Grande do Sul, da Universidade de São Paulo, da Universidade Federal do Rio de Janeiro e da Universidade Federal de Pernambuco).

${ }^{52} \mathrm{O}$ campo em que em que a artificialidade das delimitações disciplinares vem sendo denunciada de modo mais veemente parece ser o do direito antitruste. Pense, por exemplo, em temas de fronteira como a fixação de preços de revenda, a determinação de cláusulas de exclusividade ou o abuso de dependência econômica, para não falar da recente Resolução 10/2014 do Conselho Administrativo de Defesa Econômica (CADE) a respeito dos parâmetros para a notificação obrigatória de contratos associativos à autoridade antitruste. Para um panorama teórico, $v$. os textos reunidos em Gustavo Olivieri e Andrea Zoppini (organização), Contratto e antitrust (2008), Bari: Laterza.
} 
(especialmente diante dos acordos ou negócios jurídicos de direito processual referidos pelo novo Código de Processo Civil). ${ }^{53}$ Apartar essas dimensões parece ser, afinal, um expediente justificado apenas na medida em que nosso ponto de partida for constituído por leituras 'legalistas' de teorias da norma e do ordenamento. ${ }^{54}$

Parece, mas, ao menos no campo contratual, não é. O direito dos contratos pode ser encarado como um específico conjunto de disposições jurídicas agrupadas neste ou naquele código, nesta ou naquela lei, mas também pode ser visto como uma trama de proposições voltadas para um objeto específico, qual seja, o contrato como prática social distinta. ${ }^{55} \mathrm{E}$ a diferença não é pequena. Em vez de alcançar o contrato a partir de disposições normativas reputadas contratuais, percorremos o caminho contrário: a partir de uma determinada prática social - e uma prática que representa "a forma central de associação humana na sociedade moderna," como diz Collins,$-{ }^{56}$ alcançamos as proposições que compõem seu horizonte de sentidos. E alcançamo-las onde quer que elas estejam. No primeiro caso, fatalmente cairíamos em uma controvérsia a respeito de quais disposições podem ser legitimamente empregadas pelo agente ou intérprete. Aqui está, aliás, o velho debate sobre a teoria das fontes, conforme o qual apenas a legislação e os costumes (eventualmente acrescidos da jurisprudência e dos enigmáticos princípios gerais do direito) podem ser considerados fontes formais do direito. No segundo, isto é, quando tomamos o contrato como prática social distinta, o que está em jogo são os sentidos de um conjunto de comportamentos. Sentidos orientados por proposições que podem corresponder às velhas fontes formais do direito, mas que também podem ser buscadas, para usar o exemplo que aqui importa, na doutrina. Observe que a razão ontológica da delimitação contratual deste trabalho ganha,

${ }^{53} v$. Lei 13.105/2015, art. 190: "Versando o processo sobre direitos que admitam autocomposição, é lícito às partes plenamente capazes estipular mudanças no procedimento para ajustá-lo às especificidades da causa e convencionar sobre os seus ônus, poderes, faculdades e deveres processuais, antes ou durante o processo. [q] Parágrafo único. De ofício ou a requerimento, o juiz controlará a validade das convenções previstas neste artigo, recusando-lhes aplicação somente nos casos de nulidade ou de inserção abusiva em contrato de adesão ou em que alguma parte se encontre em manifesta situação de vulnerabilidade." E art. 191, ainda do novo Código de Processo Civil: "De comum acordo, o juiz e as partes podem fixar calendário para a prática dos atos processuais, quando for o caso."

${ }^{54}$ Para uma alternativa, $v$. notas 661 e 662 infra e referências no texto.

${ }^{55} v$. Herbert L. A. Hart, The concept of law (1961; $2^{\mathrm{a}}$ ed., 1994), Oxford: Oxford University Press, 55-61.

${ }^{56}$ Hugh Collins, Regulating Contracts (1999), Oxford: Oxford University Press, 13. O contrato tornou-se uma forma de associação hipertrofiada, é verdade, mas ainda asssim segue sendo uma forma de associação diferente daquela estabelecida entre o Estado e seus contribuintes, entre um homicida e sua vítima, entre pessoas que compartilham a vida doméstica ou entre ascendentes e descendentes. 
neste ponto, ainda mais relevância. A doutrina deixa de ser uma fonte 'indireta' ${ }^{57}$ para tornar-se um referencial normativo de primeira ordem, um atalho para a identificação de regras constitutivas e regulativas de determinada prática, ainda quando essa prática não tenha sido objeto de legislação, decisão judicial ou mesmo reiteração consuetudinária. ${ }^{58}$

\section{Ordem da exposição}

Além desta introdução, o texto conta com três capítulos, seguidos de uma breve conclusão. O primeiro deles trata da formação da doutrina contratual. Ele está dividido em três seções, cada uma delas subdividida em alguns itens. A primeira seção diz respeito à iurisprudentia romana. Trata-se, aqui, do período compreendido entre o século v a.C. e a segunda metade do século vi d.C., momento em que um imperador bizantino chamado Justiniano decide consolidar em um único documento, hoje chamado de Corpus iuris civilis, o pensamento jurídico produzido desde os tempos republicanos. De modo ainda fragmentário, e com propósitos eminentemente práticos, seus artífices vão estabelecer os alicerces daquilo que hoje chamamos de direito dos contratos. É sobre esses alicerces que trabalharão os autores apresentados na segunda seção do capítulo, que trata do pensamento jurídico medieval - mais especificamente, do pensamento jurídico desenvolvido entre os séculos XI e XV. Nessa empreitada, civilistas e canonistas buscarão conciliar os textos romanos e as escrituras sagradas com problemas que não foram figurados por seus autores. Eles também tentarão articular esses textos a fimm de conferir-lhes unidade. Para tanto, lançarão as bases de algumas técnicas hermenêuticas que permanecem em uso na prática jurídica contemporânea. Finalmente, a terceira seção do capítulo trata do pensamento de teólogos-juristas espanhóis que viveram entre os séculos XVI e XVII. Este é o ponto de chegada da formação apresentada neste capítulo. A partir daqui - e não a partir do século XIX, como sugerem

\footnotetext{
${ }^{57}$ Caio Mário da Silva Pereira, Instituições de direito civil, vol. I, Introdução ao direito civil. Teoria geral de direito civil (1961; 20a ed., 2004), Rio de Janeiro: Forense, 75.

${ }^{58}$ A dimensão normativa ou referencial da doutrina é historicamente negligenciada no Brasil. Até cinquenta ou sessenta anos atrás, essa negligência podia ser explicada pela incipiência da advocacia consultiva e da prática contratual no País. Hoje ela não se justifica. e.g. Orlando Gomes, Introdução ao direito civil (1957), Rio de Janeiro: Forense, 55: "Evidentemente, a doutrina não pode ser considerada fonte formal do Direito. [...] Mas, através das divergências que os autores mantêm, forma-se o pensamento jurídico, de larga influência na elaboração do direito. [...] A sua influência se manifesta em três sentidos: primeiro, pelo ensino ministrado nas Faculdades de Direito; segundo, sôbre o legislador; terceiro, sôbre o juiz."
} 
autores importantes -, ${ }^{59}$ a doutrina contratual se consolida, enveredando, em seguida, por um longo período de fragmentação que, ao que tudo indica, segue em curso.

Essa fragmentação é o objeto do segundo capítulo. Desta vez, as seções são quatro. Na primeira, que não conta com subitens, examina-se aquilo que está por trás da turbulência enfrentada pela doutrina a partir do século XVI: o humanismo jurídico. Recuperando uma leitura do direito figurada em Roma, mas abandonada por autores medievais e escolásticos, os humanistas abrirão caminho para o recrudescimento formal da literatura doutrinária e a emancipação literária da teoria. Quanto à doutrina, discutida na segunda seção do capítulo, uma sequência de movimentos iniciada com o jusnaturalismo dos séculos XVI e XVII e encerrada com as escolas de Savigny no curso do século XIX cuidará de depurar as categorias jurídicas dos fundamentos aristotélico-tomistas que as sustentavam, transformando, ao cabo, e já diante de razões positivistas, a velha síntese teórico-doutrinária salmantina naquilo que hoje chamamos de dogmática jurídica. Este será o momento de radicalização daquilo que Gorla chamou de "tendência à generalização e à abstração própria dos juristas de civil law. ${ }^{, 60}$ O percurso da teoria, discutido na terceira seção, será parecido. No primeiro ensaio de emancipação, realizado ainda no século XVI, autores do humanismo protestante lançarão perguntas especificamente teóricas que, já diante do debate voluntarista desencadeado no século XIX, serão adaptadas ao campo contratual, compondo, a partir daí, um gênero jurídico-literário autônomo. O segundo capítulo se encerra com a discussão dos aportes científicos na literatura contratual. Além da ideia de ciência dogmática, sugerida na Alemanha pelo usus modernus pandectarum e definitivamente abraçada no século XIX, serão discutidos aqui os movimentos de crítica ao pensamento jurídico clássico, tanto pela via factual quanto pela via formal, bem como, e especialmente, a ideia de direito como ciência social em sentido estrito, ideia que está por trás do desenvolvimento contemporâneo da literatura empírica. Esta seção conta também com um excurso a respeito das relações entre o pensamento teórico ou científico e o direito comparado.

Os itinerários históricos apresentados nos dois primeiros capítulos envolvem, inescapavelmente, uma série de omissões. Elas são menos drásticas no primeiro. Nele, como se

\footnotetext{
${ }^{59} v$. nota 784 infra.

${ }^{60}$ Gino Gorla, Il contratto. Problemi fondamentali trattati con il metodo comparativo e casistico, vol. I (1954), Milano: Giuffrè, 325.
} 
disse, serão privilegiados três momentos formativos da doutrina contratual: o primeiro, localizado em Roma entre meados do século v a.C. e 565; o segundo, mais difuso, situado nas cidades universitárias da Europa ocidental entre os séculos XII e XV; e o terceiro, concentrado na Península Ibérica, e particularmente em Salamanca, entre os séculos XVI e XVII. Ao menos quinhentos anos ficam de fora desse recorte, o que não é pouco. Essa ausência, entretanto, se justifica pela dissolução do direito como prática social autônoma entre as últimas décadas do século VI e o início do século XI. Uma "era sem juristas", dirá Belluomo; "61 "sem escolas de direito, sem livros jurídicos, sem uma classe profissional de juízes e advogados", especificarão Berman e Reid. ${ }^{62}$ Sem esses elementos - sem escolas, sem livros e sem juristas - não pode haver doutrina. As omissões do segundo capítulo serão mais significativas. Serão mais significativas, em primeiro lugar, porque entre os séculos XVI e XIX a literatura jurídica torna-se uma empreitada global. Seu mapeamento integral, por conseguinte, deixaria de ser impressionista para tornar-se (na melhor das hipóteses) um exercício de arte abstrata. As omissões do segundo capítulo também serão mais significativas do que as do primeiro por conta de um às vezes anacrônico e quase sempre metamórfico, conquanto adaptativo sincretismo metodológico assumido pela literatura a partir de então, sobretudo na América Latina, ${ }^{63}$ e particularmente no Brasil.

Um exemplo precoce desse sincretismo pode ser encontrado nas reflexões de uma figura proeminente no debate do início do século XIX como José Luís de Carvalho e Melo (1774-1826), o Visconde de Cachoeira, responsável pelos estatutos que orientariam as primeiras décadas de estudos jurídicos no País. ${ }^{64}$ Escrevendo em 1825 , o jurista criticava

\footnotetext{
${ }^{61}$ Manlio Bellomo, L'Europa del diritto comune (1989), tradução de Lydia G. Cochrane, The Common Legal Past of Europe (1995), Washington: Catholic University of America Press, 34.

${ }^{62}$ Harold J. Berman e Charles J. Reid, Jr., Roman Law in Europe and the Jus Commune: a Historical Overview with Emphasis on the New Legal Science of the Sixteenth Century, in Syracuse Journal of International Law and Commerce 20 (1994), 4. Isso não significa, todavia, que o direito dos contratos não tenha avançado no período. v. Gino Gorla, Il contratto, vol. I (1954), 27-32.

${ }^{63}$ v. Diego Eduardo López Medina, Teoría impura del derecho. La transformación de la cultura juridica latino-americana (2004), Bogotá: Legis, passim (discutindo as apropriações e adaptações latino-americanas, e sobretudo colombianas do direito social, especialmente quanto a François Geny); e Jorge L. Esquirol, The 'Three Globalizations' in Latin America, in Comparative Law Review 3 (2012), 10-11 (sugerindo que as duas primeiras 'globalizações do pensamento jurídico' de Duncan Kennedy - v. notas 357, 437 e 597 infra teriam se transformado em uma linguagem híbrida nas recepções latino-americanas).

${ }^{64}$ Baiano formado em Coimbra, Carvalho e Melo havia sido dos responsáveis pelo texto da Constituição Imperial de 1824, elaborando, pouco depois, os estatutos de um curso de direito criado provisoriamente no Rio de Janeiro pelo Decreto de 9 de janeiro de 1825. Por força do art. $10^{\circ}$ da Lei de 11 de agosto de 1827, esses
} 
os usos do humanismo jurídico (um movimento do século XVI) no ensino jurídico português (que experimentara no final do século XVIII), propugnando, ainda que discretamente, por um modelo similar àquele avançado pelos comentadores (dos séculos XIV e XV), tudo isso a partir de um vocabulário cientificista que nos remete ao usus modernus pandectarum (localizado nos séculos XVI), e que ganharia sua formulação mais bem acabada no pensamento de seu contemporâneo Savigny (ainda na primeira metade do século XIX). ${ }^{65}$

Finalmente, o terceiro e último capítulo da dissertação conta com quatro seções. $\mathrm{Na}$ primeira delas, procura-se organizar as noções de doutrina, teoria e empiria a partir de seus propósitos, métodos e destinatários, como se terá sugerido nos capítulos anteriores. Passase em seguida àquele que parece ser o dilema mais frequente nas discussões a respeito da literatura jurídica: a tensão entre teoria e prática. Neste ponto, um conhecido debate travado nos Estados Unidos no início da década de 90 servirá de paradigma para a contraposição de leituras polarizantes e conciliatórias. Trata-se do debate estabelecido entre Harry Edwards, para quem a literatura jurídica deveria orientar-se prioritariamente pela prática, e George Priest, um defensor da diluição do direito nos cânones metodológicos de outros campos do conhecimento. Ainda nesta segunda seção, as tensões entre teoria e prática serão exploradas no debate meta-literário brasileiro, um debate que, em sucessivas ondas de interesse, vem sendo construído desde a segunda metade do século XX por autores como Miguel Reale, Antonio Luis Machado Neto e Tercio Sampaio Ferraz Junior. A última seção do capítulo (e também da dissertação) cuida de algumas implicações da distinção entre

estatutos seriam aproveitados nas Faculdades de Direito de São Paulo e de Olinda. v. Alberto Venâncio Filho, Das Arcadas ao bacharelismo (1977; $2^{\text {a }}$ ed., 2011), São Paulo: Perspectiva, 30-31.

65 "Além do que fica dito" escrevia o Visconde em seus estatutos de 1925, "cumpre observar que a nimia erudição dos autores dos estatutos de Coimbra; a profusão com que a derramaram na sua obra, o muito e demasiado cuidado com que introduziram o estudo de antiguidades e as amiudadas cautelas que só deveriam servir para aclarar, e alcançar o sentido dos difficeis, fizeram que os estudantes sahissem da Universidade mal aproveitados na sciencia do direito patrio, e sobrecarregados de subtilezas, e antiguidades, que mui pouco uso prestaram na pratica dos empregados a que se destinaram. [1] Os mesmos mestres e doutores, para se acreditarem de sabios perante seus companheiros e discipulos, faziam longos e profundos estudos de direito romano e antiguidade, e seguindo nelles a escola Cujaciana, philosophavam muito theoricamente sobre os principios de direito, e por fugirem o rumo da de Bartholo, Alciato, e mais glosadores e casuitas, ensinavam jurisprudencia mais polemica do que apropriada á pratica da sciencia de advogar, e de julgar. Não foi só nimio estudo de direito romano a causa principal de se não formarem verdadeiros jurisconsultos; foi tambem, como já dissemos, a falta de outras partes necessarias da jurisprudencia, e que, fundadas na razão, preparam os animos dos que aprendem para conseguirem aos menos os principios geraes de tudo, que constitue a sciencia da jurisprudencia em geral, e cujo conhecimento forma os homens para os diversos empregos da vida civil." Anexo à Lei de 11 de agosto de 1827, o texto integral dos estatutos está disponível em http://www.planalto.gov.br/ccivil_03/leis/LIM/LIM-11-08-1827.htm. Todas as referências a textos disponíveis online foram checadas dia 11.01.2016. 
doutrina, teoria e empiria sobre a organização do discurso acadêmico. Seu propósito é evidenciar que a relevância dessa tripartição não se esgota na história, mas, ao invés, pode trazer uma série de benefícios para a produção jurídico-literária contemporânea. 


\section{Conclusão}

Os dois primeiros capítulos deste trabalho cuidaram do passado da doutrina contratual. O terceiro, do seu presente. Em todos eles a exposição foi orientada por um argumento pluralista: um argumento conforme o qual a literatura jurídica não pode ser tomada de maneira monolítica, mas deve, em vez disso, ser desdobrada em três gêneros: a doutrina seu gênero elementar, objeto específico da dissertação -, a teoria e a empiria. $\mathrm{O}$ argumento pluralista foi tomado de duas maneiras ao longo do longo do texto. Primeiro, como abstração histórica de um movimento de fragmentação da literatura contratual. Depois, como critério para uma proposta epistemológica de desfragmentação dessa mesma literatura. Neste último caso, a distinção de gêneros jurídico-literários também serviu de base para propostas de reconciliação entre teoria e prática e reorganização do discurso acadêmico. Algumas das indicações traçadas até aqui, entretanto, foram além do passado e do presente da doutrina contratual, apontando também para o seu futuro. É hora de sumariá-las.

Tomada como um gênero jurídico-literário dotado de propósitos, métodos e destinatários próprios, a doutrina contratual é algo relativamente novo na cultura jurídica ocidental. Relativamente novo porque não surgiu na antiguidade romana, mas na escolástica tardia salmantina, ou, de modo mais preciso, em um movimento que começa na Universidade de Bolonha entre os séculos XI e XII e alcança seu auge, que é também seu estertor, na Universidade de Salamanca entre séculos XVI e XVII. É correto dizer que o direito romano tenha sido seu elemento nuclear, mas não foi ele, e sim sua abstração, - ou, para seguir com a precisão, uma combinação entre sua abstração e um conjunto de categorias emprestadas do pensamento filosófico de Aristóteles e Tomás de Aquino - que daria forma ao conteúdo dos textos que hoje chamamos de doutrinários. A doutrina contratual é resultado de um esforço que começa com Irnério e Acúrsio nos séculos XI e XII, passa por Bártolo, Baldo e seus discípulos entre os séculos XIV e XV e chega às suas melhores formulações em Lessius, Molina e Oñate nos séculos XVI e XVII. Direito e filosofia, aqui, formam uma síntese. A ideia de contrato, longamente abstraída a partir dos textos jurídicos romanos, encontraria na justiça comutativa seu fundamento. É a partir daqui que categorias como oferta e aceitação, erro, dolo e coação, lesão, causa e responsabilidade contratual ganham os contornos que hoje nos são familiares. Essa é a origem da doutrina contratual moderna. 
Preservadas por jusnaturalistas como Grócio, Pufendorf e Barbeyrac, essas categorias - as categorias, mas não seus fundamentos, - seriam absorvidas por Domat e Pothier, e deles chegariam ao Código Napoleão de 1804. Elas também seriam aproveitadas pelos exegetas do Código francês e dos diplomas que o emularam, entre os quais um número significativo codificações latino-americanas. Juristas alemães também se apropriariam das categorias medievais e escolástico-tardias preservadas pelo jusnaturalismo. No território alemão, entretanto, essa apropriação ganharia, especialmente com Savigny, um novo método, e particularmente no campo contratual, um novo fundamento. O novo método envolveria uma combinação de historicismo, conceitualismo e pensamento sistemático. O novo fundamento corresponderia à realocação da ideia da vontade. Realocação, e não descoberta ou redescoberta, porque a vontade sempre esteve presente no pensamento jurídico. Os jurisconsultos romanos nunca deixariam de recorrer à voluntas, e ela já havia desempenhado um papel central nas abstrações propostas por glosadores e comentadores. Ao cabo, a vontade serviria de critério para muitas das proposições doutrinárias ditadas pelos autores salmantinos. A novidade, portanto, não estava no conceito, mas no espaço que ele viria a ocupar. Esse espaço seria aquele deixado pela noção de justiça comutativa. Criam-se, assim, as condições intelectuais para a emancipação da teoria contratual.

Esse movimento, entretanto, foi mais turbulento do que o parágrafo anterior pode sugerir. A passagem do voluntarismo à literatura teórica foi intermediada pela emergência de novos métodos e propósitos na literatura contratual. Embora a ideia de vontade tenha sido objeto de reflexões altamente sofisticadas, especialmente pelo inédito diálogo estabelecido pelos juristas com uma incipiente psicologia, ela não parecia explicar adequadamente as velhas categorias contratuais elaboradas a partir justiça comutativa. Diante de um impasse a respeito da explicação desta ou daquela categoria, teríamos duas saídas. Uma seria abandonar a ideia de vontade em favor de outro fundamento. Outra, aprofundá-la. A saída mais comum - explicada, talvez, pela convergência das ideias disponíveis - foi o aprofundamento da vontade. O problema é que em alguns casos o mergulho foi tão profundo que deixou de ser possível apontar para a superfície. E a superfície, neste caso, era a prática jurídica. Os ganhos de sofisticação trazidos pelo debate voluntarista são acompanhados, assim, por perdas maciças de utilidade dos textos jurídicos. Os desacordos se multiplicam - e a doutrina, como vimos, não é o melhor lugar para manter um desacordo. 
Para além da disjunção entre doutrina e teoria, uma série de componentes da síntese jurídico-filosófica promovida entre juristas bolonheses e salmantinos se perderia entre os séculos XVIII e XIX. Um deles, como se vem dizendo, foi a ideia de justiça comutativa. Outro - a metáfora é boa o suficiente para ser repetida pela terceira vez -, foi aquilo que Wieacker chamou de 'imagem da sociedade', ${ }^{833}$ ou seja, uma representação que desse conta da prática a que a doutrina diz respeito. Alguns juristas procuraram sanar esta última baixa a partir de reviravoltas na teoria. O problema, acreditavam eles, estaria no caráter individualista, ensimesmado ou excessivamente abstrato do positivismo legalista ou, no caso alemão, do positivismo histórico-conceitual de Savigny e seus seguidores. Agrupadas sob a rubrica do 'sociologismo jurídico', suas primeiras propostas, rapidamente globalizadas, não foram propriamente um sucesso, embora não tenham deixado de impactar certas parcelas da doutrina contratual e de uma já emancipada teoria do contrato. As repercussões do sociologismo, entretanto, não se limitariam aos gêneros jurídico-literários já existentes. Mais do que isso, esse movimento contribuiria para a aproximação entre direito e ciências sociais, e com ela, para o surgimento da empiria como um gênero autônomo.

Esse resumo pode sugerir que tudo ficou bem a partir de então: que textos doutrinários, teóricos e empíricos passaram a perseguir suas vocações de modo consciente e articulado, reconhecendo suas particularidades e explorando suas convergências e conexões. Infelizmente não foi isso que aconteceu. Doutrina, teoria e empiria não seguiram caminhos bem definidos, tampouco aprofundaram suas sinergias. No fim das contas, prevaleceu a ideia de que a tarefa das pessoas que se dedicam ao direito é uma só - ou que ela se fragmentou de tal modo que já não poderia ser organizada tipologicamente. Disputas em torno do que seja a melhor ou mais adequada maneira de pesquisar no campo jurídico se tornaram recorrentes. Elaborando sobre seus métodos e propósitos, juristas teóricos, e aqui se incluem teóricos da pesquisa empírica, passaram a censurar a superficialidade, o conservadorismo e mesmo as pretensões normativas da doutrina. Praxis sine theoria, caecus in via. Atentos às demandas de seus destinatários, doutrinadores passaram a criticar o hermetismo, o desconhecimento da tradição e sobretudo, como não poderia deixar de ser, o alheamento prático dos textos teóricos. Theoria sine praxis, rota sine axis.

${ }^{833}$ v. nota 645 supra; e antes dela, a nota 12. 
Esta dissertação começou com o relato de impressões muito pouco otimistas sobre os rumos da pesquisa em direito. O quadro apresentado no terceiro capítulo, entretanto, parece indicar que alguns desses diagnósticos, quase sempre orientados pela ideia de 'crise', são um tanto quanto exagerados, senão mesmo equivocados - e isso vale especialmente para aqueles que veem em uma alegada vulgarização a raiz de todos os males da literatura jurídica. ${ }^{834}$ Se há uma crise com a qual nós devemos nos preocupar, essa crise diz respeito, como se vem dizendo, àquilo que Jan Smits chamou de 'identidade' da pesquisa em direito e da literatura jurídica produzida a partir dela. ${ }^{835}$ Doutrina, teoria e empiria assumem posições diferentes no discurso acadêmico contemporâneo. Essas posições nem sempre são reconhecidas quando o que está em jogo é definir questões práticas como o que seja um bom texto jurídico, em que medida esse texto pode ser tomado como referência normativa, qual o papel da interdisciplinaridade em sua elaboração, quem devem ser os responsáveis pela sua avaliação ou mesmo em que língua ele deve ser escrito, para mencionar apenas os temas explorados na última parte desta dissertação.

A boa notícia é que não é preciso reinventar a roda para recobrar a relevância da literatura jurídica, sobretudo no campo contratual. Basta reconhecer que as distinções literárias forjadas entre os dez séculos que separam a criação da Universidade de Bolonha e a emergência da pesquisa empírica em direito não precisam ficar para trás. Que a identificação de propósitos, métodos e destinatários específicos para os textos doutrinários, teóricos e empíricos não é apenas um achado histórico, mas uma forma de aperfeiçoar seu modo presente de ser e de conhecer o direito. Que o pluralismo literário, enfim, não representa um aprofundamento da fragmentação experimentada pela doutrina entre os séculos XVI e XIX, mas corresponde, ao invés, a uma tentativa de recobrar sua unidade. O futuro da doutrina contratual - e com ele, o futuro da teoria e da empiria - tem aqui um norte promissor.

\footnotetext{
${ }^{834}$ e.g. Tomás Rubio Garrido, La doctrina de los autores (2006), 67-70. v. nota 420 supra.

${ }^{835}$ v. nota 2 supra.
} 


\section{BIBLIOGRAFIA}

AARNIO, Aulis — Essays on the Doctrinal Study of Law (2011), Dordrecht: Springer;

AARNIO, Aulis — On Legal Reasoning (1976), Loimaa: Turun Yliopisto;

ABREU FiLHo, José - O negócio jurídico e sua teoria geral (1984; $3^{\mathrm{a}}$ ed., 1995), São Paulo: Saraiva;

Ackerman, Bruce A. - Law, Economics, and the Problem of Legal Culture, in Duke Law Journal 6 (1986);

AdeOdAto, João Maurício - Bases para uma metodologia da pesquisa em direito, in Revista CEJ 7 (1999);

AgUiar JúNIOR, Ruy Rosado de - Extinção dos contratos por incumprimento do devedor (1991; $2^{\mathrm{a}}$ ed., 2004), Rio de Janeiro: Aide;

AKBARI, Sina - Against the Reductionism of an Economic Analysis of Contract Law, in Canadian Journal of Law and Jurisprudence 28 (2015);

Alces, Peter A. - A Theory of Contract Law. Empirical Insights and Moral Psychology (2011), Oxford: Oxford University Press;

Alchourrón, Carlos E.; Bulygin, Eugenio - Análisis lógico y Derecho (1991), Madrid: Centro de Estudios Constitucionales;

AlmeIDA, Carlos Ferreira de - Responsabilidade civil pré-contratual: reflexões de um jurista português (porventura) aplicáveis ao direito brasileiro, in Alexandre dos Santos Cunha (organização), Direito da empresa e das obrigações no novo Código Civil brasileiro (2006), São Paulo: Quartier Latin;

AlmeidA, Carlos Ferreira de - Texto e enunciado na teoria do negócio jurídico, vol. I (1992), Coimbra: Almedina;

AlmeidA, Fernando Dias Menezes de - Contrato Administrativo (2012), São Paulo: Quartier Latin,

AlPA, Guido - European private Law: Results, Projects and Hopes, in European Business Law Review 14 (2003); 
Alves, José Carlos Moreira - A formação romanística de Teixeira de Freitas e seu espírito inovador, in Sandro Schipani (organização), Augusto Teixeira de Freitas e il Diritto Latinoamericano (1983), Padova: Cedam

Alves, José Carlos Moreira — Da Alienação Fiduciária Em Garantia (1973), São: Saraiva;

Alves, José Carlos Moreira — Direito romano, vol. I (1965; 6 a ed., 1987), Rio de Janeiro: Forense;

Alves, José Carlos Moreira - Notas sobre a carta de conforto, in Marcelo Vieira von Adamek (organização), Temas de direito societário e empresarial contemporâneos. Liber amicorum Prof. Dr. Erasmo Valladão Azevedo e Novaes França (2011), São Paulo: Malheiros;

- O novo Código Civil brasileiro: principais inovações na disciplina do negócio jurídico e suas bases romanísticas, in Revista Jurídica 51 (2003);

AmAdIO, Giuseppe - La condizione di inadempimento. Contributo alla teoria del negozio condizionato (1996), Padova: Cedam;

AMARI, Emerico - Critica di una scienza della legislazione comparata (1857), Genoa: Istituto dei Sordomuti

AQuINO, Tomás de - Suma teológica (1265-1273), tradução de Gabriel C. Galache e Danilo Mondoni, vol. v (2004; 4 a ed., 2014), São Paulo: Loyola;

ARANGIO-RUIZ, Vincenzo — Istituzioni di diritto romano (1921-192; 14a ed., 1960), Napoli: Jovene;

Arangio-Ruiz, Vincenzo — Storia del diritto romano (1936; 7ª ed., 1957), Milano, Giuffrè;

ARANTES, Paulo Eduardo - Um departamento francês ultramar (1994), São Paulo: Paz e Terra;

ARAúJO, Fernando — Teoria económica do contrato (2007), Coimbra: Almedina;

Arguelhes, Diego Werneck; FalCão, Joaquim; Schuartz, Luis Fernando - Jurisdição, Incerteza e Estado de Direito, in Revista de direito administrativo 243 (2006); 
Argyres, Nicholas S.; Bercovitz, Janet; Mayer, Kyle J. - Complementarity and Evolution of Contractual Provisions: An Empirical Study of IT Services Contracts, in Organization Science 18 (2007);

ARIDA, Pérsio; BACHA, Edmar Lisboa; LARA-RESENDE, André - Credit, Interest, and Jurisdictional Uncertainty: Conjectures on the Case of Brazil, in Francesco Giavazzi, Ilan Goldfajn e Santiago Herrera, Inflation Targeting, Debt, and Brazilian Experience. 1999 to 2003 (2005), Cambridge: Mit Press;

ARistóteles - Ética a Nicômaco, tradução de António de Castro Caeiro (2004; $3^{\mathrm{a}}$ ed., 2009), Lisboa: Quetzal;

Aristóteles - Política, tradução de Benjamin Jowett, Politics, in Jonathan Barnes (organização), The Complete Works of Aristotle (1984; 1995), Princeton: Princeton Univesity Press;

Arlen, Jennifer H.; TAlley, Eric L. (organização) — Experimental Law and Economics (2015), Cheltenham: Elgar;

ARMitage, David; Guldi, Jo — Le retour de la longue durée: Une perspective angloaméricaine, in Annales 70, 2 (2015);

ARNAUD, André-Jean — Les origines doctrinales du code civil français (1969), Paris: LGDJ;

Assis, Araken de - Dano positivo e negativo na dissolução do contrato, in Revista do Advogado 40 (1994);

Association Henri Capitant des Amis de la Culture Juridique Française, Les droits de tradition civiliste en question. À propos des rapports Doing Business de la Banque Mondiale, vol. 2 (2006), Paris: Société de Législation Comparée;

Astuti, Guido - Contratto (diritto intermedio), in Enciclopedia del diritto, vol. IX (1961), Milano: Giuffrè;

AStUTI, Guido - I principi fondamentali dei contratti nella storia del diritto italiano, in Annali di storia del diritto I (1957);

Astuti, Guido - Mos Italicus e Mos Gallicus nei dialoghi "De iuris interpretibus" di Alberico Gentili (1937), Bologna: Zanichelli;

Atias, Christian — Epistémologie juridique (1985), Paris: PuF; 
AtiYah, Patrick S. - Contracts, Promises and the Law of Obligations, in Essays on Contract (1978/1986), Oxford: Clarendon;

AtiYah, Patrick S. - The Rise and Fall of Freedom of Contract (1979; 1985), Oxford: Oxford University Press;

Aubenque, Pierre — La prudence chez Aristot (1963), tradução de Marisa Lopes, A prudência em Aristóteles (2003), São Paulo, Discurso;

Avenarius, Martin - Roman Law: Historiography, in Stanley N. Katz (organização), The Oxford International Encyclopedia of Legal History, vol. 5 (2009), Oxford: Oxford University Press;

Ávila, Humberto Bergmann - A doutrina e o direito tributário, in Fundamentos do direito tributário (2012), São Paulo: Marcial Pons;

ÁvilA, Humberto Bergmann — Notas sobre o papel da doutrina na interpretação, in Conversa sobre a interpretação no direito: estudos em homenagem ao centenário de Miguel Reale (2011), Canela, Instituto de Estudos Culturalistas;

Ayres, Ian; GerTnER, Robert - Filling Gaps in Incomplete Contracts: An Economic Theory of Default Rules, in Yale Law Journal 99 (1989)

AzEVEDo, Antônio Junqueira de - Diferenças de natureza e efeitos entre o negócio jurídico sob condição suspensiva e o negócio jurídico a termo inicial. A colaboração de terceiro para o inadimplemento de obrigação contratual. A doutrina do terceiro cúmplice. A eficácia externa das obrigações, in Estudos e Pareceres de Direito Privado (1998; 2004), São Paulo: Saraiva;

AzEVEDo, Antônio Junqueira de - Insuficiências, deficiências e desatualização do projeto de código civil na questão da boa-fé objetiva nos contratos, in Revista dos Tribunais 89 (2000);

AzEVEDo, Antônio Junqueira de — Negócio jurídico e declaração negocial (Noções gerais e formação da declaração negocial) (1986), Tese de Titularidade apresentada à Faculdade de Direito da Universidade de São Paulo;

AzEvedo, Antônio Junqueira de — Negócio Jurídico. Existência, Validade e Eficácia (1974; 4ª ed., 2002; 2008), São Paulo: Saraiva; 
AzEVEDo, Antônio Junqueira de — Novos estudos e pareceres de direito privado (2009), São Paulo: Saraiva;

AzEVEDo, Antônio Junqueira de - O direito como sistema complexo de $2^{a}$ ordem; sua autonomia. Ato nulo e ato ilícito. Diferença de espírito entre responsabilidade civil e penal. Necessidade de prejuízo para haver direito de indenização na responsabilidade civil (2001), in Estudos e Pareceres de Direito Privado (2004), São Paulo: Saraiva;

AZEVEDO, Antônio Junqueira de — O direito pós-moderno, in Revista USP 42 (1999);

BAgChI, Aditi - Contract as Procedural Justice, in Jurisprudence: An International Journal of Legal and Political Thought 1 (2016);

BAGCHI, Aditi - Distributive Injustice and Contract Law, in Gregory Klass, George Letsas e Prince Saprai (organização), Philosophical Foundations of Contract Law (2015), Oxford: Oxford University Press;

BAGCHI, Aditi - Separating Contract and Promise, in Florida State University Law Review 38 (2011);

BALKIN, Jack M. - Interdisciplinarity as Colonization, in Washington \& Lee Law Review 53 (1996);

BAR, Christian von; et alii - Principles, Definitions and Model Rules of European Private Law. Draft Common Frame of Reference (2009), München: Sellier;

BARBIERI, Catarina Helena Cortada - O formalismo jurídico de Ernest Weinrib e seus reflexos na teoria da responsabilidade civil (2012), Tese de doutorado apresentada ao Departamento de Filosofia e Teoria Geral do Direito da Universidade de São Paulo;

BARNARD, Chester - The Functions of the Executive (1938; 1962), Cambridge: Harvard University Press;

Barnett, Randy E. - A Consent Theory of Contract, in Columbia Law Review 86 (1986); 
BEATSON, Jack; ZIMMERMANN, Reinhard (organização) — Jurists Uprooted: Germanspeaking Émigré Lawyers in Twentieth-century Britain (2004), Oxford: Oxford University Press;

Beazley, Mary Beth; Edwards, Linda H. - The Process and the Product: A Bibliography of Scholarship About Legal Scholarship, in Mercer Law Review 49 (1998);

BECHER, Tony - Academic Tribes and Territories. Intellectual Enquiry and the Culture of Disciplines (1989), Milton Keynes: Open University Press;

Becher, Tony; Trowler, Paul R. - Academic Tribes and Territories. Intellectual Enquiry and the Culture of Disciplines (1989; 2a ed., 2001), Milton Keynes: Open University Press,

BeEver, Alan; Rickett, Charles — Interpretive Legal Theory and the Academic Lawyer, in Modern Law Review 68 (2005);

BEHRENDS, Okko — Institut und Prinzip (2004), Göttingen: Wallstein;

Behrends, Okko - The Natural Freedom of the Human Person and the Rule of Law in the Perspective of the Classical Roman Legal Theory, in The Tulane European \& Civil Law Forum 26 (2011);

BELL, John - Legal Research and the Distinctiveness of Comparative Law, in Mark Van Hoecke (organização), Methodologies of Legal Research: Which Kind of Method for What Kind of Discipline? (2011), Portland: Hart;

Bellomo, Manlio - L'Europa del diritto comune (1989), tradução de Lydia G. Cochrane, The Common Legal Past of Europe (1995), Washington: Catholic University of America Press;

BENEDETTI, Giuseppe - Il diritto comune dei contratti e degli atti unilaterali tra vivi a contenuto patrimoniale (1991; 2 ed., 1997), Napoli: Jovene;

Benson, Peter - Contract, in Dennis Patterson (organização), A Companion to Philosophy of Law and Legal Theory (1996; 2 a ed, 2010), Oxford: Blackwell;

Benson, Peter - The Unity of Contract Law, in Peter Benson (organização), The Theory of Contract Law: New Essays (2001), Cambridge: Cambridge University Press; 
Bergh, Rena van den - Roman Law: 27 B.C.E.-250 C.E., in in Stanley N. Katz (organização), The Oxford International Encyclopedia of Legal History, vol. 5 (2009), Oxford: Oxford University Press;

Berman, Harold - Law and Revolution. The Formation of the Western Legal Tradition (1983), Cambridge: Harvard University Press;

Berman, Harold; ReID, JR., Charles J. - Roman Law in Europe and the Jus Commune: a Historical Overview with Emphasis on the New Legal Science of the Sixteenth Century, in Syracuse Journal of International Law and Commerce 20 (1994);

Bernstein, Lisa - Opting Out of the Legal System: Extralegal Contractual Relations in the Diamond Industry, in Journal of Legal Studies 115 (1992);

BERTANI, Corrado - Eduard Gans e i problemi del diritto internazionale, in Materiali per una storia della cultura giuridica 2 (2004);

BETTI, Emilio - Teoria generale del negozio giuridico (1943; 2a ed., 1950; 1994), Napoli: Edizioni Scientifiche Italiane;

Bevilaqua, Clovis - Código Civil dos Estados Unidos do Brasil commentado (1916; 2a ed., 1921), Rio de Janeiro: Francisco Alves;

BeVIlaqua, Clovis - Resumo das lições de legislação comparada sobre direito privado (1893), Recife: Boulitreau;

BIROCCHI, Italo - Causa e categoria generale del Contratto. Un problema dogmatico nella cultura privatistica dell'età moderna. I. Il cinquecento (1997);

BIROCCHI, Italo - La questione dei patti nella dottrina tedesca dell'usus modernus, in Saggi sulla formazione storica della categoria generale di contratto (1988), Cagliari: Cuec;

BLACK, Julia - Financial Markets, in Peter Cane e Herbert H. Kritzer (organização), The Oxford Handbook of Empirical Legal Research (2012), Oxford: Oxford University Press;

Blackstone, William - Commentaries on the Laws of England, tomo 2 (17651769/1893), Philadelphia: Lippincott;

BoвbIO, Norberto - Teoria generale del diritto (1993), tradução de Denise Agostinetti, Teoria geral do direito (2007), São Paulo: Martins Fontes; 
BoRDAT, Joseph — Late Scholasticism, in Stanley N. Katz (organização), The Oxford International Encyclopedia of Legal History, vol. 4 (2009), Oxford: Oxford University Press;

Bork, Robert H. - Saving Justice: Watergate, the Saturday Night Massacre, and Other Adventures of a Solicitor General (2013), New York: Mary Ellen;

BRANDEIS, Louis D. - The Opportunity in the Law, in American Law Review 39 (1905);

BRAUDEL, Fernand [Paul Achille] — La longue durée, in Annales 13 (1958);

BRAUDEL, Fernand [Paul Achille] — La Méditerranée et le monde méditerranéen à l'époque de Philippe II (1949; $2^{\mathrm{a}}$ ed., 1966), Paris: Armand Colin;

Braun, Alexandra - Giudici e accademia nell'esperienza inglese (2006), Bologna: Il Mulino;

Braun, Alexandra - The English Codification Debate and the Role of Jurists in the Development of Legal Doctrines, in Michael Lobban e Julia Moses (organização), The Impact of Ideas on Legal Development (2002), Cambridge: Cambridge University Press;

BRESCIANI, Rafael Helou - Reflexões sobre a competência do BC em analisar questões de concorrência no âmbito do SFN (2015), disponível em http://jota.info/8g10n;

Brest, Paul — Plus ça Change, in Michigan Law Review 91 (I993);

BRETONE, Mario - La storia del diritto romano e la romanistica come storia, in Diritto e tempo nella tradizione europea (1996), Bari: Laterza;

BreWer, Scott - Scientific Expert Testimony and Intellectual Due Process, in Yale Law Journal 107 (1998);

BuRKe, Peter — The French Historical Revolution: The Annales School, 1929-1989 (1990), tradução de Nilo Odalia, A Escola dos Annales (1929-1989). A revolução francesa da historiografia (1990; $2^{\mathrm{a}}$ ed., 2010), São Paulo: Editora Unesp;

CALABresi, Guido - Some Thoughts on Risk Distribution and the Law of Torts, in Yale Law Journal 70 (1961);

Calabresi, Guido - The Cost of The Accidents. A Legal and Economic Analysis (1970), New Haven: Yale Unviersity Press; 
CALAMANDReI, Piero — La cassazione civile (1920), Roma: Fratelli Bocca;

CALASSO, Francesco - Il negozio giuridico (1960), Milano: Giuffrè;

Campilongo, Celso Fernandes; Rocha, Jean Paul Cabral Veiga da; Mattos, Paulo Todescan Lessa (organização), Concorrência e regulação no sistema financeiro (2002), São Paulo: Max Limonad;

CANARIS, Claus-Wilhelm — Die Bedeutung der iustitia distributiva im deutschen Vertragsrecht (1997), München: Bayerischen Akademie der Wissenschaften;

CANARIS, Claus-Wilhelm — Die Vertrauenschaftung im deutschen Privatrecht (1971), München: Beck;

CÂNDIDo, Antônio — Literatura e Sociedade (1965; $9^{\circ}$ ed., 2006), Rio de Janeiro: Ouro Sobre Azul;

CANe, Peter; e Kritzer, Herbert M. - Introduction, in Peter Cane e Herbert M. Kritzer (organização), The Oxford Handbook of Empirical Legal Research (2012), Oxford: Oxford University Press;

CAPOBIANCO, Ernesto - Il contratto: dal testo alla regola (2006), Milano: Giuffrè;

Cappelletti, Mauro - The Doctrine of Stare Decisis and the Civil Law: A Fundamental Difference - Or No Difference at All?, in Herbert Bernstein, Ulrich Drobnig, Hein Kötz, Festschrift für Konrad Zweigert (1981), Tübingen: Mohr;

CAPPELlini, Paolo - Negozio giuridico (storia), in Digesto delle discipline privatistiche. Sezione civile. vol. XII (1995), Torino: Unione Tipografico-Editrice Torinese;

CAPPELlini, Paolo - Sulla formazione del moderno concetto di 'dottrina generale del diritto', in Quaderni fiorentini per la storia del pensiero giuridico moderno 10 (1981);

CARone, Pio - Saggi sulla storia della codificazione (1998), Milano: Giuffrè;

Castro, Dinorah; PinheIro, Francisco - Idéias filosóficas na Faculdade de Direito da Bahia (1997), Salvador: UfBa;

Castro, Marcus Faro de - Análise Jurídica da Política Econômica, in Revista da Procuradoria-Geral do Banco Central 3 (2009),

CASTRO, Marcus Faro de - Formas jurídicas e mudança social. Interações entre o direito, a filosofia, a política e a economia (2012), São Paulo, Saraiva; 
Castronovo, Carlo - Liability Between Contract and Tort, in Thomas Wilhelmson (organização), Perspectives of Critical Contract Law (1993), Aldershot: Dartmouth;

Cataudella, Antonino - Sul contenuto del contratto (1974), Milano: Giuffrè;

CAzzetTA, Giovanni - Scienza giuridica e trasformazioni sociali. Diritto e lavoro in Italia tra otto e novecento (2007), Milano: Giuffrè;

CÉSAR, José Augusto - Sobre o projeto do Código Civil brazileiro, in Ensaio sobre os actos jurídicos (1913), Campinas: Casa Genoud

Cesarino Júnior, Antônio Ferreira - Contrato coletivo de trabalho, in Revista da Faculdade de Direito da Universidade de São Paulo 35 (1939);

Chambost, Anne-Sophie (organização) - Histoire des manuels de droit (2014), Paris, LGDJ;

Cherednychenko, Olha O. - Freedom of Contract in the Post-Crisis Era: Quo Vadis? European Review of Contract Law 10(3) (2014);

CHeVallier, Jacques - Doctrine juridique et science juridique, in Droit et société 50 (2002);

Cimbali, Enrico - La nuova fase del diritto civile nei rapporti economici e sociali con proposte di riforma della legislazione civile vigente (1885), tradução de Adherbal de Carvalho, A nova phase do direito civil: suas relações economicas e sociaes (1900), Rio de Janeiro; Livraria Clássica;

Clavero Salvador, Bartolomé - Historia del derecho común (1979; 1994), Salamanca: Ediciones Universidad de Salamanca;

CoAse, Ronald H. - The Problem of Social Cost, in Journal of Law and Economics 3 (1960);

Cogliolo, Pietro - Filosofia del diritto privato (1888), tradução de Eduardo Espínola, Filosofia do direito privado (1898), Salvador: Impreza;

CoHEN, Felix S. - Bentham's Theory of Fictions [book review], in Yale Law Journal 42 (1933),

CoHen, Morris R. - The Place of Logic in the Law, in Harvard Law Review 29 (1912); 
CoING, Helmut — Europäisches Privatrecht (1985-1989), tradução de Antonio Pérez Martín, Derecho privado europeo, tomo II (1996), Madrid: Fundación Cultural del Notariado;

Coleman, Jules L. - Methodology, in Jules Coleman e Scott Schapiro (organização), The Oxford Handbook of Jurisprudence \& Philosophy of Law (2002), Oxford: Oxford University Press;

Coleman, Jules L. - Legal Theory and Practice, in Georgetown Law Journal 83 (1995);

Coleman, Jules L. - Negative and Positive Positivism, in Journal of Legal Studies 11 (1982);

Collins, Hugh — Regulating Contracts (1999), Oxford: Oxford University Press;

COMParato, Fábio Konder — A civilização capitalista (2014), São Paulo: Saraiva;

Comparato, Fábio Konder - Notas sobre a resolução de contratos, in Direito empresarial: estudos e pareceres (1990), São Paulo, Saraiva;

Cooter, Robert D.; Ulen, Thomas S. — Law \& Economics (1988; 6ª ed., 2011), Boston: Pearson;

CordeIro, António Manuel da Rocha e Menezes - Da boa fé no direito civil (1983; 2007), Coimbra: Almedina;

CorreiA, Alexandre; ScIACIA, Gaetano - Manual de direito romano, vol. I (1949), São Paulo, Saraiva;

CORTESE, Ennio - Il rinascimento giuridico medievale (1996), Roma: Bulzoni;

COURTIS, Christian - El juego de los juristas. Ensayo de caracterización de la investigación dogmatica, in Christian Courtis (organização), Observar la ley. Ensayos sobre metodología de la investigación jurídica (2006), Madrid: Trotta;

Craswell, Richard - Contract Law, Default Rules, and the Philosophy of Promising, in Michigan Law Review 88 (1989);

CRUZ, Guilherme Braga da - O direito subsidiário na história do direito português, in Revista portuguesa de história XIV (1975);

CuEna Boy, Francisco José — La doctrina de los autores (resenha), in Quaderni fiorentini per la storia del pensiero giuridico moderno 37 (2008); 
DagAn, Hanoch - Pluralism and Perfectionism in Private Law, in Columbia Law Review 112 (2012);

DAGAN, Hanoch - Reconstructing American Legal Realism \& Rethinking Private Law Theory (2013);

Dalton, Claire - An Essay in the Deconstruction of Contract Doctrine, in Yale Law Journal 94 (1985);

DAN-COHEN, Meir - Listeners and Eavesdroppers: Substantive Legal Theory and Its Audience, in University of Colorado Law Review 63 (1992);

DANnER, Richard A. — Oh, The Treatise!, in Michigan Law Review 111 (2013);

Dantas, Francisco Clementino de San Tiago - Ciência e consciência - um estudo sobre Clovis Bevilaqua, in Figuras do direito (1962; 2a ed., 2002), Rio de Janeiro: Forense;

Daube, David — Roman Law: Linguistic, Social, and Philosophical Aspects (1969), Edinburgh: Edinburgh University Press;

Dawson, John P. — Gifts and Promises (1980), New Haven: Yale University Press;

DAwson, John P. - The Oracles of The Law (1968; 1986), New York: William S. Hein.

DE NovA, Giorgio - Il tipo contrattuale (1974), Padova: Cedam;

DeCock, Win - Theologians and Contract Law. The Moral Transformation of the Ius Commune (ca. 1500-1650) (2013), Leiden: Martinus Nijhoff;

Del Nero, João Alberto Schützer — Conversão Substancial do Negócio Jurídico (2001), Rio de Janeiro: Renovar;

Del Vecchio, Giorgio - La crise della scienza del diritto, tradução de Luiz Antônio de Andrade, A crise da ciência do direito, in Revista forense 85 (1941);

Di SPIRITo, Marco Paulo Denucci — O papel da doutrina no Estado Democrático de Direito, in Conjur (06.01.2006), disponível em http://www.conjur.com.br/2006-jan06/papel_doutrina_estado_democratico_direito; 
DibADJ, Reza - Fashions and Methodology, in Rob van Gestel, Hans Micklitz e Edward L. Rubin (organização), Rethinking Legal Scholarship: A Transatlantic Interchange (2016), Cambridge: Cambridge University Press;

DomAt, Jean - Les loix civiles dans le ordre naturel, tomo I (1698; $2^{\mathrm{a}}$ ed., 1967), Paris: Pierre Auboüin;

Donahue, Jr., Charles - Jus Commune, Canon Law, and Common Law In England, in Tulane Law Review 66 (1992);

Dosse, François, L'Histoire (2000), tradução (da $2^{\mathrm{a}}$ ed., 2010) de Roberto Leal Ferreira, $A$ história (2012), São Paulo: Editora Unesp;

DOUVERNY, Felipe Epprecht - Agere, cavere, respondere: a atividade consultiva dos juristas romanos como fonte do direito (2013), Dissertação de mestrado apresentada ao Departamento de Direito Civil da Faculdade de Direito da Universidade de São Paulo;

DuXbury, Neil - Ambition and Adjudication, in University of Toronto Law Journal 47 (1997);

Dworkin, Ronald - Hard Cases (1975), in Taking Rights Seriosly (1978), Cambridge: Harvard University Press;

Dworkin, Ronald — In Praise of Theory, in Arizona State Law Journal 29 (1997);

Dworkin, Ronald — Law's Empire (1986), Cambridge, Belknap;

Dworkin, Ronald - The Model of Rules I, in Taking Rights Seriously (1977), Cambridge: Harvard University Press;

DwORKIN, Ronald — Thirty Years On, in Harvard Law Review 115 (2003);

EDWARDs, Harry T. - The Growing Disjunction Between Legal Education and the Legal Profession, in Michigan Law Review 91 (1992);

EIDEnMÜller, Horst G. M. - Party Autonomy, Distributive Justice and the Conclusion of Contracts in the DCFR, in European Review of Contract Law 5 (2009);

Ellickson, Robert C. - Of Coase and Cattle: Dispute Resolution Among Neighbors in Shasta Count, in Stanford Law Review 38 (1986); 
ElLiCKSON, Robert C. - Unpacking the Household: Informal Property Rights Around the Hearth, in Yale Law Journal 116 (2006);

Englard, Izhak - Corrective and Distributive Justice: From Aristotle to Modern Times (2009), Oxford, Oxford University Press;

ERPEN, Décio Antonio - Da promessa de doar nas separações judiciais, in Revista dos Tribunais 77 (1988);

Ertman, Martha - Love's Promises: How Formal and Informal Contracts Shape All Kinds of Families (2015), Boston: Beacon;

ESPÍNOLA, Eduardo — Sistema do direito civil brasileiro (1908), Bahia: Reys;

EsQUIROL, Jorge L. - The 'Three Globalizations' in Latin America, in Comparative Law Review 3 (2012);

FALZEA, Angelo - Rilevanza giuridica, in Enciclopedia del diritto, vol. XL (1989), Milano: Giuffrè;

FARBer, Daniel A. - What (If Anything) Can Economics Say About Equity?, in Michigan Law Review 101 (2003);

FARIA, José Eduardo Campos de Oliveira; CAMPILONGO, Celso Fernandes - A sociologia jurídica no Brasil (1991), Porto Alegre: Sergio Antonio Fabris;

FASSÒ, Guido — Storia della filosofia del diritto (1966), vol. I, Bologna: Il Mulino;

FASsÒ, Guido — Storia della filosofia del diritto (1968), vol. III. Bologna: Il Mulino;

FEEnstra, Robert - L'influence de la Scolastique espagnole sur Grotius en droit privé: quelques expériences dans des questions de fond et de forme, concernant notamment les doctrines de l'erreur et de l'enrichissement sans cause, in Paolo Grossi (organização), La seconda scolastica nella formazione del diritto privato moderno (1972), Milano: Giuffrè;

FeInman, Jay M. - The Jurisprudence of Classification, in Stanford Law Review 41 (1989);

FELDMAN, David — The Nature of Legal Scholarship, in Modern Law Review 52 (1989), 
FERGUSON, Robert - The Judicial Opinion as a Literary Genre, in Yale Journal of Law and Humanities 2 (1990);

FERNANDES, Adaucto - O contrato no direito brasileiro, vol. I (1945), Rio de Janeiro: Coelho Branco;

FERRÃO; Brisa Lopes de Mello; RiBEIRO, Ivan César - Os juizes brasileiros favorecem a parte mais fraca?, in Revista de direito administrativo 244 (2007);

Ferraz Junior, Tercio Sampaio - Conceito de sistema no direito (1976), São Paulo: Revista dos Tribunais;

FERraz Junior, Tercio Sampaio — Função social da dogmática jurídica (1980), São Paulo: Revista dos Tribunais;

Ferraz Junior, Tercio Sampaio - Introdução ao Estudo do Direito. Técnica, Decisão, Dominação (1988; 6ª ed., 2011), São Paulo: Atlas;

FERREIRA, Waldemar Martins - A história do direito nos cursos jurídicos do Brasil, in Revista da Faculdade de Direito de São Paulo 45 (1950);

FERRI, Giovanni Battista - Causa e tipo nella teoria del negozio giuridico (1968), Milano, Giuffrè;

FERRI, Giovanni Battista — Il negozio giuridico (2004), Padova: Cedam;

FERRI, Giovanni Battista - Il negozio giuridico tra libertà e norma (1987; $5^{\mathrm{a}}$ ed., 1995), Rimini: Maggioli;

FERRI, Luigi — L'autonomia privata (1959), Milano, Giuffrè;

FINNIS, John - Natural Law and Natural Rights (1980; 2a ed., 2011), Oxford: Oxford University Press;

FISHER III, William W. - Texts and Contexts: The Application to American Legal History of the Methodologies of Intellectual History, in Stanford Law Review 49 (1997);

FiSHER III, William W.; HorwITZ, Morton J. — American Legal Realism (1993), Oxford: Oxford University Press;

FLEISCHACKER, Samuel - A Short History of Distributive Justice (2004), Cambridge: Harvard University Press; 
FLÜCKIGER, Alexandre; TANQUEREL, Thierry (organização) — L'evaluation de la recherche en droit: enjeux et methodes (2015), Bruylant: Penser le droit;

Flume, Werner - Das Rechtsgeschäft (1964), tradução (da $4^{\mathrm{a}}$ ed., 1992) de José María Miquel Gonzávez e Esther Gómez Calle, El negocio jurídico (1998), Madrid: Fundación Cultural del Notariado;

FonseCA, Maria Guadalupe Piragibe da - Ligações melindrosas: uma reflexão a respeito da sociologia aplicada ao direito, in Luciano Oliveira e Eliane Botelho Junqueira, Ou isto ou aquilo. A sociologia jurídica nas faculdades de direito (2002), Rio de Janeiro: Letra Capital;

Forgioni, Paula A. - Teoria geral dos contratos empresariais (2010; 2a ed., 2011), São Paulo: Revista dos Tribunais;

ForRAY, Vincent - Property Structures Underlying Contract, in European Review of Contract Law 9 (2013);

FoucAult, Michel — Naissance de la biopolitique (1978-1979; 2004), tradução de Eduardo Brandão, Nascimento da Biopolítica (2008), São Paulo: Martins Fontes;

Fragale Filho, Roberto - Prefácio a Fernando de Castro Fontainha e Pedro Heitor Barros Geraldo (organização), Sociologia Empírica do Direito (2015), Rio de Janeiro: FGV;

Frank, Jerome N. - Civil Law Influences on the Common Law - Some Reflections on "Comparative" and "Contrastive” Law, in University of Pennsylvania Law Review 104 (1956);

Freedland, Mark — The Personal Employment Contract (2003; 2006), Oxford: Oxford University Press;

Freitas, Augusto Teixeira de - Codigo Civil. Esbôço (1864; 1983), Brasília: Ministério da Justiça;

Freitas, Augusto Teixeira de - Consolidação das Leis Civis (1857), Rio de Janeiro: Laemmert;

Freitas, Augusto Teixeira de - Nova Apostilla à Censura do Senhor Alberto de Moraes Carvalho sobre o Projecto do Codigo Civil Portuguez (1859), Río de Janeiro: Laemmert; 
FrIED, Charles - Contract as Promise. A Theory of Contractual Obligation (1981), Cambridge: Harvard University Press;

FulLer, Lon L. - Consideration and Form, in Columbia Law Review 41 (1941);

Fuller, Lon L.; Perdue, Jr., William R. - The Reliance Interest in Contract Damages [partes I e II], in Yale Law Journal 46 (1936);

Galgano, Francesco - Negozio giuridico (dottrine gen.), in Enciclopedia del diritto, vol. XXVII (1977), Milano, Giuffrè;

GaLlo, Filippo - Sulla definizione celsina del diritto, in Studia et documenta historiae et iuris 53 (1987);

Garcia Neto, Paulo Macedo - A questão social na Era Vargas: entre a regulação de trabalho da CLT e os "fins sociais" da Lei de Introdução ao Código Civil, in Carlos Guilherme Mota e Natasha Schmitt Caccia Salinas, Os juristas na formação do Estado-Nação brasileiro. 1930-dias atuais (2010), São Paulo: Saraiva;

GARCía y García, Antonio - The Faculties of Law, in Hilde de Ridder-Symoens (organização), A History of the University in Europe (1992), Cambridge: Cambridge University Press;

GARDNER, John - Legal Positivism: 5 1/2 Myths (2001), in Law as a Leap of Faith (2012), Oxford: Oxford University Press;

Garro, Alejandro M. - Unification and Harmonization of Private Law in Latin America, in American Journal of Comparative Law 40 (1992);

GAvA, John - How Should Judges Decide Commercial Contract Cases?, in Journal of Contract Law 133 (2013);

GENY, François - Méthode d'interprétation et sources en droit privé positif (1899; 2a ed., 1919) Paris: LGDJ;

Gestel, Rob van; MicKlitz, Hans-Wolfgang - Why Methods Matter in European Legal Scholarship, in European Law Journal 20 (2014);

GHESTIN, Jacques - Cause de l'engagement et validité du contrat (2006), Paris: LGDJ; 
GHESTIn, Jacques - The Contract as Economic Trade, in Eric Brousseau e Jean-Michel Glachant (organização), The Economics of Contracts: Theories and Applications (2002), Cambridge: Cambridge University Press;

GHIRARDI, José Garcez; et alii — Observatório do Ensino de Direito [relatório] (2013), São Paulo;

GiAquinto, Adolfo di Majo — L'esecuzione del contratto (1967), Milano: Giuffrè;

GiLissen, John - Introduction historique au droit (1979), tradução de António Manuel Botelho Hespanha e Luís Manuel Macaísta Malheiros, Introdução histórica ao direito (1986; $3^{\mathrm{a}}$ ed., 2001), Lisboa, Calouste Gulbenkian;

GILLESPIE, Michael Allen — The Theological Origins of Modernity (2008), Chicago: The University of Chicago Press;

GILMORE, Grant — The death of contract (1974; 1995), Ohio: Ohio State University;

Gilson, Ronald J.; SABel, Charles F.; ScotT, Robert E. - Contract and Innovation: The Limited Role of Generalist Courts in the Evolution of Novel Contractual Forms, in New York University Law Review 170 (2013);

GILsOn, Ronald J.; SABEL, Charles F.; SCOTT, Robert E. - Text and Context: Interpretation as Contract Design, in Cornell Law Review 100 (2014);

Giorgianni, Michele - Volontà (dir. priv.), in Enciclopedia del diritto, vol. XLVI (1993), Milano: Giuffrè;

GLEZER, Rubens Eduardo - O positivismo de Joseph Raz: autoridade e razão prática sem prática social (2015), Tese de doutorado apresentada à Faculdade de Direito da Universidade de São Paulo;

Gobert, Michelle - Le temps de penser la doctrine, in Droits. Revue Française de Théorie Juridique 20 (1994);

Godoy, Arnaldo Sampaio de Moraes — Direito e Economia: Introdução ao movimento Law and Economics, in Revista jurídica 73 (2005);

Goetz, Charles J.; ScotT, e Robert E. - The Limits of Expanded Choice: An Analysis of the Interactions Between Express and Implied Contract Terms, in California Law Review 73 (1985); 
Goetz, Charles J.; ScotT, e Robert E. - Liquidated Damages Penalties and the Just Compensation Principle: Some Notes on an Enforcement Model of Efficient Breach, in Columbia Law Review 77 (1977);

Goldberg, John C. P. - Introduction: Pragmatism and Private Law, in Harvard Law Review 125 (2012);

Gomes, Orlando - A crise do direito matrimonial, in A crise do direito (1955), São Paulo, Max Limonad Gomes, Orlando - Contratos (1959), Rio de Janeiro: Forense;

Gomes, Orlando - A literatura jurídica no Brasil, in Revista forense 177 (1958);

Gomes, Orlando - Decadência do voluntarismo jurídico e novas figuras jurídicas, in Transformações gerais do direito das obrigações (1967), São Paulo: Revista dos Tribunais;

GOMES, Orlando - Influência da inflação nos contratos, in Transformações gerais do direito das obrigações (1967), São Paulo: Revista dos Tribunais;

Gomes, Orlando - Influência da legislação do trabalho na evolução do direito, in Direito do trabalho. Estudos (1941), Salvador: Forum;

GOMES, Orlando — Introdução ao direito civil (1957; $2^{\mathrm{a}}$ ed., 1965), Rio de Janeiro: Forense;

GoMes, Orlando - Introdução ao direito civil (1957), Rio de Janeiro: Forense;

GOMES, Orlando - O tetragrama da justiça (1936), in A crise do direito (1945), Salvador: Vera-Cruz;

Gomes, Orlando - Sinais novos da crise do direito, in Escritos menores (1981), São Paulo: Saraiva;

Gomes, Orlando - Socialização do direito privado (1932), in A crise do direito (1945), Bahia: Vera-Cruz;

GORDLEY, James R. - Codification and Legal Scholarship, in University of California Davis Law Review 31 (1998);

Gordley, James R. - Morality and Contract: The Question of Paternalism, in William \& Mary Law Review 48 (2007);

Gordley, James R. - Myths of the French Civil Code, in American Journal of Comparative Law 42 (1994); 
GordLey, James R. — Equality in Exchange, in California Law Review 69 (1981);

Gordley, James R. - Foundations of Private Law. Property, Tort, Contract, Unjust Enrichment (2006), Oxford: Oxford University Press;

GORDLEY, James R. — The Jurists (2014), Oxford: Oxford University Press;

Gordley, James R. - The Philosophical Origins of Modern Contract Doctrine (1991), Oxford: Oxford University Press;

Gordley, James R. - Tort Law in the Aristotelian Tradition, in David G. Owen, Philosophical Foundations of Tort Law (1995), Oxford: Oxford University Press;

GordLeY, James R.; MEHREN, Arthur [Taylor] von — An Introduction to the Comparative Study of Private Law (2006), Cambridge: Cambridge University Press;

Gordon, Robert W. - Critical Legal Histories, in Stanford Law Review 36 (1984);

Gordon, Robert W. - Lawyers, Scholars, and the "Middle Ground", in Michigan Law Review 91 (1992);

Gordon, Robert W. - Macaulay, Macneil and the Discovery of Solidarity and Power in Contract Law, in Wisconsin Law Review [s.n.] (1985);

Gorla, Gino - Il contratto. Problemi fondamentali tratatti con il metodo comparativo e casistico (1954), Milando: Giuffrè;

GraZiadeI, Michele — [Resenha de Foundations of Private Law, de James Gordley], in American Journal of Comparative Law 58 (2010);

Grechenig, Kristoffel; Gelter, Martin - The Transatlantic Divergence in Legal Thought: American Law and Economics vs. German Doctrinalism, in Hastings International and Comparative Law Review 31 (2008);

GreEn, Leslie - Law and Obligations, in Jules Coleman e Scott Schapiro (organização), The Oxford Handbook of Jurisprudence \& Philosophy of Law (2002), Oxford: Oxford University Press;

Grisez, Germain - The First Principle of Practical Reason. A Commentary on the Summa Theologiae, 1-2, Question 94, Article 2 (1965), tradução de José Reinaldo de Lima Lopes, O primeiro princípio da razão prática, in Revista Direito GV 6 (2007);

Grossi, Paolo — L'ordine giuridico medievale (2006), Roma: Laterza; 
Grossi, Paolo - Pensiero giuridico (Appunti per una 'voce' enciclopedica), in Quaderni fiorentini 17 (1988);

Grossi, Paolo - Scienza giuridica italiana. Un profilo storico (1860-1950) (2000), Milano: Giuffrè;

Grossi, Paolo (organização) — La seconda scolastica nella formazione del diritto privato moderno (1972), Milano: Giuffrè;

Grundman, Stefan - The Architecture of European Codes and Contract Law Structures and Contents, in Stefan Grundamnn (organização), The Architecture of European Codes and Contract Law (2006), Dordrecht: Kluwer;

GUASTINI, Riccardo — Dalle fonti alle norme (1990), Torino: Giappichelli;

GuASTINI, Riccardo - Juristenrecht: Inventing Rights, Obligations, and Powers, in Jordi Ferrer Beltrán, José Juan Moreso e Diego M. Papayannis, Neutrality and Theory of Law (2013), Dordrecht: Springer;

Gutmann, Daniel — La fonction sociale de la doctrine juridique, in Revue trimmestrielle de droit civil 3 (2002);

HAFERKAMP, Hans-Peter - The Science of Private Law and the State in Nineteenth Century Germany, in The American Journal of Comparative Law 56 (2008);

Hage, Jaap - A Model of Juridical Acts: Part 1: The World of Law, in Artificial Intelligence and Law 19 (2011);

HAKIM, Nader — L'autorité de la doctrine civiliste française au XIXème siécle (2002), Paris: LGDJ;

HALPÉRIN, Jean-Louis — Histoire du droit privé français depuis 1804 (1996; $2^{\mathrm{a}}$ ed., 2012), Paris: PuF;

HAN, Shiyuan — Principles of Asian Contract Law: An Endeavor of Regional Harmonization of Contract Law in East Asia, in Villanova Law Review 58 (2013);

HART, Dieter — Towards Risk Management contract Law?, in Thomas Wilhelmson (organização), Perspectives of Critical Contract Law (1993), Aldershot: Dartmouth;

Hart, Henry M.; SACKS, Albert M. - The Legal Process: Basic Problems in the Making and Application of Law (1958), Cambridge: Foundation [edição tentativa]; 
HART, Herbert L. A. - Jhering's Heaven of Concepts and Modern Analytical Jurisprudence, in Essays in Jurisprudence and Philosophy (1983; 2001), Oxford: Clarendon;

HART, Herbert L. A. - The concept of law (1961; 2a ed., 1994), Oxford: Oxford University Press;

HART, Oliver; MOORE, John - Incomplete Contracts and Renegotiation, in Econometrica 56 (1988);

HAYEK, Friedrich - The Use of Knowledge in Society, in American Economic Review 35 (1945)

Healy, Thomas — The Great Dissent. How Oliver Wendell Holmes Changed His Mindand Changed the History of Free Speech in America (2013), New York: Metropolitan;

HECK, Philipp — Gesetzesauslegung und Interessenjurisprudenz (1914), tradução de José Osório, Interpretação da lei e jurisprudência dos interesses (1947), Coimbra: Arménio Amado;

HedLeY, Steve - The Shock of the Old: Interpretivism in Obligations, in Charles Rickett e Ross Grantham, Structure and Justification in Private Law: Essays for Peter Birks (2008), Oxford: Hart;

Hespanha, António Manuel [Botelho] - Direito comum e direito colonial, in Panóptica 3 (2006);

Hespanha, António Manuel [Botelho] - Imbecillitas. As bem-aventuranças da inferioridade nas sociedades do Antigo Regime (2010), São Paulo: Annablume;

Hesselink, Martijn W. - Democratic Contract Law, in European Review of Contract Law 11 (2015);

HesselinK, Martijn W. - Five political ideas of European contract law, in European Review of Contract Law 7 (2011);

HesselinK, Martijn W. - Towards a Sharp Distinction between b2b and b2c? On Consumer, Commercial and General Contract Law after the Consumer Rights Directive, in European Review of Private Law 18 (2010); 
Hevia, Martín - Reasonableness and Responsibility: A Theory of Contract Law (2013), Dordrecht: Springer;

Hillman, Robert A. - Court Adjustment of Long-Term Contracts: An Analysis Under Modern Contract Law, Duke Law Journal 1 (1987);

HobBes, Thomas — Leviathan (1651; 1955), Oxford: Oxford University Press;

HoecKe, Mark van — Legal Doctrine: Which Method(s) for What Kind of Discipline?, in Mark van Hoecke (organização), Methodologies of Legal Research: Which Kind of Method for What Kind of Discipline? (2011), Oxford: Hart Publishing;

Hoeflich, Michael H. — Law \& Geometry: Legal Science from Leibniz to Langdell, in American Journal of Legal History 30 (1986);

HoHFeld, Wesley N. - Some Fundamental Legal Conceptions as Applied in Judicial Reasoning. Yale Law Journal 23 (1913);

Holmes, JR., Oliver Wendell — The Common Law (1881; 1991), New York: Dover;

Holmes, JR., Oliver Wendell — The Path of the Law, in Harvard Law Review 10 (1897);

HonORÉ, Tony — Gaius (1962), Oxford, Oxford University Press;

Honoré, Tony — Ulpian. Pioner of Human Rights (1982; 2a ed,, 2002), Oxford, Oxford University Press;

HuME, David - A Tratise of Human Nature (excerto: livro III, Of Morals, 1738), in Moral Writings (2006), Indianapolis: Hackett;

Hyland, Richard - Gifts. A Study in Comparative Law (2009; 2011), Oxford: Oxford University Press;

HYland, Richard - Pacta Sunt Servanda: A Meditation, in Virginia Journal of International Law 34 (1994);

IBBETSON, David - A Historical Introduction to the Law of Obligations (1999), Oxford: Oxford University Press;

IRTI, Natalino - Esecizî di lettura sul nichilismo giuridico, in Nichilismo giuridico (2004), Bari: Laterza; 
IRTI, Natalino - Il negozio giuridico come categoria storiografica (1990), in Letture bettiane sul negozio giuridico (1991), Milano: Giuffrè;

IRTI, Natalino — Letture bettiane sul negozio giuridico (1991), Milano: Giuffrè;

IRTI, Natalino - Scambi senza accordo, in Norma e luoghi. Problemi di geo-diritto (1998; 2001), Bari: Laterza;

IRTI, Natalino - Scuole e figure del diritto civile (1986), Milano: Giuffrè;

IRTI, Natalino (organização) — La polemica sui concetti giuridici (2004), Milano: Giuffrè;

JAMIN, Christophe - A construção do pensamento jurídico francês: interrogações sobre um modelo original à luz de seu antimodelo, in Revista de direito público da economia 21 (2008);

JAMIN, Christophe — Le droit des manuels de droit ou l'art de traiter la moitié du sujet, in Anne-Sophie Chambost, Histoire des manuels de droit (2014), Paris, LGDJ;

JELLINEK, Georg — System der subjektiven öffentlichen Rechte (1892), tradução de Gaetano Vitagliano, Sistema dei diritti pubblici subbiettivi (1912), Milano: Società Editrice Libraria;

JENSEN, Erik M. - The Shortest Article in Law Review History, in Journal of Legal Education 50 (2000);

JestaZ, Philippe; Jamin, Christophe — La doctrine (2004), Paris: Dalloz;

JHERING, Rudolf von - Culpa in contrahendo, oder Schadensersatz bei nichtigen Oder nicht zur Perfection gelangten Vertragen (1861), tradução de Paulo Mota Pinto, Culpa in contrahendo ou indemnização em contratos nulos ou não chegados a perfeição (2008), Coimbra: Almedina;

JHERING, Rudolf von - Geist des römischen Rechts auf den verschiedenen Stufen seiner Entwicklung (1865), tradução de Rafael Benaion, O espírito do direito romano nas diversas fases de seu desenvolvimento, vol. I (1943), Rio de Janeiro: Alba;

JHERING, Rudolf von — Geist des römischen Rechts auf den verschiedenen Stufen seiner Entwicklung (1865), tradução de Rafael Benaion, O espírito do direito romano nas diversas fases de seu desenvolvimento, vol. II (1943), Rio de Janeiro: Alba; 
JHERING, Rudolf von - Im juristischen Begriffshimmel, in Scherz und Ernst in der Jurisprudenz, tradução de Giuseppe Lavaggi, in Serio e faceto nella giurisprudenza (1954), Firenze: Sansoni;

Jolls, Christine; Sunstein, Cass R.; Thaler, Richard - A Behavioral Approach to Law \& Economics, in Stanford Law Review 50 (1998);

Joskow, Paul L. - Contract Duration and Relationship-Specific Investments: Empirical Evidence from Coal Markets, in The American Economic Review 77 (1987);

JOSSERAND, Louis - De l'esprit des droits et de leur relativité, théorie dite de l'abus des droits (1927; 2a ed., 1939; 2006), Paris: Dalloz;

JUnQUeIRA, Eliane Botelho — A sociologia do direito no Brasil - introdução ao debate atual (1993), Rio de Janeiro: Lúmen Juris;

Kahneman, Daniel — Thinking Fast and Slow (2011), New York, Ferrar, Straus and Giroux;

Kantorowicz, Hermann — The Quaestiones Disputatae of the Glossators, in Tijdschrift voor Rechtsgeschiedenis 16 (1939);

KAPlow, Louis; Shavell, Steven — Fairness versus Welfare (2002), Cambridge: Harvard University Press;

KAPLOW, Louis; SHAVELL, Steven - Why the legal system is less efficient than the income tax in redistributing income, in Journal of Legal Studies 23 (1994);

KASER, Max — Römisches Privatrecht (Studienbuch) (1960), tradução (da edição de 1992) de Samuel Rodrigues e Ferdinand Hämmerle, Direito privado romano (1999), Lisboa: Calouste Gulbenkian;

Kelley, Donald — François Hotman. A Revolutionary's ordeal (1973), Princeton: Princeton University Press;

Kelley, Donald — Gaius noster: Substructure of Western Social Thought, in The American Historical Review 84 (1979);

KELSEN, Hans — Reine Rechtslehre (1934; 2a ed., 1960), tradução de João Baptista Machado, Teoria Pura do Direito (1962; 6 ed., 1984), Coimbra: Arménio Amado; 
Kennedy, Duncan - Distributive and Paternalist Motives in Contract and Tort Law, with Special Reference to Compulsory Terms and Unequal Bargaining Power, in Maryland L. Rev. 41 (1982);

Kennedy, Duncan - Form and Substance in Private Law Adjudication, in Harvard Law Review 89 (1976);

KENNEDy, Duncan - From the Will Theory to the Principle of Private Autonomy, in Columbia Law Review 100 (2000);

Kennedy, Duncan - Savigny's Family/Patrimony Distinction and its Place in the Global Genealogy of Classical Legal Thought, in The American Journal of Comparative Law 58 (2010);

Kennedy, Duncan — The Political Stakes in "Merely Technical" Issues of Contract Law, in European Review of Private Law 1 (2001);

KENNEDY, Duncan - The Structure of Blackstone's Commentaries, in Buffalo Law Review 28 (1979), 210;

KENNEDY, Duncan - Three Globalizations of Legal Thought: 1850-2000, in David Trubek e Álvaro Santos (organização) The New Law and Economic Development. A Critical Appraisal (2006), Cambridge: Cambridge University Press;

Kessler, Friedrich; FINE, Edith - Culpa in Contrahendo, Bargaining in Good Faith, and Freedom of Contract: A Comparative Study, in Harvard Law Review 77 (1964);

KIMEL, Dori - From Promise to Contract. Towards a Liberal Theory of Contract (2003), Oxford: Hart;

KLASS, Gregory; LetSAS, George; e SAPRAI, Prince (organização) - Philosophical Foundations of Contract Law (2015), Oxford: Oxford University Press;

KLEINHEISTERKAMP, Jan - Development of Comparative Law in Latin America, in Mathias Reimann and Reinhard Zimmermann (organização), The Oxford Handbook of Comparative Law (2009), Oxford: Oxford University Press;

KNIGHT, Frank H. - Risk, Uncertainty, and Profit (1921; 1965), New York: Harper \& Row;

Kordana, Kevin A.; Blankfein-TABachnick, David H. - Rawls and Contract Law, in Washington Law Review 73 (2005); 
Korobkin, Russell - Empirical Scholarship in Contract Law: Possibilities and Pitfalls, in University of Illinois Law Review 4 (2002);

KoschaKer, Paul - Europa und das Römische Recht (1947), tradução de José Santa Cruz Teijeiro, Europa y el Derecho Romano (1955), Madrid: Editorial Revista de Derecho Privado;

Kraus, Jody S. - Philosophy of Contract Law, in Jules Coleman e Scott Schapiro (organização), The Oxford Handbook of Jurisprudence \& Philosophy of Law (2002), Oxford: Oxford University Press;

KreCKÉ, Elisabeth - Economic Analysis And Legal Pragmatism, in International Review of Law and Economics 23 (2004);

KreITNER, Roy — Calculating Promises (2007), Stanford: Stanford University Press;

Kronman, Anthony T. - Contract Law and Distributive Justice, in Yale Law Journal 89 (1980);

Kronman, Anthony T. - Specific Performance, in University of Chicago Law Review 45 (1978);

Kronman, Anthony T.; Posner, Richard A. - Economics of Contract Law (1979), New York: Little Brown;

La Porta, Rafael; Lopez-De-Silanes, Florencio; ShleIfer, Andrei - The Economic Consequences of Legal Origins, in Journal of Economic Literature 46 (2008);

LAmounier, Bolivar; Sousa, Amaury de - As elites brasileiras e o desenvolvimento nacional: fatores de consenso e dissenso (2002), São Paulo: Instituto de Estudos Econômicos, Sociais e Políticos;

LANDO, Ole - My life as a lawyer, in Zeitschrift für Europäische Privatrecht 3 (2002);

LANDO, Ole; et alii — Principles of European Contract Law (2003), Dordrecht: Kluwer;

LANGDELL, Christopher C. - A Selection of Cases on The Law of Contracts (1871), Cambridge: Harvard University Press;

LARENZ, Karl — Geschäftsgrundlage und Vertragserfüllung (1951), tradução de Carlos Fernández Rodríguez, Base del negocio jurídico e cumplimento de los contratos (1956), Madri: Editorial Revista de Derecho Privado; 
LARENZ, Karl - Methodenlehre der Rechtswissenschaft (1960), tradução (da $6^{\mathrm{a}}$ ed., 1991) de José Lamego, Metodologia da ciência do direito (2012), Lisboa: Calouste Gulbenkian;

LAVI, Shai — Turning the Tables on "Law and ...": A Jurisprudential Inquiry into Contemporary Legal Theory, in Cornell Law Review 96 (2010);

Le Goff, Jacques - Pour un autre Moyen Âge (1977), in Un autre Moyen Age (1999), Paris: Gallimard;

LEÃEs, Luís Gastão Paes de Barros - A obrigação de melhores esforços (best efforts), in Revista de direito mercantil 134 (2004);

LEITER, Brian - Holmes, Economics, and Classical Realism, in Steven J. Burton (organização), The Path of Law and its Influence. The Legacy of Oliver Wendell Holmes, $J r$. (2000; 2007), Cambridge: Cambridge University Press;

LEME, Lino de Morais — Direito civil comparado (1962), São Paulo: Saraiva;

LeOnARdo, Rodrigo Xavier - Associações sem fins econômicos (2014), São Paulo, Revista dos Tribunais;

LERMINIER, Jean Louis Eugène - Cours d'histoire des législations comparées (1838), Bruxelles: Societè Belge;

LESAFFER, Randall — Inleiding tot de Europese rechtsgeschiedenis (2004), tradução de Jan Arriens, European Legal History. A Cultural and Political Perspective (2009), Cambridge: Cambridge University Press;

LESSA, Pedro - Estudos de filosofia do direito (1912; 2a ed., 1916), Rio de Janeiro: Francisco Alves;

LEVINSON, Sanford - Judge Edwards' Indictment of “Impractical” Scholars: The Need for a Bill of Particulars, in Michigan Law Review 91 (1992);

LeVy, Ernst - West Roman Vulgar Law: The Law of Property (1951), Philadelphia: The Society;

LEWIS, Andrew — Roman Law: 753-27 B.C.E., in Stanley N. Katz (organização), The Oxford International Encyclopedia of Legal History, vol. 5 (2009), Oxford: Oxford University Press; 
LILly, Grahan C. - Law Schools Without Lawyers? Winds of Change in Legal Education, in Virginia Law Review 81 (1995);

Lima, Alvino - Aspectos da crise do direito (1957), in Revista da Faculdade de Direito da Universidade de São Paulo 53 (1958);

Lima, Alvino - Da influência, no direito civil, do movimento socializador do direito, in Revista da Faculdade de Direito da Universidade de São Paulo 35 (1939);

LiMA, Luís Corrêa - Fernand Braudel e o Brasil. Vivência e brasilianismo (1935-1945) (2009), São Paulo: Edusp;

Llewellyn, Karl N. - On the Current Recapture of the Grand Tradition (1959), in Jurisprudence: Realism in Theory and Practice (1962), Chicago: University of Chicago Press;

Llewellyn, Karl N. - Realistic Jurisprudence - The Next Step, in Columbia Law Review 30 (1930);

Llewellyn, Karl N. - Some Realism About Realism. Responding to Dean Pound, in Harvard Law Review 44 (1931);

Locke, John - Two Treatises of Government (1689; 1966, 3ª ed., 1988), Cambridge: Cambridge University Press;

LOPES, José Reinaldo de Lima - A pesquisa em direito e a pesquisa em ciências sociais [intervenção no I Encontro de Pesquisa Empírica em Direito] (2011), Ribeirão Preto: FDRP;

LOPES, José Reinaldo de Lima - As palavras e a lei (2004), São Paulo, Editora 34;

LOPES, José Reinaldo de Lima - Direito e transformação social. Ensaio interdisciplinar das mudanças do direito (1997), São Paulo: Max Limonad;

LOPES, José Reinaldo de Lima - Entre a teoria da norma e a teoria da ação, in Alfredo Carlos Storck e Wladimir Barreto Lisboa, Norma, moralidade e interpretação: temas de filosofia política e do direito (2009), Porto Alegre: Linus;

LOPES, José Reinaldo de Lima - Naturalismo jurídico no pensamento brasileiro (2014), São Paulo: Saraiva;

LOPES, José Reinaldo de Lima — O direito na história. Lições introdutórias (2008; $4^{\mathrm{a}}$ ed., 2012), São Paulo: Atlas; 
LOPES, José Reinaldo de Lima - Régla y compás, o metodología para un trabajo jurídico sensato, in Christian Courtis (organização), Observar la ley. Ensayos sobre metodología de la investigación juridica (2006), Madrid: Trotta;

Lopes, José Reinaldo de Lima; FreITAS FILHO, Roberto - Law and Society in Brazil at the Crossroads: A Review, in Annual Review of Law and Social Science 10 (2014);

LÓPEZ Medina, Diego Eduardo - Teoría impura del derecho. La transformación de la cultura juridica latino-americana (2004), Bogotá: Legis;

LoPucki, Lynn M. — Disciplining Legal Scholarship, in Tulane Law Review 90 (2015);

LoPuCKI, Lynn M.; WARREN, Elizabeth — Secured Credit: A Systems Approach (1995; $7^{\mathrm{a}}$ ed., 2011), New York: Aspen;

Losano, Mario G. - Sistema e struttura nel diritto, 2 vols. (2002), Milano: Giuffrè

LuMIA, Giuseppe - Lineamenti di teoria e ideologia del diritto (1973), tradução (da $3^{\mathrm{a}}$ ed., 1981) de Denise Rossato Agostinetti, Lineamentos de teoria e ideologia do direito (2003), São Paulo: Martins Fontes;

Macaulay, Stewart - Non-Contractual Relations in Business: A Preliminary Study, in American Sociological Review 28 (1963);

Macaulay, Stewart - The Real and the Paper Deal: Empirical Pictures of Relationships, Complexity and the Urge for Transparent Simple Rules, in Modern Law Review 66 (2003);

MACCORMICK, [Donald] Neil — Legal Obligation and the Imperative Fallacy, in Alfred W. B. Simpson (organização), Oxford Essays in Jurisprudence. Second Series (1973), Oxford: Oxford University Press;

MacCormick, [Donald] Neil - Voluntary Obligations and Normative Powers, in Aristotelian Society Supplementary Volume 46 (1972);

MacCormick, [Donald] Neil - What is Wrong with Deceit, in Sydney Law Review 10 (1983);

Macedo Junior, Ronaldo Porto - Contratos Relacionais e a Defesa do Consumidor (1998, 2a ed., 2006) São Paulo: Revista dos Tribunais; 
Macedo Junior, Ronaldo Porto - Do xadrez à cortesia. Dworkin e a teoria do direito contemporânea (2013), São Paulo: Saraiva;

Machado Neto, Antônio Luís — História das ideias jurídicas no Brasil (1969), São Paulo, Grijalbo;

Machado Neto, Antônio Luís - Teoria da ciência jurídica (1975), São Paulo: Saraiva;

Machado Neto, Antônio Luís - Contribuição baiana à Filosofia Jurídica e à Sociologia do Direito, in Revista da Faculdade de Direito de São Paulo 61 (1966);

MACKIE, John — The Third Theory of Law, in Philosophy \& Public Affairs 7 (1977);

MACNEIL, Ian R. - Contracts: Adjustment of Long-Term Economic Relations under Classical, Neoclassical, and Relational Contract Law, in Northwestern University Law Review 72 (1978);

MaCNEIL, Ian R. - The Many Futures of Contract, in University of Souther California Law Review 47 (1974);

MacneIL, Ian R. — The New Social Contract (1980), New Haven: Yale University Press;

Maggs, Douglas B. - Concerning the Extent to Which the Law Review Contributes to the Development of the Law, in South California Law Review 3 (1930);

MAINE, Henry [James Summer] — Ancient Law: Its Connection with the Early History of Society, and Its Relation to Modern Ideas (1861), London: John Murray;

MARINI, Giuliano — La polemica sulla codificazione (1982; 4ª ed., 2000), Napoli: Edizioni Scientifiche Italiane;

MARINO, Francisco Paulo De Crescenzo — Interpretação do negócio jurídico (2011), São Paulo: Saraiva;

MARMOR, Andrei — How Law Is Like Chess, in Legal Theory 12 (2006);

MARMOR, Andrei — Philosophy of Law (2011), Princeton: Princeton University Press;

MARMOR, Andrei - Social Conventions: From Language to Law (2009), Princeton: Princeton University Press;

MARMOR, Andrei — The Language of Law (2014), Oxford: Oxford University Press;

MARTINS-COSTA, Judith Hofmeister - A cláusula de hardship e a obrigação de renegociar os contratos de longa duração, in Maurício Jorge Pereira da Mota and Gustavo 
Kloh Müller Neves (organização), Transformações contemporâneas do direito das obrigações (2010), Rio de Janeiro: Elsevier;

MARTINS-COSTA, Judith Hofmeister - Autoridade e utilidade da doutrina: a construção dos modelos doutrinários, in Modelos de Direito Privado (2014), São Paulo, Marcial Pons;

MARTins-Costa, Judith Hofmeister - Contratos. Conceito e evolução, in Renan Lotufo e Giovanni Ettore Nanni (organização), Teoria geral dos contratos (2011), São Paulo: Atlas;

Martins-Costa, Judith Hofmeister - O que é pesquisa em direito, in VvaA, O que é pesquisa em direito? (2002; 2005), São Paulo: Quartier Latin;

Martins-Costa, Judith Hofmeister (organização) - Narração e normatividade. Ensaios de direito e literatura (2013), Rio de Janeiro: GZ;

Martins-Costa, Judith Hofmeister; Branco, Gerson Luiz Carlos — Diretrizes Teóricas do Novo Código Civil Brasileiro (2002), São Paulo: Saraiva;

MARX, Karl — Das Kapital. Kritik der politischen Ökonomie (1867), tradução de Rubens Enderle, O capital. Crítica da economia política, livro I, O processo de produção do capital (2013), São Paulo: Boitempo;

MatteI, Ugo - Comparative Law and Economics (1998), Ann Arbor: The University of Michigan Press;

MatteI, Ugo; Reimann, Mathias - New Directions in Comparative Law. Introduction, in American Journal of Comparative Law 46 (1998);

MAuss, Marcel — Essai sur le don (1924), in Sociologie et anthropologie (1950; $11^{\mathrm{a}} \mathrm{ed}$., 2009), Paris: Presses Universitaires de France;

MCCRUdDEN, Christopher - Legal Research and the Social Sciences, in Law Quarterly Review 122 (2006);

Mehren, Arthur T. von - An Academic Tradition for Comparative Law?, in American Journal of Comparative Law 19 (1971);

MeIrA, Sílvio [Augusto de Bastos] — A Lei das XII Tábuas. Fonte do Direito Público e Privado (1961; $3^{\mathrm{a}}$ ed., 1972), Rio de Janeiro: Forense; 
Mello, Marcos Bernardes de - Teoria do Fato Jurídico. Plano da Existência (Contribuição à teoria do fato jurídico, 1985; $15^{\mathrm{a}}$ ed., 2008), São Paulo: Saraiva;

MÉnARD, Claude; MARAIS, Bertrand du - Can We Rank Legal Systems According to Their Economic Efficiency?, in Peter Nobel (organização), New Frontiers of Law and Economics (2006), St. Gallen: Schulthess;

Mendes, Rodrigo Octávio Broglia - Arbitragem, lex mercatoria e direito estatal: uma análise dos conflitos ortogonais no direito (2010), São Paulo: Quartier Latin;

Menger, Anton - Das Bürgerliche Recht und die besitzlosen Volksklassen. Eine Kritik des Entwurfs eines Bürgerlichen Gesetzbuches für das Deutsche Reich (1890), tradução de Adilfo G. Posada, El derecho civil y los pobres (1947), Buenos Aires: Atalaya;

Mercuro, Nicholas; Medema, Steven G. - Economics and the Law. From Posner to Post-Modernism and Beyond (1998; 2a ed., 2006), New Jersey: Princeton University Press

MiCKLITZ, Hans-Wolfgang — On the Intellectual History of Freedom of Contract and Regulation, in Penn State International Law Review 33 (2015);

MirandA, Francisco Cavalcanti Pontes de — Systema de Sciencia positiva do direito, vol. I (1922), Rio de Janeiro: Jacintho Robeiro dos Santos;

MIRANDA, Francisco Cavalcanti Pontes de - Tratado de direito privado, tomo XXXVIII (1962), São Paulo: Revista dos Tribunais;

Miranda, Francisco Cavalcanti Pontes de - Tratado de Direito Privado, tomo III (1954), Rio de Janeiro: Borsoi;

MirandA, Francisco Cavalcanti Pontes de - Tratado de direito privado, tomo I (1954), Rio de Janeiro: Borsoi;

Mitchell, Catherine - Contract Law and Contract Practice: Bridging the Gap between Legal Reasoning and Commercial Expectation (2013), Oxford: Hart;

MolfESSIS, Nicolas — Les prédictions doctrinales, in Jean Carbonnier et alii, L'avenir du droit. Mélanges en hommage à Frençois Terré (1999), Paris: Dalloz;

Momberg, Rodrigo - Harmonization of Contract Law in Latin America: Past and Present Initiatives, in Uniform Law Review [s.n.] (2014); 
MonteIro, João Pereira - Cosmópolis do direito, in Revista da Faculdade de Direito de São Paulo 3 (1895);

Montredon, Jean-François — La désolennisation des libéralités (1989), Paris: LGDJ;

Moraes, Maria Celina Bodin de — Notas sobre a promessa de doação, in Civilistica 2 (2013);

Morgan, Jonathan - Contract Law Minimalism: A Formalist Restatement of Commercial Contract Law (2013), Cambridge: Cambridge University Press;

Mozos, José Luis De Los — La renovación dogmática del concepto de "causa” del negocio en Emilio Betti y su recepción en la doctrina española, in Quaderni fiorentini 7 (1978).

Muñoz, Maria Paula Costa Bertran - Justiça e contrato: entre comutar e distribuir (2010), Tese de doutorado apresentada ao Departamento de Filosofia e Teoria Geral do Direito da Faculdade de Direito da Universidade de São Paulo;

NACATA JUNIOR, Edson Kiyoshi - O programa de estudos de justiniano para as escolas de direito do Império Bizantino - A constituição Omnem, a reorganização dos cursos e o "novo método" de ensino jurídico no "período dos antecessores", in Revista da Faculdade de Direito da Universidade de São Paulo 105 (2010);

NARD, Craig A. - Empirical Legal Scholarship: Reestablishing a Dialogue Between the Academy and the Profession, in Wake Forest Law Review 30 (1995);

Negreiros, Teresa - Teoria do contrato: novos paradigmas (2001; $2^{\mathrm{a}}$ ed., 2006), Rio de Janeiro: Renovar;

NichOLAS, Barry — An Introduction to Roman Law (1962; 2010), Oxford: Oxford University Press;

Nobre, Marcos - Apontamentos sobre a pesquisa em direito no Brasil, in Novos estudos CEBRAP (2003);

Nobre, Marcos - O que é pesquisa em direito?, in VvaA, O que é pesquisa em direito? (2002; 2005), São Paulo: Saraiva;

Nussbaum, Martha C. - Still Worthy of Praise, in Harvard Law Review 111 (1998); 
Oliphant, Herman — A Return to Stare Decisis, in American Bar Association Journal 14 (1928);

OliveIRA, Cândido Luís Maria de - Curso de legislação comparada (1903), Rio de Janeiro: Jacintho Ribeiro dos Santos;

Oliveira, Luciano — «No me venga con el Código de Hammurabi...». La investigación socio-juridica en los estudios de posgrado en derecho (2004), in Christian Courtis (organização), Observar la ley. Ensayos sobre metodología de la investigación juridica (2006), Madrid: Trotta;

OliveIRA, Luciano - Direito, sociologia jurídica e sociologismo, in Sua Excelência o Comissário e outros ensaios de Sociologia Jurídica, Rio de Janeiro: Letra Legal;

Oliveira, Luciano; AdeOdAto, João Maurício - O estado da arte da pesquisa jurídica e sócio-jurídica no Brasil (1996), Brasília: Centro de Estudos Judiciários do Conselho da Justiça Federal;

Olivieri, Gustavo; ZoPPINI, Andrea (organização) - Contratto e antitrust (2008), Bari: Laterza;

PAPAYANNIS, Diego M.; RAMÍREZ Ludeña, Lorena - Una respuesta pluralista al problema de los desacuerdos jurídicos, in Pau Luque Sánchez e Giovanni Battista Ratti (organização), Acordes y desacuerdos: cómo y por qué los juristas discrepan (2012), Madrid: Marcial Pons;

PARgendler, Mariana Souza - Modes of Gap Filling: Good Faith and Fiduciary Duties Reconsidered, in Tulane Law Review 82 (2008);

PARgendler, Mariana Souza - Sincretismo jurídico na evolução do direito societário brasileiro, in Judith Hofmeister Martins-Costa, Modelos de direito privado (2014), São Paulo: Marcial Pons;

PARgendler, Mariana Souza - The Rise and Decline of Legal Families, in The American Journal of Comparative Law 60 (2012);

Pargendler, Mariana Souza; Salama, Bruno Meyerhof - Direito e consequência no Brasil: em busca de um discurso sobre o método, in Revista de direito administrativo 262 (2013); 
PECZENIK, Aleksander - Doctrinal Study of Law and Science, in Österreichise Zeitschrift für öffentliches Recht 1 (1967), Dordrecht: Springer;

PECZENIK, Aleksander - On Law and Reason (1989; 2a ed., 2008), Dordrecht: Springer;

PeCZENIK, Aleksander — Scientia Juris. Legal Doctrine as Knowledge of Law and as a Source of Law [A Treatise of Legal Philosophy and General Jurisprudence, vol. 4] (2005), Dordrecht: Springer;

PeCZeniK, Aleksander; Lindahl; Lars; Roermund, Bert Van - Theory of Legal Science. Proceedings of the Conference on Legal Theory and Philosophy of Science, Lund, Sweden (1983), Dordrecht: Springer;

Pellegrini, Lorenzo — La donazione costitutiva di obbligazione (2004) Milano: Giuffrè;

PereIrA, Caio Mário da Silva - Instituições de direito civil, vol. I, Introdução ao direito civil. Teoria geral de direito civil (1961; 20ª ed., 2004), Rio de Janeiro: Forense;

PEREÑA, Luciano - Génesis del Tratado de las leyes [estudo preliminar], in Francisco Suárez, De legibus, edição bilíngue de Luciano Pereña (1971), Madrid: Consejo Superior de Investigaciones Cientificas;

PINHEIRO, Armando Castelar — Judiciário, reforma e economia: uma visão dos magistrados (2002), disponível em http://www.febraban.org.br/Arquivo/Destaques/armando _castelar_pinheiro2.pdf;

Pinto Junior, Mario Engler; Silva Filho, Osny da - Ensino, pesquisa e prática jurídica no Brasil (2015), disponível em http://jota.info/w0xpa;

PINTO, Paulo [Cardoso Correia da] Mota - Interesse contratual negativo e interesse contratual positivo, vol. 1 (2008), Coimbra: Coimbra Editora;

PINTO, Paulo [Cardoso Correia da] Mota - Interesse contratual negativo e interesse contratual positivo, vol. 2 (2008), Coimbra: Coimbra Editora;

PIRIE, Fernanda — The Anthropology of Law (2014), Oxford, Oxford University Press.

PiZARro Wilson, Carlos (organização) - El derecho de los contratos en Latinoamerica. Bases para unos principios de derecho de los contratos (2012), Santiago: Fundación Fernando Fueyo;

Plato [Platão], Republic, tradução de Robin Waterfield (1993; 2008), Oxford: Oxford University Press; 
Plessis, Paul du - The Age of Justinian, in Stanley N. Katz (organização), The Oxford International Encyclopedia of Legal History, vol. 5 (2009), Oxford: Oxford University Press;

PORTALIS, Jean-Étienne-Marie - Discours préliminaire du premier projet de Code civil (1801), tradução de Gabriela Nunes Ferreira, Discurso preliminar ao primeiro projeto de Código civil, in José Reinaldo de Lima Lopes, Rafael Mafei Rebelo Queiroz e Thiago dos Santos Acca, Curso de história do direito (2006; 2a ed., 2009), São Paulo: Método;

Posner, Eric - Contract Theory, in Martin P. Golding e William A. Edmundson, The Blackwell Guide to the Philosophy of Law and Legal Theory (2005), Oxford: Blackwell;

Posner, Eric - Economic Analysis of Contract Law After Three Decades: Success or Failure?, in Yale Law Journal 112 (2003);

Posner, Richard A. - Economic Analysis of Law (1973; 9ª ed., 2014), New York: Aspen;

Posner, Richard A. - In Memoriam: Bernard D. Meltzer (1914-2007), in The University of Chicago Law Review 74 (2007);

Posner, Richard A. - Law and Literature (1988; $3^{\mathrm{a}}$ ed., 2009), Cambridge: Harvard University Press;

Posner, Richard A. - Legal Scholarship Today, in Harvard Law Review 115 (2002);

Posner, Richard A. — The Decline of Law as an Autonomous Discipline: 1962-1987, in Harvard Law Review 100 (1987);

Posner, Richard A. - The Economics of Justice (1983), Cambridge: Harvard University Press;

Posner, Richard A. - The Problems of Jurisprudence (1990), Cambridge: Harvard University Press;

Posner, Richard A. - Utilitarianism, Economics, and Legal Theory, in Journal of Legal Studies 8 (1979);

Postema, Gerald — Jurisprudence as Practical Philosophy, in Legal Theory 4 (1998); 
PothiER, Robert-Joseph — Traité des obligations (1761), tradução de Adrian Sotero De Witt Batista e Douglas Dias Ferreira, Tratado das obrigações (2001), Campinas: Servanda;

Pound, Roscoe - Mechanical Jurisprudence, in Columbia Law Review 8 (1908);

Pound, Roscoe — The Need of a Sociological Jurisprudence, in Green Bag 19 (1907);

PRIEST, George L. - Social Science Theory and Legal Education: The Law School as University, in Journal of Legal Education 33 (1983);

PRIEST, George L. - The Growth of Interdisciplinary Research and the Industrial Structure of the Production of Legal Ideas: A Reply to Judge Edwards, in Michigan Law Review 91 (1992);

Purcell, JR., Edward A. - Paradoxes of Court Centered-Legal History: Some Values of Historical Understanding for a Practical Legal Education, in Journal of Legal Education 64 (2014);

RabBan, David - Law's History. American Legal Thought and the Transatlantic Turn to History (2013), Cambridge: Cambridge University Press;

Ramos, Luiz Felipe Rosa - Por trás dos casos dificeis: a dogmática jurídica e o paradoxo da decisão indecidível (2015), Dissertação de mestrado apresentada à Faculdade de Direito da Universidade de São Paulo;

Ramos, Luiz Felipe Rosa; SiLva FiLho, Osny da - Orlando Gomes (2015), Rio de Janeiro: Elsevier;

RAWLS, John — A Theory of Justice (1971), Cambridge: Belknap;

RAWLS, John - Two Concepts of Rules, in The Philosophical Review 64 (1955);

RAZ, Joseph - Promises and Obligations, in Peter M. S. Hacker e Joseph Raz, Law, Morality, and Society: Essays in Honour of H.L.A. Hart (1977), Oxford: Oxford University Press;

RAZ, Joseph — Promises in Morality and Law, in Harvard Law Review 95 (1982);

RAz, Joseph - Two Views of the Nature of the Theory of Law: A Partial Comparison, in Legal Theory 4 (1998); 
RAZ, Joseph - Voluntary Obligations and Normativa Powers [II], in Proceedings of the Aristotelian Society, Supplementary Volumes 46 (1972);

REALE, Miguel - Concreção de fato, valor e norma no direito romano clássico (ensaio de interpretação à luz da teoria tridimensional do direito), in Revista da Faculdade de Direito da Universidade de São Paulo 49 (1954);

REAlE, Miguel — Filosofia do direito (1953; 11ª ed., 1986), São Paulo: Saraiva;

REALE, Miguel — Fontes e modelos do direito (1994), São Paulo: Saraiva;

ReAle, Miguel — Horizontes do direito e da história (1956), São Paulo: Saraiva;

REale, Miguel — Lições Preliminares de Direito (1973; 10ª ed., 1983), São Paulo: Saraiva;

REALE, Miguel — O direito como experiência (1968; 1992), São Paulo: Saraiva;

REALE, Miguel — Vida e morte dos modelos jurídicos, in Estudos de Filosofia e Ciência do Direito (1978), São Paulo: Saraiva;

Reimann, Mathias - Nineteenth Century German Legal Science, in Boston College Law Review 31 (1990);

REIS [e Souza], Thiago — Direito e método na teoria possessória de Savigny (2013), Porto Alegre: Sergio Antonio Fabris;

REIS [e Souza], Thiago - From "factum" to juridical fact: Modern legal rationality between facts and norms, in Direito e justiça 40 (2014);

REIS [e Souza], Thiago - Teixeira de Freitas, lector de Savigny, in Revista de historia del derecho 49 (2015) [versão online disponível em http://ref.scielo.org/skczyx].

REMY, Philippe - Éloge de l'Éxegèse, in Revue de la recherche juridique 7 (1982);

REMY, Philippe - Préfaces de Troplong, préface aux préfaces, in Revue d'histoire des Facultés de droit et de la science juridique 18 (1997);

RHode, Deborah L. - Legal Scholarship, in Harvard Law Review 115 (2002);

RIBAS, Antônio Joaquim - Curso de direito civil brasileiro (1865; 2a ed., 1880; 1977), Rio de Janeiro: Editora Rio; 
RIBEIRO, Renato Janine - A sociedade contra o social ou a sociedade privatizada, in $A$ sociedade contra o social. O alto custo da vida pública no Brasil (2000), São Paulo: Companhia das Letras;

RICHTER, Melvin - The History of Political and Social Concepts: A Critical Introduction (1995), Oxford, Oxford University Press;

Ricoeur, Paul — On Interpretation (1983), in From Text to Action (1991), Evanston: Northwestern University Press;

Ricoeur, Paul — The Model of the Text: Meaningful Action Considered as a Text (1971), in From Text to Action (1991), Evanston: Northwestern University Press;

RIPERT, Georges — La règle morale dans les obligations civiles (1926; 4ª ed., 1949), Paris: LGDJ;

Robertson, Michael — Stanley Fish on Philosophy, Politics and Law: How Fish Works (2014), Cambridge: Cambridge University Press;

Rodell, Fred - Goodbye to Law Reviews, in Virginia Law Review 23 (1936);

Rodrigues Junior, Otavio Luiz — A influência do BGB e da doutrina alemã no direito civil brasileiro do século XX, in Revista dos Tribunais 102 (2013);

RODRIGUes JUNIOR, Otavio Luiz — Dogmática e crítica da jurisprudência (ou da vocação da doutrina em nosso tempo), in Revista dos tribunais 891 (2010);

Rodrigues Junior, Otavio Luiz — Revisão judicial dos contratos. Autonomia da vontade e teoria da imprevisão (2002; $2^{\mathrm{a}}$ ed., 2006), São Paulo: Atlas;

Romano, Santi — L'ordinamento giuridico (1917-1918; 2a ed., 1945), Firenze: Sansoni;

Roppo, Enzo - Il contratto (1977), tradução de Ana Coimbra e Manuel Januário da Costa Gomes. O contrato (2000; 2008), Coimbra: Almedina;

RoPPO, Vincenzo - From consumer contracts to asymmetric contracts: a trend in European contract law?, in European Review of Contract Law 5 (2009);

RORTY, Richard - Objectivity, Relativism, and Truth. Philosophical Papers, vol. 1 (1991), Cambridge: Cambridge University Press

RosA, Felippe Augusto de Miranda - Sociologia do direito. O fenômeno jurídico como fato social (1973), Rio de Janeiro: Zahar; 
RouSSEAU, Jean-Jacques - Du contrat social; ou, principes du droit politique (1762), tradução de Antonio de Pádua Danese, O contrato social: princípios do direito político (1989; $3^{\mathrm{a}}$ ed., 1996), São Paulo: Martins Fontes;

Rubin, Edward L. - Legal Scholarship, in Dennis Patterson, A Companion to Philosophy of Law and Legal Theory (1996; $2^{\mathrm{a}}$ ed, 2010), Oxford: Blackwell;

Rubin, Edward L. - Obstructing Law's Future with Conceptions from its Past, in Sam Muller et alli (organização), The Law of the Future and the Future of Law, vol. II (2012), The Hague: Torket Opsahl;

Rubin, Edward L. - The Nonjudicial Life of Contract: Beyond the Shadow of the Law, in Northwestern Law Review 90 (1995);

Rubin, Edward L. - The Practice and Discourse of Legal Scholarship, in Michigan Law Review 86 (1988);

RUBIO Garrido, Tomás — La doctrina de los autores: de fuente jurídica primaria a la vulgarización e irrelevancia (2006), Granada: Comares;

RÜCKERT, Joachim — Das Bürgerliche Gesetzbuch - ein Gesetzbuch ohne Chance? (2003), tradução de Thiago Reis, $O$ BGB - um código sem oportunidade?, in Max Planck Institute for European Legal History Research Paper Series 2 (2013);

SaCco, Rodolfo - Legal Formants: A Dynamic Approach to Comparative Law, in The American Journal of Comparative Law 39 (1991);

SACCO, Rodolfo - Metodo del diritto civile e scontri di generazionali, in Cesare Massimo Bianca et alii (organização), La civilistica italiana dagli anni '50 ad oggi tra crisi dogmatica e riforme legislative (1991), Padova: Cedam;

SaCco, Rodolfo - Negozio giuridico (circolazione del modello), in Digesto delle Discipline Privatistiche. Sezione Civile, vol. XII (1995), Torino: Unione TipograficoEditrice Torinese;

SAFAtle, Vladimir Pinheiro - O circuito dos afetos. Corpos políticos, desamparo e o fim do indivíduo (2015), São Paulo: Cosac Naify;

Salama, Bruno Meyerhof - O fim da responsabilidade limitada no Brasil (2014), São Paulo: Malheiros; 
Salama, Bruno Meyerhof - O que é pesquisa em direito e economia, in Cadernos Direito GV 22 (2008);

SAlama, Bruno Meyerhof; PARgendler, Mariana Souza - Para além do "empreendedorismo intelectual": fatores de demanda na cientificização da produção jurídica, in Antônio Maristrello Porto e Patrícia Sampaio (organização), Direito e economia em dois mundos: doutrina jurídica e pesquisa empírica (2014), Rio de Janeiro: FGV;

Salama, Bruno Meyerhof; Silva FilHo, Osny da - Elasticity, Incompleteness, and Constitutive Rules, in The CLS Blue Sky Blog (30.07.2013);

SAlEILles, Raymond - De la déclaration de volonté (contribution à l'étude de l'acte juridique dans le code civil allemand, art. 116 à 144) (1901), Paris: Pichon;

Salomão Filho, Calixto - Comentário ao artigo do Professor Christophe Jamin, in Revista de direito público da economia 21 (2008);

SAlomão FILHO, Calixto — Função social do contrato: primeiras anotações, in Teoria crítico-estruturalista do direito comercial (2015), São Paulo: Marcial Pons;

SANCHIRICO, Chris W. - Taxes versus legal rules as instruments for equity: a more equitable view, in Journal of Legal Studies 29 (2000);

SAVAuX, Eric — La Théorie générale du contrat: mythe ou réalité? (1997), Paris: LGDJ;

SAVIGNY, Friedrich Carl von — Geschichte des römischen Rechts im Mittelalter (18151831), tradução de Charles Genoux, Histoire du droit romain au Moyen-Age, tomo IV (1839), Paris: Charles Hingray;

SAVIGNY, Friedrich Carl von - System des heutigen römischen Rechts (1840-1849), tradução de Jacinto Mesía e Manuel Poley, Sistema del derecho romano actual, vol. I (1878; $2^{\mathrm{a}}$ ed., 2004), Navarra: Anacleta;

SCANLON, Thomas - Promises and Contracts, in Peter Benson (organização), The Theory of Contract Law: New Essays (2001), Cambridge: Cambridge University Press

SCHAUER, Frederick F. - Nonlegal Information and the Delegalization of Law, in The Journal of Legal Studies 29 (2000);

SCHIPANI, Sandro - Principia iuris potissima pars principium est: principi generali del diritto (schede sulla formazione di un concetto), tradução de Osny da Silva Filho, Principia iuris potissima pars principium est: princípios gerais do direito (notas 
sobre a formação de um conceito), in Sandro Schipani e Danilo Borges dos Santos Gomes de Araújo (organização), Sistema jurídico romanístico e subsistema jurídico latino-americano (2015), São Paulo: FGV Direito SP;

Schlag, Pierre - Spam Jurisprudence, Air Law, and the Rank Anxiety of Nothing Happening (A Report on the State of the Art), in The Georgetown Law Journal 97 (2009);

Schlossman, Siegmund — Der Vertrag (1876), Leipzig: Breitkopf und Haertel;

SCHUARTZ, Luis Fernando - A práxis recalcada na teoria da norma de Kelsen, in Norma, contingência e racionalidade. Estudos preparatórios para uma teoria da decisão jurídica (2005), Rio de Janeiro: Renovar;

SCHUARTZ, Luis Fernando - Consequencialismo jurídico, racionalidade decisória e malandragem, in Revista de Direito Administrativo 248 (2008);

SCHUARTZ, Luis Fernando - Interdisciplinaridade $e$ adjudicação: caminhos $e$ descaminhos da ciência no direito, in Revista brasileira de filosofia 58 (2009);

SCHUlz, Fritz — Bracton and Raymond de Penafort, in Law Quarterly Review 61 (1945);

Schulz, Fritz - Classical Roman Law (1951), Oxford: Clarendon;

ScHUlz, Fritz - History of Roman Legal Science (1946), Oxford, Clarendon;

Schwartz, Alan — The Case for Specific Performance, in Yale Law Journal 89 (1979);

Schwartz, Alan; ScOTt, Robert E. - Contract Interpretation Redux, in Yale Law Journal 119 (2010);

Scognamiglio, Renato Contributo alla teoria del negozio giuridico (1950; $2^{\mathrm{a}}$ ed., 1969), Napoli: Jovene;

SEARle, John R. - How to Derive "Ought" from "Is", in The Philosophical Review 73 (1964);

SEARLE, John R. - Making the Social World (2010), Oxford: Oxford University Press;

SEARle, John R. - Rationality in Action (2001), Cambridge: The Mit Press;

SEARle, John R. - Speech Acts. An Essay in the Philosophy of Language $(1969 ; 2011)$ Cambridge: Cambridge University Press;

SEN, Amartya K. - Development as Freedom (1999), New York: Anchor; 
SEN, Amartya K. - Introduction: Rationality and Freedom, in Rationality and Freedom (2002), Cambridge: Harvard University Press;

SERRAo, Feliciano - Diritto privato, economia e società nella storia di Roma, vol. 1, Dalla società gentilizia alle origini dell'economia schiavistica (2006), Napoli: Jovene;

Shavell, Steven - A Note on Efficiency vs. Distributional Equity in Legal Rulemaking: Should Distributional Equity Matter Given Optimal Income Taxation?, in American Economic Review Papers \& Proceedings 71 (1981);

SHECAIRA, Fábio P. — Legal Scholarship as a Source of Law (2013), New York: Springer;

SheCAIRA, Fábio P. - Sources of Law Are not Legal Norms, in Ratio Juris 28 (2015);

SHIfFrin, Seana Valentine - The Divergence of Contract and Promise, in Harvard Law Review 120 (2007);

SidoU, José Maria Othon - A literatura jurídica através dos tempos (1990), Recife, [edição privada];

SIEMS, Mathias M. — Legal Originality, in Oxford Journal of Legal Studies 28 (2008);

Siems, Mathias M.; Síthigh, Daithí mac - Mapping Legal Research, in The Cambridge Law Journal 71 (2012);

Silva Filho, Osny da — Entre mercado e hierarquia: repercussões da desverticalização na disciplina dos contratos empresariais, in Revista de direito mercantil, industrial, econômico e financeiro 163 (2012);

Silva Filho, Osny da - Punitive (and) Pain-and-Suffering Damages in Brazil, in Mark D. White (organização), Law and Social Economics: Essays in Ethical Values for Theory, Practice, and Policy (2015), New York: Palgrave;

Silva, Clóvis [Veríssimo] do Couto e - A obrigação como processo (1964; 2006), Rio de Janeiro, FGV;

Silva, Clóvis [Veríssimo] do Couto e - A teoria da causa no direito privado, in Vera Maria Jacob de Fradera (organização), O direito privado brasileiro na visão de Clóvis do Couto e Silva (1997), Porto Alegre: Livraria do Advogado;

SILVA, Clóvis [Veríssimo] do Couto e - Negócios jurídicos e negócios jurídicos de disposição, in Vera Maria Jacob de Fradera (organização), O direito privado na visão de Clóvis do Couto e Silva (1997; 2ª ed, 2014), Porto Alegre: Livraria do Advogado; 
SILVA, Clóvis [Veríssimo] do Couto e - O direito civil brasileiro em perspectiva histórica e visão de futuro, in Revista de informação legislativa 97 (1988);

SILVA, Nuno J. Espinosa Gomes da - Humanismo e direito em Portugal no século XVI (1964), Dissertação de doutoramento em Ciências Histórico-Jurídicas na Faculdade de Direito da Universidade de Lisboa;

Silva, Virgílio Afonso da - Interpretação Constitucional (2005), São Paulho: Malheiros;

SilveIRA, Alípio - O Fator Político-social na Interpretação das Leis (1946), São Paulo: Tipografia Paulista;

SimmONDS, Nigel — Law as a Moral Idea (2007), Oxford: Oxford University Press;

Singer, Joseph W. - Property and Social Relations: From Title to Entitlement, in Charles Geisler e Gail Daneker, Property and Values: Striking an Equitable Balance of Public and Private Interests (2009), Washington: Island;

SIRKS, Boudewijn - Roman Law: 250-527 C.E., in Stanley N. Katz (organização), The Oxford International Encyclopedia of Legal History, vol. 5 (2009), Oxford: Oxford University Press;

SKINNER, Quentin - The Foundations of Modern Political Thought, vol. I (1978), Cambridge: Cambridge University Press;

SKInNER, Quentin — The Foundations of Modern Political Thought, vol. II (1978), Cambridge: Cambridge University Press;

SKINNER, Quentin - Thomas Hobbes et le vrai sens du mot liberté, in Archives de philosophie du droit 36 [Droit et science] (1991);

Smith, Barry — John Searle: From Speech Acts to Social Reality, in John Searle (2003), Cambridge, Cambridge University Press;

Smith, Henry E. - Property as the Law of Things, in Harvard Law Review 125 (2012);

SMITH, Stephen A. - Comparative Legal Scholarship as Ordinary Legal Scholarship, in Journal of Comparative Law 5 (2010);

SMITH, Stephen A. - Contract Theory (2004/2007), Oxford: Oxford University Press;

SMITH, Stephen A. - Towards a Theory of Contract, in Jeremy Horder (organização), Oxford Essays in Jurisprudence [4th series] (2000) Oxford: Oxford University Press; 
Smits, Jan M. - What is Legal Doctrine? On the Aims and Methods of Legal-Dogmatic Research (2015), Maastricht European Private Law Institute, Working Paper No. 2015/06;

SMits, Jan M. - Contract Law: a Comparative Introduction (2014), Cheltenham: Elgar;

SMITS, Jan M. — Law and Interdisciplinarity: On the Inevitable Normativity of Legal Studies, in Critical Analysis of Law 1 (2014);

SMITS, Jan M. - The Mind and Method of the Legal Academic (2012), Cheltenham: Elgar;

Somma, Alessandro - Autonomia privata e struttura del consenso contrattuale. Aspetti storico-comparativi di uma vicenda concettuale (2000), Milano: Giuffrè;

Somma, Alessandro - Dal lavoratore al consumatore. Cittadinanza e paradigma giuslavoristico nell'economia sociale di mercato, in Gian Guido Balandi e Giovanni Cazzetta (organização), Diritti e lavoro nell'Italia repubblicana (2009), Milano: Giuffrè;

Souto, Cláudio Fernando da Silva - Introdução ao direito como ciência social (1971), Brasília: Tempo Brasileiro;

TIERSMA, Peter M. - The Language of Offer and Acceptance: Speech Acts and the Question of Intent, in California Law Review 74 (1987);

Tiersma, Peter M. - Reassessing Unilateral Contracts: The Role of Offer, Acceptance and Promise, in U.C. Davis Law Review 26 (1992);

Schane, Sanford - A Speech-Act Analysis of Consideration in Contract Law, in Paul Pupier e José Woehrling (organização), Language and Law (1989), Montreal: Wilson \& Lafleur;

Schane, Sanford - Contract Formation as a Speech Act, in Lawrence M. Solan e Peter M. Tiersma (organização), The Oxford Handbook of Language and Law (2012), Oxford: Oxford University Press;

SouZA, Jessé [José Freire de] — É preciso teoria para compreender o Brasil contemporâneo? Uma crítica a Luis Eduardo Soares, in Jessé Souza (organização), A invisibilidade da desigualadade brasileira (2006), Belo Horizonte: Editora UFMG;

SPENCER, Herbert - The Man versus the State, with Six Essays on Government, Society and Freedom (1884; 1960), Caldwell: Caxton; 
STANicia, Sergio Tuthill — Liberalidade e gratuidade no âmbito da doação (2016), Tese de doutorado apresentada ao Departamento de Direito Civil da Faculdade de Direito da Universidade de São Paulo;

Stanojević, Obrad — Gaius and Pomponius: Notes on David Pugsley, in Revue Internationale des Droits de l'Antiquite 44 (1997);

STOLFI, Giuseppe - Teoria del negozio giuridico (1947), Padova: Cedam;

STRECK, Lênio Luiz - Devemos nos importar, sim, com o que a doutrina diz, in Conjur (05.01.2006), disponíel em http://www.conjur.com.br/2006-jan-05/devemos_importar_sim_doutrina;

Sunstein, Cass R. - Beyond Judicial Minimalism, in Tulsa Law Review 43 (2008);

SunsteIn, Cass R. — From Theory to Practice, in Arizona State Law Journal 29 (1997);

Sunstein, Cass R. - Incompletely Theorized Agreements, in Harvard Law Review 108 (1995);

Sunstein, Cass R. - Legal Reasoning and Political Conflict (1996), Oxford: Oxford University Press;

Sunstein, Cass R. — On Analogical Reasoning, in Harvard Law Review 106 (1993);

TALAMANCA, Mario — Istituzioni di diritto romano (1990), Milano: Giuffrè;

Talley, Eric L. - Contract Renegotiation, Mechanism Design, and the Liquidated Damages Rule, in Stanford Law Review 46 (1995);

TARELlo, Giovanni - Storia della cultura giuridica moderna. Assolutismo e codificazione del diritto (1976), Bologna: Il Mulino;

Tepedino, Gustavo - O Código Civil e o direito civil constitucional, in Temas de direito civil [Tomo II] (2006), Rio de Janeiro: Renovar;

TePedino, Gustavo - Premissas metodológicas para a constitucionalização do direito civil, in Temas de direito civil [Tomo I] (1999), Rio de Janeiro: Renovar;

Teubner, Gunther — Piercing the Contractual Veil? The Social Responsibility of Contractual Networks, in Thomas Wilhelmson (organização), Perspectives of Critical Contract Law (1993), Aldershot: Dartmouth; 
Thaler, Richard H.; Sunstein, Cass R. - Nudge: Improving Decisions About Health, Wealth, and Happiness (2008), New Haven: Yale University Press;

TIERnEY, Brian - Liberty \& Law. The Idea of Permissive Natural Law, 1100-1800 (2014), Washington: Catholic University of America Press;

Tiller, Emerson H.; Cross, Frank B. - What Is Legal Doctrine?, in Northwestern University Law Review 100 (2006);

TIMM, Luciano Benetti - Direito contratual brasileiro. Críticas e alternativas ao solidarismo jurídico (O novo direito contratual brasileiro, 2008; $2^{\mathrm{a}}$ ed., 2015), São Paulo: Atlas;

TIMm, Luciano Benetti - Direito, economia e a função social do contrato, in Luciano Benetti Timm e Rafael Bicca Machado (organização), Função Social do direito (2009), São Paulo: Quartier Latin;

TODESCAN, Franco - Le radici teologiche del giusnaturalismo laico. II. Il problema della secolarizzazione nel pensiero giuridico di Jean Domat (1987), Milano: Giuffrè;

TrebiLCOCK, Michael — The Limits of Freedom of Contract (1993), Cambridge: Harvard University Press;

TrubeK, David M.; SAntos, Alvaro - Introduction: The Third Moment in Law and Development Theory and the Emergence of a New Critical Practice, in David M. Trubek e Alvaro Santos (organização), The New Law and Economic Development: A Critical Appraisal (2006), Cambridge: Cambridge University Press;

Tucci, José Rogério Cruz; Azevedo, Luís Carlos de - Lições de história do processo civil romano (2001), São Paulo: Revista dos Tribunais;

TwINING, William — Blackstone's Tower: The English Law School (1994), London: Stevens \& Sons;

UgAs, Anna Paola - Il negozio giuridico come fonte di qualificazione e disciplina di fatti (2002), Torino: Giappichelli;

Ullmann, Walter — The Growth of Papal Government in the Middle Ages (1955), London: Methuen; 
Unger, Roberto Mangabeira — The Critical Legal Studies Movement (1983; 1986), Cambridge: Harvard University Press;

Unger, Roberto Mangabeira — What Should Legal Analysis Become? (1996), London: Verso;

VARELA, João de Matos Antunes — Das obrigações em geral, vol. II (1974; $2^{\mathrm{a}}$ ed., 1997), Coimbra: Almedina;

VARRONE, Claudio - Ideologia e dogmatica nella teoria del negozio giuridico (1972), Napoli: Jovene;

VenÂNCIO FILHO, Alberto — Das Arcadas ao bacharelismo (1977; 2ª ed., 2011), São Paulo: Perspectiva;

VERNEY, Luis Antonio - Verdadeiro método de estudar para ser útil à República, e à Igreja. Proporcionado ao estilo, e necesidade de Portugal, vol. II (1746), Valensa: Oficina de Antonio Valle;

Vianna, Francisco José de Oliveira — Problemas de direito corporativo (1938), Rio de Janeiro: José Olympio;

VignALI, Giovanni - Corpo del diritto, vol. viII (Codice, vol. I) (1860), Napoli: Achille Morelli;

VILlelA, João Baptista - Contrato de doação: pouca luz e muita sombra, in Antonio Jorge Pereira Júnior e Gilberto Haddad Jabur (organização), Direito dos contratos (2006), São Paulo: Quartier Latin;

VILLEY, Michel - Essor et decadence du volontarisme juridique (1954), in Leçons d'histoire de la philosophie du droit (1957), Paris: Dalloz;

VILLEY, Michel — La formation de la pensée juridique moderne (1968), Paris [edição privada];

VinCENT-Jones, Peter - Relational Contract and Social Learning in Hybrid Organization, in David Campbell, Linda Mulcahy e Sally Wheeler (organização), Changing Concepts of Contract. Essays in Honour of Ian Macneil (2013), New York: Palgrave;

VInCENTI, Umberto — Diritto senza identità (2007), Bari: Laterza; 
VITUCCI, Paolo - Parte generale e parte speciale nella disciplina dei contratti, in VvAA, La civilistica italiana dagli anni '50 ad oggi tra crisi dogmatica e riforme legislative (1991), Milano: Cedam;

Vogenauer, Stefan - An Empire of Light? II: Learning and Lawmaking in Germany Today, in Oxford Journal of Legal Studies 26 (2006);

VolANTE, Raffaele - Il sistema contrattuale del diritto comune classico (2001), Milano: Giuffrè;

WEBER, Max — Die römische Agrargeschischte in ihrer Bedeutung für das Staats- und Privatrecht (1891), tradução de Richard I. Frank, Roman Agrarian History (2008), Claremont: Regina;

WEBER, Max — Wirtschaft und Gesellschaft (1910-1921), tradução de Guenther Roth e Claus Wittich, Economy and Society, vol. II (1978), Berkeley: University of California Press;

WEBER, Max - Zur Geschichte der Handelsgesellschaften im Mittelalter (1889), tradução de Lutz Kaelber, The History of Commercial Partnerships in the Middle Ages (2003), Lanham: Rowman \& Littlefield;

WeINRIB, Ernest J. - Legal Formalism: On the Immanent Rationality of Law, in The Yale Law Journal 97 (1988);

WeInRIB, Ernest J. — The Idea of Private Law (1995/2012), Oxford: Oxford University Press;

West, Glenn D. - That Pesky Little Thing Called Fraud: An Examination of Buyers' Insistence Upon (and Sellers' Too Ready Acceptance of) Undefined "Fraud CarveOuts" in Acquisition Agreements, in The Business Lawyer 69 (2014);

WeSterman, Pauline — Open or autonomous: The debate on legal methodology as a reflection of the debate on law, in Mark van Hoecke (organização), Methodologies of Legal Research: Which Kind of Method for What Kind of Discipline? (2011), Oxford: Hart Publishing;

Westwood, Howard C. - The Law Review Should Become the Law School, in Virginia Law Review 31 (1945); 
WheEler, Sally — Contracts and Corporations, in Peter Cane e Herbert Kritzer (organização), The Oxford Handbook of Empirical Legal Research (2012), Oxford: Oxford University Press;

Whitman, James Q. - Historical Vision and Legal Change (1990), Princeton: Princeton University Press;

WIEACKER, Franz - Contractus und Obligatio im Naturrecht zwischen Spätscholastik und Aufklärung, in Paolo Grossi (organização), La seconda scolastica nella formazione del diritto privato moderno (1972), Milano: Giuffrè;

WIEACKER, Franz - Privatrechtsgeschichte der Neuzeit unter besonderer Berücksichtigung der deutschen Entwicklung (1952), trad. (da 2a ed., 1967) de António Manuel Botelho Hespanha, História do Direito Privado moderno (1980; $3^{\mathrm{a}}$ ed., 2004), Lisboa: Calouste Gulbenkian;

Wilhelmsson, Thomas - Critical Studies in Private Law. A Treatise on Need-Rational Principles in Modern Law (1992), Dordrecht: Kluwer;

Wilhelmsson, Thomas - Questions for a Critical Contract Law - and a Contradictory Answer: Contract as Social Cooperation, in Thomas Wilhelmson (organização), Perspectives of Critical Contract Law (1993), Aldershot: Dartmouth;

WiLkins, John R. - Hans Kelsen at Boalt Hall: A Personal Impression, in California Law Review 59 (1971);

Williamson, Oliver E. - Comparative Economic Organization: The Analysis of Discrete Structural Alternatives, in Administrative Science Quarterly 36 (1991);

Williamson, Oliver E. - Contract Analysis: The Transaction Cost Approach, in Paul Burrows e Cento G. Veljanovski, The Economic Approach to Law (1981), London: Butterworths;

Williamson, Oliver E. - Markets and Hierarchies: Analysis and Antitrust Implications (1975), New York: Free Press;

Williamson, Oliver E. - The Economic institutions of Capitalism (1985), New York: Free Press;

Williamson, Oliver E. - Transaction Cost Economics Meets Posnerian Law and Economics, in Journal of Institutional and Theoretical Economics 149 (1993); 
WILSON, Lyman P. - The Law Schools, the Law Reviews, and the Courts, in Cornell Law Quarterly 30 (1945);

WINDSCHEID, Bernhard - Wille und Willenserklärung. Eine Studie, in Archiv für die civilistische Praxis 63 (1880);

WinRoth, Anders — The Making of Gratian's Decretum (2000), Cambridge: Cambridge University Press;

WolkMER, Antonio Carlos (organização) — Fundamentos do humanismo jurídico no Ocidente (2005), Barueri: Manole;

WooD, Diane P. — Legal Scholarship for Judges, in Yale Law Journal 124 (2015);

WoOdWARD, Jr., William J. - Neoformalism in a Real World of Forms, in Wisconsin Law Review [s.n.] (2001);

XAVIER, José Roberto - Algumas notas teóricas sobre a pesquisa empírica em direito, in FGV Direito SP Research Paper Series 122 (2015);

ZANETTI, Cristiano de Souza - Direito contratual contemporâneo (2008), São Paulo: Método;

ZANITELli, Leandro Martins - Direito privado, justiça distributiva e o argumento da dupla distorção: uma revisão da literatura, in Revista Brasileira de Políticas Públicas 5 (2015);

ZhenG, Jurong; RoEHrich, Jens K.; LewIS, Michael A. — The dynamics of contractual and relational governance: Evidence from long-term public-private procurement arrangements, in Journal of Purchasing and Supply Management 14 (2008);

Zimmermann, Reinhard — Law Reviews: A Foray Through a Strange World, in Emory Law Journal 47 (1998);

Zimmermann, Reinhard - Roman Law, Contemporary Law, European Law. The Civilian Tradition Today (2001; 2004), Oxford: Oxford University Press;

Zimmermann, Reinhard - Roman-Dutch Jurisprudence and Its Contribution to European Private Law, in Tulane Law Review 66 (1992); 
Zimmermann, Reinhard - The Law of Obligations. Roman Foundations of the Civilian Tradition (1990; 1996), Oxford: Clarendon;

ZweIGERT, Konrad; KöTz, Hein — Einführung in die Rechtsvergleichung (1977; $3^{\mathrm{a}}$ ed., 1998), tradução de Tony Weir, An Introduction to Comparative law (1998), Oxford: Oxford University Press. 